\title{
The Feedback between Real and Credit Markets
}

Report submitted by Emanuele Ciola in order to be eligible for a doctoral degree awarded under joint supervision by Università Politecnica delle Marche and Universitat Jaume I

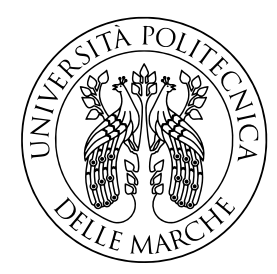

Doctoral Programme in Economics

Università Politecnica delle Marche Doctoral School

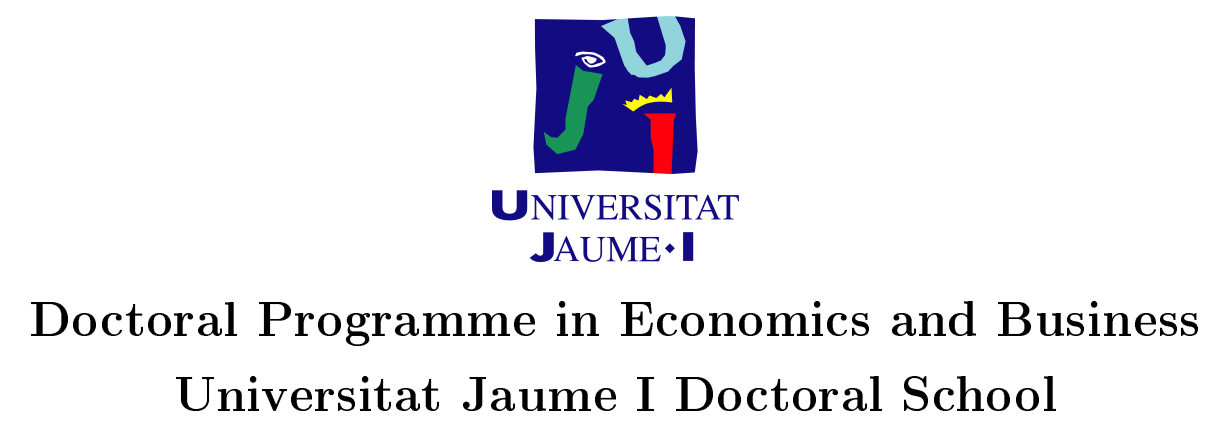

Candidate

Supervisors

Emanuele Ciola

Prof. Mauro Gallegati

Prof. Gabriele Tedeschi

Ancona, February 2019 



\section{Abstract}

The main purpose of this thesis is to extend the theoretical knowledge on the relationship between the financial and the real sectors. Specifically, we investigate how the allocation of capital affects the dynamics of macroeconomic cycles and the long-term growth rate. Indeed, given the position of financial intermediaries between the demand and the supply of loanable funds, banks can change the market equilibrium influencing the choices of households and firms. Moreover, also the competitive pressure arising from incumbent institutions can play a major role in the definition of the final outcome.

First, we develop a computational agent-based model, where the channeling of funds from savers to investors occurring through intermediaries is affected by information frictions. Since banks compete in both the deposit and the loan markets, the whole dynamics is driven by endogenous fluctuations in the size of the intermediaries balance sheet. Accordingly, the introduction of an interbank market, reducing the pressure on the liability side of banks' balance sheets, improves the performance of the system. However, the result depends on the topology of the network. Indeed, the functioning of a highly centralized financial system relies on the current state of the hub and vice-versa.

Lastly, we develop a simple general equilibrium model to study the effects of financialization on aggregate growth and systemic risk. The main driver of this process is the bargaining power of intermediaries. Indeed, financial institutions, by absorbing a larger quota of income from entrepreneurs, can reduce the incentive for new firms to enter the market. As a result, both the long-term potential growth rate and the overall stability of the system can be negatively affected by an overdeveloped financial sector. 



\section{Contents}

Abstract $i$

Introduction 1

\begin{tabular}{ll}
\hline Chapter 1 & 3
\end{tabular}

1.1 Introduction . . . . . . . . . . . . . . . . . 3

1.2 Model . . . . . . . . . . . . . . . . 6

1.2 .1 Model Initialization . . . . . . . . . . . . . . . 7

1.2 .2 Sequence of Events . . . . . . . . . . . . 8

$1.2 .3 \quad$ Margin of Intermediation and Cash Reserves . . . . . . 12

1.3 Simulation Results . . . . . . . . . . . . . . 13

1.3 .1 Initial Setting and Sensitivity Analysis . . . . . . 13

$1.3 .2 \quad$ Credit Cycles $\ldots \ldots \ldots \ldots \ldots$

1.4 Bank Run and Persistent Slump. . . . . . . . . . . . . . . 18

1.5 Concluding Remarks $\ldots \ldots \ldots \ldots \ldots \ldots$

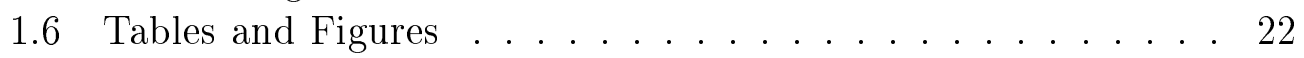

\begin{tabular}{ll}
\hline Chapter 2 & 37
\end{tabular}

$2.1 \quad$ Introduction $\ldots \ldots \ldots \ldots \ldots \ldots \ldots \ldots \ldots$

2.2 Sequence of Events $\ldots \ldots \ldots \ldots$

2.2 .1 Model Initialization . . . . . . . . . . . . . . . 40

2.2 .2 Production and Interest Rates . . . . . . . . . . . . 41

2.2 .3 Deposit Market . . . . . . . . . . . . . . . . 42

2.2 .4 Intermediaries Behavior and Interbank Market . . . . . 43

2.2 .5 Credit market . . . . . . . . . . . . . . . . . . . . . . 48

2.3 Network Topology, Steady State and Cycles . . . . . . . . . 49

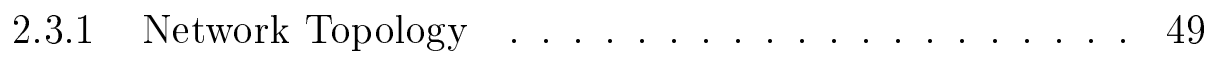

$2.3 .2 \quad$ Credit Cycles $\ldots \ldots \ldots \ldots \ldots$. . . . . . . . . . . . 51

$2.3 .3 \quad$ Steady State . . . . . . . . . . . . . . . . . . . . 54

2.4 Calibration Analysis $\ldots \ldots \ldots \ldots \ldots \ldots$

$2.4 .1 \quad$ Macro Properties $\ldots \ldots \ldots \ldots$ 
$2.4 .2 \quad$ Micro Properties $\ldots \ldots \ldots \ldots$. . . . . . . . 57

2.5 Concluding Remarks . . . . . . . . . . . . . . . 59

2.6 Tables and Figures . . . . . . . . . . . . . . . . 61

\begin{tabular}{lr}
\hline Chapter 3 & 85
\end{tabular}

3.1 Introduction . . . . . . . . . . . . . . . . 85

3.2 Bargaining Power and Growth . . . . . . . . . . . . . . . 86

3.3 Bargaining Power and Risk. . . . . . . . . . . . . . . . . 90

3.4 Concluding Remarks . . . . . . . . . . . . . . . . . . . . . . . . . . . . . . .

3.5 Figures $\ldots \ldots \ldots \ldots \ldots \ldots$. . . . . . . . . . . . . . 97

\begin{tabular}{lr}
\hline Conclusions & 99
\end{tabular}

\begin{tabular}{ll}
\hline Bibliography & 102
\end{tabular} 


\section{Introduction}

The financial sector plays a fundamental role in ensuring the correct and efficient functioning of modern economies. Indeed, it can enhance both the resilience to shocks and the growth prospects of a Country through an optimal allocation of resources. However, the Great Recession in 2009 showed, after nearly a century from the Great Depression, that finance can also be the source of severe instability and widespread economic downturns.

The main aim of this thesis is thus to study how the financial and, in particular, the credit sectors affect the overall performance of the real economy. Specifically, we investigate the effects of the mechanism of capital allocation on the dynamic of macroeconomic cycles and on the long-run potential growth rate. Indeed, given the position of financial intermediaries between the demand and the supply of loanable funds, banks can modify the market equilibrium by influencing the choices of households and firms. Moreover, also the competitive pressure arising from incumbent institutions can play a major role in the definition of the final result. Therefore, the focus of this work is on the feedback mechanisms within the financial sector and between the latter and the real one.

The thesis is a collection of three articles which concentrate on various aspects of this topic and employ different methodologies to obtain and analyze the results. Specifically, in the first two chapters we rely on the agent-based literature to investigate the role of the financial sector on the formation of economic cycles. Indeed, macroeconomic dynamics can emerge endogenously through this methodology because of the localized interactions of heterogeneous agents (see, for example, Delli Gatti et al. (2005) and Tesfatsion (2006)). Accordingly, agent-based models (ABM) seem to be the natural choice to analyze economic fluctuations. On the contrary, in the last chapter we introduce a representative agent framework to study the effects of banks' bargaining power on aggregate growth and systemic risk. In fact, in this case, the focus is on the static properties of the economy rather than on its dynamic features.

As stated before, in the first chapter we develop a macroeconomic model 
with decentralized matching in which resources flow from households to firms through financial institutions. Specifically, we implement an ABM in which families and entrepreneurs move from an intermediary to another one without any constraint. As a result, banks react to changes in their demand for credit and their supply of deposit modifying their interest rates. Overall, we find that the decentralized mechanism of capital reallocation can produce endogenous fluctuations in the system. Indeed, the competitive pressure on the asset and liability side of banks' balance sheets can give rise to a strategic complementarity in the behavior of intermediaries. Moreover, the continuous creation and destruction of credit lines can modify the aggregate productivity of the economy, thus leading to further amplification of cycles.

The second chapter extends the preceding work by including an interbank market. Moreover, we modify the model introducing a preferential attachment mechanism whereby agents react to reductions in the fit of their existing counterparty by switching to a new one (Bianconi and Barabási, 2001). Indeed, this framework allow us to analyze our results on the basis of network theory (as in Delli Gatti et al. (2010), Riccetti et al. (2013) and Lenzu and Tedeschi (2012)). Overall, the new specification of the model confirms the idea that the interbank market can be an indisputable source of economic development. In fact, counterbalancing depositors movements, it can dampen the continuous creation and destruction of credit lines, thus reducing the implicit loss of banks' informational capital and increasing the overall efficiency of the system. Nevertheless, that result depends on the topology of the network. Indeed, a highly centralized financial market can amplify the effects of exogenous shocks in the economy. In fact, in that situation, the state of the system heavily relies on the overall efficiency of the core bank and vice-versa.

Lastly, the third chapter introduces a representative agent model to study the effects of financialization on aggregate growth and systemic risk. Specifically, the idea is to provide an explanation for the parallel development of the financial sector, the reduction of aggregate growth and the overall increase in financial fragility of Western economies during the last three decades (Palley, 2013). We find that the main driver of this process can be the bargaining power of intermediaries. Indeed, financial institutions, by absorbing a larger quota of income from entrepreneurs, can reduce the incentive for new firms to enter the market. As a result, both the long-term growth rate and the overall stability of the system can be negatively affected by an overdeveloped financial sector. 


\section{Chapter 1}

\subsection{Introduction}

Credit to non-financial businesses and households is notoriously pro-cyclical (Covas and Haan, 2011, Schularick and Taylor, 2012), a fact that in the last three decades has attracted a huge amount of theoretical work meant to explore the channels linking financial flows to real macroeconomic activity (Foglia et al., 2011). The received pre-2007 approach was centered on the idea that the causality runs from changes in the real sector to movements in financial flows, whereas financial frictions impinging on the borrowers' capacity amplify the macroeconomic impact of exogenous shocks to productivity or preferences (Bernanke and Gertler, 1989; Greenwald and Stiglitz, 1993, Kiyotaki and Moore, 1997). In turn, the bulk of the research emerged after the global financial crisis has offered theories pointing toward an inversion of the causality nexus. In the models surveyed in e.g. Brunnermeier et al. (2013) and Christiano and Ikeda (2011), a shrinkage in the total amount of funds channeled from lenders to borrowers derives from disruptions in financial markets due to shocks affecting either banks' capital or liquidity. Recessions are therefore the outcome of a cut in spending and hiring by borrowers generated by a supply-induced credit tightening.

In this paper we present an agent-based computational model in which the flowing of funds from savers to investors is intermediated by a stream of banks competing in fully decentralized markets for deposits and loans, where the only friction affecting agents is that they are imperfectly aware of the economic opportunities they potentially face. In our setting, the transmission channel between the financial and the real sectors turns out to be bidirectional, while cyclical fluctuations emerge endogenously as intermediaries adjust the size of their balance sheet to the varying competitive conditions affecting the asset and liability sides, respectively. In particular, banks compete on prices either to attract demand deposits from households and to offer long-term - but freely severable - credit contracts to firms, so that the net interest margin represents a key state variable indicating the viability 
of the banking sector while transforming maturities. Due to search costs in locating profitable opportunities, the economy is affected by matching and allocation imperfections that co-evolve endogenously, giving rise to large reallocations of credit among firms on a regular basis. The dynamics of credit creation and destruction are related to the relative strength of economic activity, however. This is due to the ensuing complementarity between the number of active bank-firm relationships and the savers' incentive to provide funds to intermediaries, which returns a pro-cyclical average productivity. The time paths we obtain through simulations show that the statistical features of the gross flows of credit, as well as its aggregate volume, are in line with those observed in real data. Interestingly enough, this result is obtained in a simplified framework completely abstracting from agency frictions, aggregate disturbances to primitive parameters, time-varying risk taking due to capital regulation or institutional arrangements like a deposit guarantee or a LOLR authority.

Having established the general features of the relationship linking the credit and the business cycles, we go on to investigate how a financial crisis - here modelled as a funding run leading to the disruption of one or more banks - affects the macroeconomic performance. We find that the interplay of credit creation and destruction associated to a financial turmoil generates downturns that are deeper and more prolonged, that the subsequent rebound can be insufficient to regain pre-crises output levels, and that these effects are more pronounced when the financial crisis coincides with a "real" downturn. Thus, our model presents two implications corroborated by the empirical evidence: 1) financial crisis can lead to permanent output losses (BoysenHogrefe et al., 2016); 2) banking crises operate as a factor limiting aggregate activity distinct from standard recessions (Dell'Ariccia et al., 2008).

While close in spirit to the stream of research dealing with equilibrium search in credit markets (Diamond, 1990; Den Haan et al., 2003; Wasmer and Weil, 2004, Becsi et al., 2013), our model is firmly rooted in the tradition of the agent-based literature exploring the emergence of macroeconomic features from the localized interactions of heterogeneous agents employing decentralized matching and bargaining protocols (Fagiolo et al., 2004; Gaffeo et al., 2008, 2015, Riccetti et al., 2015; Guerini et al., 2018). This approach offers us two key advantages. First, we can extend the macroeconomicoriented analysis of credit allocation from a static multiple equilibria framework to a dynamic one, where credit mismatches develop from feedback effects as agents interact in distinct but interrelated customer markets (Gottfries, 1991). Second, beyond overcoming the need to postulate an exogenouslygiven matching technology, we provide accurate sensitivity analyses to analyze how macroeconomic outcomes are affected by banks' behavior in ex- 
tending credit.

Our findings are also related to two other broad streams of literature. First, a large body of empirical research has persuasively shown that the dynamic process of credit reallocation across heterogeneous firms is an intense and pervasive phenomenon, that its magnitude and volatility dwarf that of the total volume of credit, and that it plays a significant role in determining the strength of macroeconomic activity and real growth rates (Jayaratne and Strahan, 1996, Herrera et al., 2011; Inklaar et al., 2015). The reshuffling of financial resources across firms due to the creation and destruction of bank debt is particularly compressed during episodes of financial turmoil (Contessi and Francis, 2013; Hyun, 2016), signalling that the interplay between resource misallocation and the endogenous worsening of financial frictions is at the heart of the deep and prolonged periods of low resource utilization following acute financial crises (Hall, 2011; Bordo and Haubrich, 2017).

We add to this essentially empirical literature by providing a theoretical justification for these stylized facts. In particular, we show that the intense credit reallocation observed in real data can be traced back not only to the way intermediaries compete in the market for loans, but also to the feedback exerted on it by the fact that banks also struggle to attract depositors as they set their passive interest rates.

Second, a rapidly growing body of work has stressed the role of financial intermediaries' balance sheets both as shock amplifiers and as a source of fluctuations in economic activity (Boyarchenko and Adrian, 2015, Brunnermeier and Koby, 2016). Accordingly, using data for the USA Adrian and Shin (2010) show how fluctuations in the balance sheets of financial institutions possess forecasting power for future GDP growth, while the evidence provided by Adrian et al. (2010) suggests the presence of a causal chain running from the term spread, moving to the net interest margin of banks, advancing to lending volumes and finally reaching real growth. We complement this literature by highlighting a different channel linking fluctuations in the size of intermediaries' balance sheets and fluctuations in real activity. In addition to the risk-taking and the leverage channels explored so far, we advance an explanation in which the net interest margin registered by banks evolves in cycles because of a "competition" channel driven by a complementarity between financial intermediation and aggregate investment.

The rest of the paper is organized as follows. Section 1.2 presents the model and provides a discussion of the initial conditions used in simulations. Section 1.3 takes stock of simulation results to highlight the existence of endogenous and co-evolving business and financial cycles. Section 1.4 extends the basic model by examining the effects of exogenously determined bank runs. Section 1.5 concludes and outlines directions for further research. 


\subsection{Model}

The economy is composed of a fixed number of households $\left(h=1, \ldots, n_{h}\right)$, intermediaries $\left(i=1, \ldots, n_{i}\right)$ and firms $\left(f=1, \ldots, n_{f}\right)$. Households are endowed with accumulable wealth, which we assume for simplicity as the only factor of production, while firms have no resources of their own and must raise funds on the credit market to start production. Families deposit their wealth in only one intermediary at a time as demand deposits and cannot establish direct connections with producing firms. Here we are implicitly assuming that investments evaluation and ex-post verification are costly and intermediaries are more efficient than households in performing these tasks. In addition, we assume that the financial sector can supply credit without sustaining any additional effort or expense. On the other hand, households can always search a new counterpart and move their wealth from an intermediary to another one without any constraint.

As in Den Haan et al. (2003), intermediaries supply credit to firms through a simple contract in which a fixed portion of production $\left(P_{i, f}\right)$ is left to the entrepreneurs as payment for the effort. Notice that this value measures both the profitability $\left(P_{i, f}\right)$ and the cost of financing $\left(r_{i, f}=\left[f\left(k_{i, f}\right)-P_{i, f}\right] / k_{i, f}\right)$ of the company, where $f(\cdot)$ is the production function and $k_{i, f}$ is the external finance supplied by the i-th intermediary to the f-th firm. Accordingly, entrepreneurs search and choose the banks paying the highest contractual profits.

The level of profit $\left(P_{i, f}\right)$ and the loan size $\left(k_{i, f}\right)$ are set at the beginning of the open-ended credit relation and are not modified through time ${ }^{1}$. With regards to the latter, we assume that the value of new issuances is extracted at random from a pre-defined distribution. Indeed, the idea is to model the implicit informational capital of banks through this mechanism (Stiglitz, $2015 b$ ). In fact, we assume that intermediaries do not know the optimal size of loans. However, when they need additional money to repay depositors, they reduce their assets starting from sub-optimal investments. Consequently, the efficiency of the banks' portfolios increases over time because of this asymmetric mechanism of credit allocation ${ }^{2}$

As stated before, firms can move to another counterpart whenever they observe a more attractive financing opportunity in the market. In this case, the credit line is closed and the funds returned to the intermediary. However, entrepreneurs do not consider exclusively contractual profits in this choice.

\footnotetext{
${ }^{1}$ Entrepreneur which are not borrowing have $P_{i, f}=\theta$ and $k_{i, f}=0$, where $\theta$ is the reserve utility, which we define later in the text.

${ }^{2}$ In other words, new issuances can return both high and low interest rates, while the loans held in the portfolio are only the most profitable ones.
} 
Specifically, we assume that firms have a reserve utility $(\theta)$ and sustain a cost $(x)$ each time they search for a new counterparty. Notice that the reserve utility can be interpreted as a home production level, which is not included in the aggregate production calculations. Therefore, entrepreneurs have the incentive to demand credit and start a new market activity only if the externally financed firm returns an expected profit higher than their reserve value. To further simplify the model, we assume also that both the home and the market activities require the same level of effort from entrepreneurs. Consequently, the reserve utility and the search cost are the only factors affecting entrepreneurs' choices. Moreover, we force intermediaries to finance the search cost of new lenders for the first period (see Table 1.1). As a result, the value of the firm and, consequently, of the credit relationship increase through time, in line with the literature on relationship banking (see e.g. Boot (2000) for a review).

Overall, intermediaries react to the behavior of households and firms in this framework. From the liability side, families can move their wealth between intermediaries without any constraint, while on the asset side entrepreneurs can shift from the current lender to a new one every time they observe a better financing opportunity in the market.

As stated before, firms must take into account search costs in this choice. In particular, an entrepreneur look for a new counterpart if

$$
E[\text { search }]-E[\text { not search }]=\frac{P_{t}}{R_{t}}-x-\frac{P_{i, f}}{R_{t}} \geq 0
$$

where we assume that firms discount future cash flows considering the current market interest rate $\left(R_{t}\right)$ as fixed and constant through time. In addition, entrepreneurs use average profits $\left(P_{t}\right)$ as a proxy for evaluating new loans and do not take into account the probability of future rescissions of the contract.

\subsubsection{Model Initialization}

At the beginning of the world, families have an homogeneous quantity of wealth $d_{h, 0}=W_{0}\left(\forall h=1, \ldots, n_{h}\right)$ which they deposit in a bank selected at random. We define the subset of households connected to the i-th intermediary at time $t$ as $H_{i, t}$. Hence, for $t=0$ we have: $\operatorname{Pr}\left(h \in H_{i, 0}\right)=U\left(1, n_{i}\right)$, where $U(\cdot)$ is a uniform distribution.

Intermediaries set the initial contractual profit $P_{i, 0}=\theta+x R_{0}$, fix a

\footnotetext{
${ }^{3}$ Firms which have just started a new credit relation $(t=1)$ must satisfy the condition: $E[$ search $]-E[$ not search $]=\frac{P_{t}}{R_{t}}-\frac{P_{i, f}}{R_{t}}+x R_{t} \geq 0$ (see Table 1.1 .
} 
minimum investment dimension $\bar{k}_{i, 0}$, evaluate the resources available for investments and generate a credit supply schedule ${ }^{4}$.

We define the minimum investment dimension as the lowest value of capital producing a non negative interest rate: $\bar{k}_{i, t}=\left\{k \mid f(k)-P_{i, t}=0\right\}$. We set this constraint to avoid negative returns, which increase excessively the volatility of simulations and, because of this, occasionally produce degenerate equilibria in which only one intermediary remains in the market $5^{5}$. However, from a theoretical point of view, this assumption allows us to define deposits as truly risk-free, in the sense that the capital quota is always repaid.

As stated before, the credit supply of every intermediary is computed according to a stochastic allocation process. The quantity of available resources is simply given by the sum of the initial deposits $\left(\bar{K}_{i, 0}=\sum_{h \in H_{i, 0}} d_{h, 0}\right)$, while the size of new loans is extracted from the distribution:

$$
k_{j}^{n e w} \sim U\left(\bar{k}_{i, 0}, \bar{K}_{i, 0}\right)
$$

until the condition

$$
\bar{K}_{i, 0}=\sum_{j \in I_{i}^{\text {new }}}\left(k_{j}^{\text {new }}+x\right)
$$

is satisfied 6 .

Lastly, firms demand for funds and start production. Given that at this stage all the intermediaries offer the same contractual profit, we allocate credit across entrepreneurs at random. In other words, we extract the composition of the initial credit network with probabilities: $\operatorname{Pr}\left(f \in F_{i, 0}\right)=$ $U\left(1, n_{i}\right) \cdot U\left(1, n_{f}\right)$, where $F_{i, t}$ is the set of firms connected with the i-th intermediary at time $t$.

\subsubsection{Sequence of Events}

Once the system starts, the economy evolves recursively following the subsequent steps in each iteration:

\footnotetext{
${ }^{4}$ We set the initial contractual profit equal to $P_{i, 0}=\theta+x R_{0}$ to start the model with a value equal to the long-term zero profit condition: $\frac{P_{i, 0}}{R_{0}}=\frac{\theta}{R_{0}}+x$.

${ }^{5}$ Degenerate equilibria are usually the effects of an excessive reactivity of the system in the early stages of the simulation. A possible solution to this problem would have been the use of a larger number of agents to avoid initial jumps and have a smoother transition. However, the system would have become excessively costly from a computational point of view.

${ }^{6}$ We define $I_{i}^{\text {new }}$ as the set of new loans supplied by the i-th intermediary.
} 
1. Entrepreneurs start production, retain profits and return to lenders the interest rate:

$$
r_{i, f}=\frac{f\left(k_{i, f}\right)-P_{i}}{k_{i, f}}
$$

and the average productivity of the economy is defined as:

$$
z_{t}=\frac{\sum_{f=1}^{n_{f}} f\left(k_{i, f}\right)}{\sum_{f=1}^{n_{f}} k_{i, f}}
$$

2. Intermediaries collect the stream of income produced by their investments and calculate the active interest rate:

$$
r_{i, t}^{a}=\frac{\sum_{f \in F_{i, t-1}} r_{i, f} \cdot k_{i, f}+\sum_{f \in F_{i, t-1} \wedge f \notin F_{i, t-2}} r_{i, f} \cdot x}{\sum_{f \in F_{i, t-1}} k_{i, f}}
$$

and its counterpart on deposits:

$$
r_{i, t}^{d}=\frac{\sum_{f \in F_{i, t-1}} r_{i, f} \cdot k_{i, f}+\sum_{f \in F_{i, t-1} \wedge f \notin F_{i, t-2}} r_{i, f} \cdot x}{\sum_{h \in H_{i, t-1}} d_{h, t-1}}
$$

where the return obtained from the financing of search costs is included only for new loans $\left(f \in F_{i, t-1} \wedge f \notin F_{i, t-2}\right)$.

The aggregate active and passive interest rates are then defined through the weighted averages:

$$
\begin{aligned}
R_{t}^{a} & =\frac{\sum_{i=1}^{n_{i}} \sum_{f \in F_{i, t-1}} r_{i, t}^{a} \cdot k_{f, t-1}}{\sum_{i=1}^{n_{i}} \sum_{f \in F_{i, t-1}} k_{f, t-1}} \\
R_{t}^{d} & =\frac{\sum_{i=1}^{n_{i}} \sum_{h \in H_{i, t-1}} r_{i, t}^{d} \cdot d_{h, t-1}}{\sum_{i=1}^{n_{i}} \sum_{h \in H_{i, t-1}} d_{h, t-1}}
\end{aligned}
$$

and we consider the latter as the reference interest rate of the entrepreneurs $\left(R_{t}=R_{t}^{d}\right.$, see Eq. 1.1).

3. Households observe the return obtained on deposits, consume and allocate capital. Specifically, families receive the interest rate paid by their corresponding intermediary, namely $r_{h, t}=r_{i, t}^{d}$ with $h \in H_{i, t}$ (see Eq. 1.7), and maximize the intertemporal problem:

$$
\max E_{t}\left[\sum_{s=0}^{\infty} \beta^{s} \log \left(c_{h, t+s}\right)\right]
$$




$$
\text { s.t. } d_{h, t+s}+c_{h, t+s}=\left(1+r_{h, t+s}\right) d_{h, t+s-1}
$$

whose solutions are:

$$
\begin{gathered}
c_{h, t}=(1-\beta)\left(1+r_{h, t}\right) d_{h, t-1} \\
d_{h, t}=\beta\left(1+r_{h, t}\right) d_{h, t-1}
\end{gathered}
$$

Subsequently, households search at random a new intermediary such that $r_{n e w, t}^{d} \geq r_{i, t}^{d}$, which implies: $h \notin H_{i, t} \wedge h \in H_{\text {new }, t}$.

Notice that the combination of this mechanism with the minimum investment condition ensures that families always allocate their wealth to an active intermediary. In fact, banks without deposits do not have the resources to supply credit and do not pay any interest. On the contrary, intermediaries with an active balance sheet can return a positive, even if low, income stream to their depositors.

Therefore, non-performing banks can only exit from the economy in this framework. Indeed, households slowly withdraw all deposits from sub-optimal intermediaries, up to the point when all the resources are completely depleted. From that moment on, families do not select those intermediaries anymore because of the zero interest rate. Consequently, this condition guarantees the emergence of an endogenous bargaining power among the agents.

4. Intermediaries evaluate liquidity, modify the contractual profit on new loans and supply credit.

The term liquidity $\left(L_{i, t}\right)$ indicates the amount of unallocated resources available for investments in each intermediary at the beginning of every period. This value is given by the difference between the current level of deposits and the portfolio of investments inherited from the preceding period:

$$
L_{i, t}=\sum_{h \in H_{i, t}} d_{h, t}-\sum_{f \in F_{i, t-1}} k_{i, f}
$$

When an intermediary experiences an excessive withdrawal of funds, namely when $L_{i, t}<0$, it has to reduce lending to repay depositors. Therefore, the bank evaluates the interest rate of each investment and close the contracts with the lowest returns until the condition

$$
\sum_{f \in F_{i, t-1}} \tilde{k}_{i, f}+L_{i, t} \geq 0
$$


is satisfied, where $\tilde{k}_{i, f}$ are the credit lines with the minimum profitability.

Subsequently, intermediaries modify the contractual profit that they will pay on new loans. Specifically, they follow the rule:

$$
P_{i, t}= \begin{cases}P_{i, t-1} & \text { if } \sum_{h \in H_{i, t}} d_{h, t} \geq \sum_{h \in H_{i, t-1}} d_{h, t-1} \\ {[1+\gamma \cdot \mathbb{1} \cdot U(0,1)] \cdot P_{i, t-1}} & \text { otherwise }\end{cases}
$$

where $\mathbb{1}= \begin{cases}+1 & \text { if } U_{i, t-1} \geq \bar{k}_{i, t-1}+x \\ -1 & \text { otherwise }\end{cases}$

When an intermediary observes an increase in the total amount of deposits, it keeps the contractual profit at the level of the previous period. In fact, it recognizes that it is paying an interest rate higher than the rest of the economy and that it is optimal not to modify the conditions which produced that result.

Conversely, when it experiences a withdrawal of deposits, the intermediary must understand why it is not able to pay a sufficiently high return to its depositors. The main driver of this decision is the amount of unallocated capital $\left(U_{i, t-1}\right)$ accrued in the preceding period. Notice that it is always optimal for the single intermediary to invest all the available resources to obtain a non-negative interest rate. Hence, an excess of uninvested funds - defined here as a positive difference between the overall quantity of unallocated resources and the minimum investment dimension plus the financing of the search cost $\left(U_{i, t-1} \geq \bar{k}_{i, t-1}+x\right)$ - indicates that the bank is not offering a sufficiently competitive contractual profit to the firms. In the opposite situation, the intermediary recognizes that it is leaving an excessively high quota of production to the entrepreneurs and is obtaining a sub-optimal return from its investments.

Lastly, as in the initialization phase of the economy, intermediaries compute the minimum investment dimension of the new contractual profit $\left(P_{i, t}\right)$ and extract the size of each new loan from the distribution: $k_{j}^{n e w} \sim U\left(\bar{k}_{i, t}, \bar{K}_{i, t}\right)$, with $\bar{K}_{i, t}=\sum_{f \in F_{i, t-1}} \tilde{k}_{i, f}+L_{i, t}$.

5. Firms observe the average contractual profit and evaluate the opportunity cost of changing their counterparts.

The average contractual profit on new loans is defined as:

$$
P_{t}=\frac{\sum_{i=1}^{n_{i}} \sum_{j \in I_{i}^{\text {new }}} P_{j, t}}{\sum_{i=1}^{n_{i}} \sum_{j \in I_{i}^{\text {new }}} 1}
$$


and is updated each time a firm borrows from a bank. Specifically, the order of firms acceding to the credit market is extracted at random and when a new loan is issued it is removed from the credit supply schedule. Entrepreneurs evaluate the potential benefit of borrowing from a new intermediary through equation (1.1) and, if positive, they look for another counterpart such that:

$$
\frac{P_{z, t}}{R_{t}}-x \geq \frac{P_{i, f}}{R_{t}}
$$

which implies: $f \notin F_{i, t} \wedge f \in F_{z, t}, P_{i, f}=P_{z, t}$ and $k_{i, f}=k_{j}^{n e w}$, with $j \in I_{z}^{\text {new }}$.

6. When the credit supply is completely depleted or there is no more demand for new loans, intermediaries evaluate the final amount of unallocated resources:

$$
U_{i, t}=\sum_{h \in H_{i, t}} d_{h, t}-\sum_{f \in F_{i, t}} k_{i, f}-\sum_{f \in F_{i, t} \wedge f \notin F_{i, t-1}} x
$$

where they subtract also the financing of new borrowers' search costs.

\subsubsection{Margin of Intermediation and Cash Reserves}

As we will explain later in the text, it is necessary to focus both on the dynamic of the interest rate differential and on the definitions of liquidity and unallocated capital to understand the circumstances behind the endogenous formation of credit cycles.

Starting from the margin of intermediation, the balance sheet equation of the intermediaries implies the following economy-wide identity:

$$
\sum_{i=1}^{n_{i}} \sum_{h \in H_{i, t-1}} d_{h, t-1}=\sum_{i=1}^{n_{i}} U_{i, t-1}+\sum_{i=1}^{n_{i}} \sum_{f \in F_{i, t-1}} k_{f, t-1}
$$

Accordingly, the aggregate interest rate differential is a function of the overall level of unallocated capital and of the return on investments:

$$
R_{t}^{a}-R_{t}^{d}=\frac{\sum_{i=1}^{n_{i}} U_{i, t-1}}{\sum_{i=1}^{n_{i}} U_{i, t-1}+\sum_{i=1}^{n_{i}} \sum_{f \in F_{i, t-1}} k_{f, t-1}} R_{t}^{a}
$$

Hence, both a rise in contractual profits and a decline in firms productivity, by reducing the active interest rate, shrink the margin of intermediation. In 
a similar manner, a contraction in the level of unallocated capital decrease the interest rate differential.

With regards to the equations of liquidity (1.14) and unallocated capital (1.19), it may appear that they represent the same economic dimension. To better understand the differences between those measures and their economic intuition, it is useful to rewrite them in terms of their past values. Specifically, by substituting 1.14 in 1.19 we find:

$$
U_{i, t}=\sum_{f \in F_{i, t-1}} k_{i, f}-\sum_{f \in F_{i, t}} k_{i, f}+L_{i, t}
$$

where we removed for simplicity the financing of the search costs of new borrowers. Similarly, by taking $(1.19)$ with one period lag and by substituting it in 1.14 we obtain:

$$
L_{i, t}=\sum_{h \in H_{i, t}} d_{h, t}-\sum_{h \in H_{i, t-1}} d_{h, t-1}+U_{i, t-1}
$$

The new versions of the two equations put under the light the main drivers of the underlying economic dynamic. Specifically, with regards to the unallocated capital $\left(U_{i, t}\right)$, it emerges that, given the current level of liquidity, entrepreneurs' movements across the intermediaries determine the overall amount of uninvested funds left in banks $\left(F_{i, t-1} \rightarrow F_{i, t}\right)$. Conversely, the resources available for supplying new credit $\left(L_{i, t}\right)$ are the result of the households' investment decisions $\left(H_{i, t-1} \rightarrow H_{i, t}\right)$. In other words, movements in the level of unallocated capital $\left(U_{i, t}\right)$ capture the changes in the asset side of the intermediaries' balance sheets, while adjustments in the liquidity $\left(L_{i, t}\right)$ provide a proxy for the evolution of banks' liabilities.

\subsection{Simulation Results}

In this section we discuss the results obtained from the simulation of the model. Specifically, we focus on the effects of the parameters on the determination of the pseudo steady-state level of the economy and on the dynamic of the endogenous cycles of the system.

\subsubsection{Initial Setting and Sensitivity Analysis}

As in all agent-based model, parameters play a major role in the definition of the results and in the emergence of endogenous dynamics. We hold particular attention to the effects on the system of the firms' reserve utility $\theta$ and 
of the intermediaries' contractual adjustment factor $\gamma$. Indeed, these two parameters modify not only the shape of the cycles and the response of the economy to a bank run but also the pseudo steady-state level of the system.

Conversely, with regards to the search cost $x$, simulations show that changes in the size of this value produce only second-order effects (Fig. 1.3). Indeed, from the point of view of the entrepreneur, this cost is relatively small compared to the expected value of the firm (see Table 1.1 and Eq. 1.1 and 1.18). Given that interest rates are close to zero near the pseudo steadystate, also the product $x R_{t}$ becomes irrelevant, thus dampening the effects of this friction on the economy. In addition, also banks and depositors are indifferent to the size of search costs. Indeed, they obtain a positive return through their funding. However, the existence itself of this friction modifies the dynamics of the system. In fact, when entrepreneurs evaluate the benefits of searching a new counterpart, they can only observe the average profit paid on new loans (Eq. 1.1). For this reason, a large number of new credits with low profitability can hide good investment opportunities. Therefore, the outcome is an increased persistence of cycles. In the light of these results, we set the search cost close to zero $(x=\varepsilon))^{7}$ to maintain its effect on the economy and to minimize the degree of subjectivity in the decisional process.

We set a sufficiently high number of households $\left(n_{h}=2000\right)$ and firms $\left(n_{f}=2000\right)$, while we limit the quantity of intermediaries $\left(n_{i}=50\right)$ to keep the computational complexity of the model at an acceptable level. If on the one hand this choice produces slightly irregular initial transition phases, on the other one it returns reasonable results in the long-run. Households parameters are set inside a realistic range. In particular, we choose a discount factor $\beta=0.95$ and an initial capital $W_{0}=0.1$. With regards to the production function, we use a common functional form with decreasing marginal productivity: $f(k)=k^{\alpha}$, where $\alpha=0.3$. Lastly, we study the pseudo steadystate level of the system on a range of the firms' reserve utility $\theta=[0.05,1.0]$ and of the intermediaries' contractual adjustment factor $\gamma=[0.05,1.0]$.

Notice that we set an upper bound for the entrepreneurs' reserve utility equal to one. This is due to the intrinsic characteristic of the interest rate function. In particular, the return of the single investment is defined as:

$$
r=\frac{k^{\alpha}-P}{k}
$$

This function presents a point of maximum, whose solution is:

$$
k^{\max }=\left(\frac{P}{1-\alpha}\right)^{1 / \alpha} \Longrightarrow r^{\max }=\alpha\left(\frac{P}{1-a}\right)^{(1-1 / \alpha)}
$$

\footnotetext{
${ }^{7} \varepsilon=2.22 \times 10^{-16}$ is the machine epsilon.
} 
Given the discount factor $\beta=0.95$ and the production function parameter $\alpha=0.3$, the maximum value of the firms' profits compatible with the households steady-state condition $(r=1 / \beta-1)$ is equal to:

$$
P^{\beta}=(1-\alpha)\left(\frac{1-\beta}{\beta \alpha}\right)^{\frac{\alpha}{\alpha-1}}=1.4759
$$

Consequently, a contractual profit over this threshold always returns an interest rate lower than the households discount factor. Therefore, in that situation, there is an overall withdrawal of resources by the families and, in the long-run, a collapse of the economy to an equilibrium without production and consumption. Moreover, firms' reserve utility posit a lower constraint on contractual profits. Indeed, values below this zero utility threshold do not meet entrepreneurs demand. In summary, to avoid degenerate equilibria and to leave enough decision space to intermediaries, we decide to limit the study of the dynamic of the system up to this value of the firms' reserve utility.

Similarly, we constrain also the intermediaries' adjustment factor to an upper bound equal to one. In fact, the range of the percentage change of the banks' contractual profit is equal to $\pm 100 \%$ in this case. In view of that, we consider this limit sufficiently high for our purposes.

The system converges to a positive level of production and the number of intermediaries always remains above the degenerate equilibrium with only one bank left in the economy (Fig. 1.2, 1.4 and 1.5). As expected, the average value of firms' profit increases with the reserve utility. Accordingly, the higher production quota left to entrepreneurs has a negative effect on the interest rate paid to the households and, in turn, on the accumulation of capital and on the overall level of production (Fig. 1.2 and 1.4). Conversely, the intermediaries' adjustment factor has a positive effect on the stability of the economy (Fig. 1.2 and 1.6): a stronger reactivity of the financial system anticipates the formation of cycles and dampens their effects. However, this characteristics comes with a drawback. When the entrepreneurs' reserve utility is high, an excessive responsiveness of intermediaries increases the number of times that firms' profits exceed the households' steady-state condition (Eq. 1.26). That explains the low number of financial institutions and the reduced level of production in those regions with high reserve utility and high contractual adjustment factor.

To end with, notice that the level of unallocated capital in the system increases with the firms' reserve utility and the intermediaries' adjustment factor (Fig. 1.7). At the same time, the extra profit of firms $(P-\theta-x R)$ decreases along those directions (Fig. 1.8). As we will explain in the next section, this feature of the system is connected to the proximity of these points to the no entry condition and to the maximum production limit. 


\subsubsection{Credit Cycles}

An emerging feature of the stylized economy introduced here is the presence of endogenous credit cycles. To study the mechanisms behind these movements and to capture all the properties of the system, we choose to analyze an intermediate combination of parameters: $\{\gamma=0.5 \wedge \theta=0.5\}$.

During periods of economic growth (Fig. 1.9), the system experiences an increase in firms' productivity and in the average interest rate paid by the intermediaries to the households (Fig. 1.10 and 1.11). At the same time, the volume of unallocated resources reaches its maximum level (Fig. 1.13), the average contractual profit decreases (Fig. 1.12) and there is an expansion in the number of new credit line and a simultaneous contraction in loans closure (Fig. 1.14 and 1.15). Conversely, during economic downturns (Fig. 1.9), the interest rate and firms' productivity collapse (Fig. 1.10 and 1.11), contractual profits increase (Fig. 1.12) and, in the initial phase of the crisis, the volume of firms switching between intermediaries hikes, with a slow process of absorption in the subsequent periods (Fig. 1.15). Finally, the credit market experiences a fast compression, with a rise in the quantity of intermediaries reducing the number of loans and a decline in the amount of banks offering new lending contracts (Fig. 1.14).

The main drivers of these dynamics are the existence of a strategic complementarity in the intermediaries' behavior and the presence of a strong inter-firm competition. All these aspects are then amplified by an allocative friction which modifies the productivity of investments and widens the reactivity of the system.

To understand the logic behind these fluctuations, it is useful to start from the beginning of an expansionary phase. In that situation, interest rates are higher than the households' discount factor and families have a strong incentive to save. In addition, contractual profits are close to firms reserve utility. Because of the positive conjuncture, intermediaries experience an inflow of funds and, on average, maintain the contractual profits at the level of the previous period. From the point of view of the entrepreneurs, only new entrants have thus the incentive to borrow at those conditions, hence leading to a positive inflow of firms. This fact, combined with a fixed amount of capital in the short run and a production function with decreasing marginal returns, brings to an increase in the total productivity of the economy and a rise in the total volume of production.

The incentive for all the intermediaries to maintain contractual profits constant holds as long as the amount of unallocated resources remains relatively low. Therefore, when the demand for new loans decreases, this policy stops being optimal and a reversal in the trend starts. This happens when 
the contractual profit exceeds the zero profit condition (Fig. 1.12). However, notice that the turnaround does not start immediately: even though there is an excess of unallocated capital, the past increases in the overall productivity of the system maintain interest rates above the households discount factor (Fig. 1.10 and 1.11). Consequently, families still have the incentive to save at a lower but positive growth rate and to avoid a sudden and unexpected withdrawal of funds. In other words, as long as the margin of intermediation of banks remains sufficiently wide, these have the opportunity and the incentive to keep supplying new credit to firms at the current market conditions.

From a theoretical point of view, this dynamic should converge to a stable equilibrium: the combined effects of high firm productivity and excess of capital should offset each other in the long-run, producing a margin of intermediation and an interest rate compatible with the households' discount factor. But the existence of a strategic complementarity in the intermediaries' behavior and the presence of a strong inter-firm competition limit the permanence of the economy at this equilibrium. Indeed, when the margin of intermediation of banks starts to squeeze because of the natural reduction of firms' productivity ${ }^{8}$, the single financial institution has the incentive to increase the contractual profit on new loans to attract new counterparts. From the point of view of the intermediary, this choice has a positive effect on its profitability. In fact, it increases the efficiency of its portfolio reducing the volume of unallocated resources. However, at the level of the whole economy, this produces a decrease in the overall productivity of the system. In fact, the new contractual profit attracts not only new entrants but also incumbent entrepreneurs (Fig. 1.15). Therefore, at the aggregate level, the same amount of capital is distributed across a smaller number of firms, with a decrease in the total productivity of the system (Fig. 1.11). This, in turn, reduces the interest rate paid to households (Fig. 1.10), driving them to a withdrawal of deposits. Furthermore, this downward trend is self-reinforcing. Indeed, the other intermediaries recognize that they are accumulating an excess of unallocated resources because of their uncompetitive contractual profit. Hence, their optimal policy is to increase the profit quota on new loans. This results in an upward trend in contractual profits (Fig. 1.12), a reduction in interest rates and firms productivity (Fig. 1.10 and 1.11) and to an overall withdrawal of resources by the households. This, in turn, produces a fast compression of the credit market (Fig. 1.14).

Lastly, the crisis stops when most of the unallocated resources are depleted and banks start to decrease contractual profits. Indeed, when an intermediary experiences a withdraw of funds it recognizes that all its re-

${ }^{8}$ In fact, the production function has decreasing marginal returns. 
sources were invested in the preceding period and it is leaving an excessively high production quota to the firms. Consequently, contractual profits start to decrease and interest rates slowly rise back to a level compatible with the households' discount factor.

In summary, the endogenous cyclicality of the system is due to the interaction between the behavior of intermediaries and firms. In fact, the absence of one of these two elements would prevent the beginning of the downward phase of the cycle. On the one hand, incumbents firms would not compete with the new ones if the intermediaries have not supplied loans at better conditions. On the other one, the relative interest rate of the single intermediary would not rise after an increase in its contractual profit if only new entrants have borrowed at the new price. Indeed, new firms require only a payment higher than their reserve utility. As a result, the reduction of the unallocated capital in the single bank and the consequent increase in its interest rate would be insignificant.

In addition, from this study emerges that the level of unallocated resources of intermediaries and the difference between the contractual profit and the reserve utility of firms are strictly connected to the phase of the cycle. This explains why different sets of parameters, which are characterized by dissimilar cyclicalities, have distinct levels of unallocated funds. In particular, economic systems featuring low volatility have also on average higher volumes of uninvested capital and smaller differences between contractual profits and reserve utilities. Indeed, in those situations the interaction between firms and intermediaries maintains the fluctuation of the system closer to the zero profit condition. In fact, in that phase of the cycle the level of unallocated capital is at its maximum level and the extra profits of the firms are close to zero.

\subsection{Bank Run and Persistent Slump}

In the preceding section we show that most of the movements in the system are the results of the interaction between firms and intermediaries. Households simply react to changes in the interest rate generated by the behavior of these agents. In this section we study the effects of a bank run, namely a sudden and unexpected withdrawal of resources by the depositors. The idea is to understand the role played by banks creditors in the formation and in the destruction of lending relations. Furthermore, we investigate whether the overall economic conditions influence the outcomes of this event.

The simplest way to model a bank run is to constrain the deposit decision of the households. Specifically, we prevent a subset of families from depositing 
their capital after they have withdrawn it. We perform this experiment under two different methodologies:

Targeted Bank Run (TBR): The subset of households belongs to a restricted group of intermediaries. The idea is to completely withdraw all the resources from a given number of banks and to interrupt all their lending activity.

General Bank Run (GBR): Families are selected at random across all the intermediaries. In this case, banks do not suffer a complete depletion of their deposits and do not close all their credit lines.

In both the experiments the volume of unallocated resources are approximately the same. In particular, we set the size of the unexpected withdrawal of funds equal to the average ratio between liquidity and capital. Indeed, the idea is to conduct a shock whose dimensions are equivalent to the normal fluctuations of the system. For the TBR experiment, we pick at random a subset of banks whose liabilities represent this capital quota, while for the GBR we chose a group of households which hold on overall the same amount of resources. To obtain a sufficiently high number of results we conduct 450 bank run of each type on a simulation of 10000 periods starting from the same random seed. The timing of the shock is then selected casually from a timespan between 4000 and 7000 periods. Lastly, the experiment is repeated over four different combinations of parameters: $\{\gamma=0.35 \wedge \theta=0.35\},\{\gamma=0.35 \wedge \theta=0.7\},\{\gamma=0.7 \wedge \theta=0.35\}$ and $\{\gamma=0.7 \wedge \theta=0.7\}$.

It appears that the GBR has a smaller and only temporary effect on the economy (Fig. 1.16, 1.17, 1.18 and 1.19). The reason behind this result is the destruction of credit lines. Indeed, by construction, the only difference in the two methodologies is the allocation of the bank run: while in the GBR it is spread across all the intermediaries, in the TBR it is concentrated on a small subset of them. Therefore, the diffusion of the shock through all the banks dampens its effects and reduces the number of credit lines which are destroyed. This is due to the fact that, on average, there is always a positive, even if small, amount of unallocated capital in the intermediaries' balance sheet. Consequently, in the GBR treatment, banks have the opportunity to draw resources from that entry rather than closing the credit lines. Conversely, in the TBR, all the loans connected to a specific intermediary are closed.

This fact explains why shocks show conflicting outcomes for different sets of parameters. In fact, the systems in which the average level of unallocated funds is low are subject to deeper and persistent recessions (Fig. 1.16 and 
1.18). Conversely, economies characterized by a higher level of uninvested capital are able not only to manage properly the shock but also to improve their steady-state performance (Fig. 1.17 and 1.19). Indeed, in these cases, the firms suffering an unexpected closure of their credit lines can immediately borrow from another intermediary. Therefore, the economy recovers faster and it is also able, in the short run, to allocate most of the exceeding capital inherited from the preceding period. In this way, this indirect rationalization of investments raises the overall productivity of the system in the long-run, with an increase in both the production level and the profitability of firms. On the contrary, in an economy with a low level of unallocated capital the intermediaries are not able to cover the additional demand for funds. Furthermore, in the subsequent periods - when the resources are reinvested in the economy by the households - banks start to decrease their contractual profits. Indeed, they try to improve their profitability through the exploitation of this temporary excess of demand. Therefore, the overall results in the short run are a reduction of the credit demand and a persistent accumulation of unallocated capital. Consequently, households have the incentive to withdraw and consume this excess of resources and the economy converges to a lower steady-state equilibrium in the long-run.

These results are confirmed by the analysis of the recovery times, namely the time required for the economy to reach the same level of production that it would have been obtained if there had not been the bank run. Specifically, we regress the logarithm of the recovery time on the logarithm of the aggregate production at the moment of the shock (Table 1.2). Estimates confirm the preceding intuition: recovery times are significant for those systems in which there is on average a lower volume of unallocated capital. In particular, an economy hit by a bank run during a period of elevated production and large uninvested resources requires a shorter time to recover. Clearly, this result does not hold for those systems in which there is always a high level of unallocated funds. To confirm this finding, we analyze also the recovery time for the GBR and, as expected, the estimations produce completely different results (Table 1.3 ).

Lastly, recovery times in the GBR and in the TBR are nearer in the moments of high production (Fig. 1.20). This finding is clearly in line with the preceding analysis of the shock: the dampening of the bank run is strictly connected to the overall level of unallocated capital of the system. In other words, it is the destruction of the credit lines which amplifies the shock: an economy in which the overall financial system can easier substitute a defaulted intermediary suffers minor losses. 


\subsection{Concluding Remarks}

This paper has developed a simple agent-based model of bank-intermediated credit flows in which information imperfections give rise to search frictions and resource misallocation. We have shown that credit and business cycles arise endogenously and co-evolve. The key driving mechanism is a pure competition effect, as banks struggle to manage their net interest margin through the activation and termination of loan relationships at varying interest rates in order to attract deposits. By assuming the possibility that banks can be affected by funding runs, we have also studied the macroeconomic impact of financial crisis in terms of output losses and speed of recovery.

The model can be extended in a number of directions to consider important issues. First, we have so far ignored agency frictions. The probability a long-run loan contract is severed - and, therefore, the extent of credit reallocation - is in general related to the effort choice of the borrower in servicing his debt, as well as on the risk appetite of the lender. Incorporating moral hazard problems associated to the level of net worth of agents are therefore likely to sensibly improve the explanatory capability of our model.

For reasons of tractability we have abstracted from the labor market or any other kind of physical production factors. As shown e.g. in Wasmer and Weil (2004), general equilibrium feedbacks between the markets for finance and productive inputs can magnify the response of the economy to exogenous shocks through a financial accelerator mechanism. Such an improvement could allow us to complement the story we offer here with an analysis of the way disruptions in financial markets affect unemployment and economic activity, and vice-versa, by exploring the issues of how credit misallocation interacts with labor misallocation (Delli Gatti et al., 2012) and income distribution (Dosi et al., 2013).

Finally, an interesting extension would be that of studying the role of the central bank in smoothing the credit cycle and responding to liquidity crisis by acting as a lender-of-last-resort. 


\subsection{Tables and Figures}

Table 1.1: Firm Value

\begin{tabular}{cccc}
\hline Time & $t=0$ & $t=1$ & $t=2, \ldots, \infty$ \\
\hline Cash flow & $P_{\text {old }}+x-x$ & $P_{\text {new }}-(1+R) x$ & $P_{\text {new }}$ \\
Firm value & $V_{0}=P_{\text {old }}+\frac{P_{\text {new }}}{R_{0}}-x$ & $V_{1}=\left(1+R_{1}\right)\left(\frac{P_{\text {new }}}{R_{1}}-x\right)$ & $V_{2}=\left(1+R_{2}\right) \frac{P_{\text {new }}}{R_{2}}$ \\
\hline
\end{tabular}

Note: the firm starts a new credit relation at time $t=0$ and considers the current interest rate $\left(R_{t}\right)$ as fixed and constant through time. Because of bounded rationality, the entrepreneur does not take account of the probability of future rescissions of the contract.

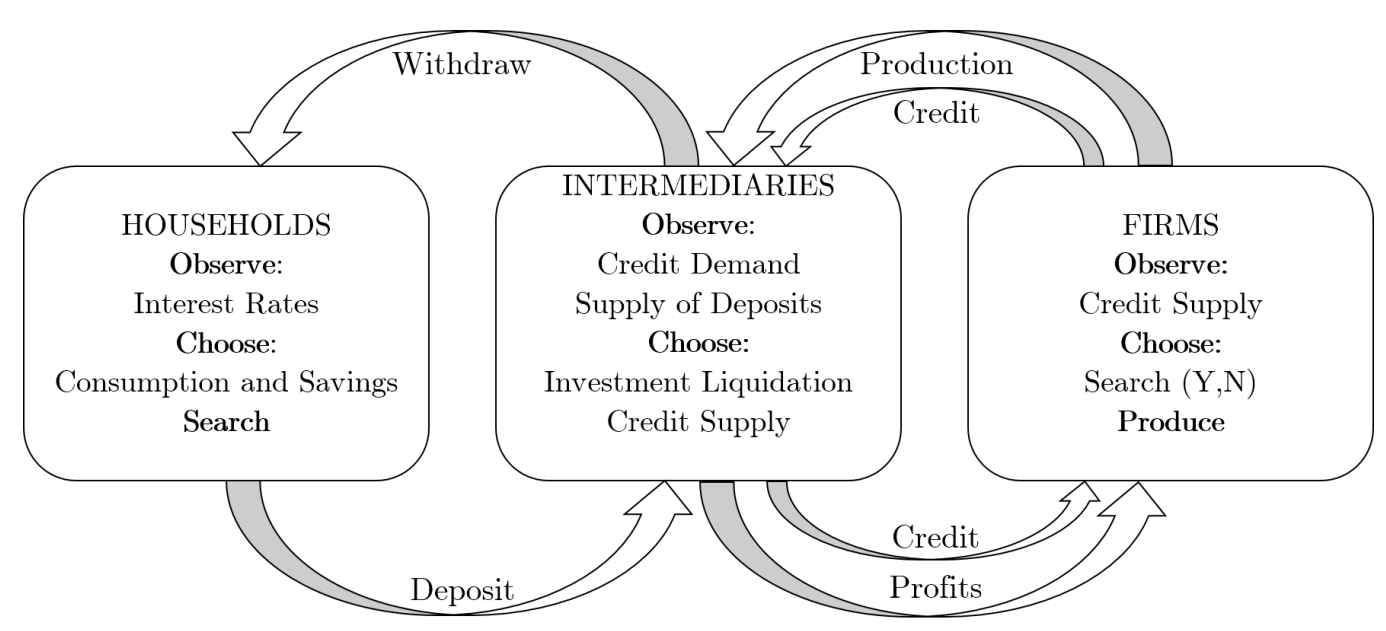

Figure 1.1: Flow of Funds and Agents Behavior 
Table 1.2: OLS Estimates of Targeted Bank Run Data

Model: OLS $(N=450)$

Dependent variable: $\log$ (Recovery Time)

Heteroskedasticity-robust standard errors

\begin{tabular}{ccccc}
\hline \multirow{2}{*}{ Model } & \multicolumn{2}{c}{ Constant } & \multicolumn{2}{c}{$\log$ (Production) } \\
& Coefficient & p-value & Coefficient & p-value \\
\hline$\{\gamma=0.35 \wedge \theta=0.35\}$ & 20.9843 & $5.99 \mathrm{e}-042$ & -2.1086 & $4.19 \mathrm{e}-027$ \\
$\{\gamma=0.35 \wedge \theta=0.70\}$ & 7.6039 & $8.27 \mathrm{e}-05$ & -0.3370 & 0.2141 \\
$\{\gamma=0.70 \wedge \theta=0.35\}$ & 7.4394 & 0.0282 & -0.1910 & 0.6636 \\
$\{\gamma=0.70 \wedge \theta=0.70\}$ & 5.3039 & 0.0032 & -0.0341 & 0.9018 \\
\hline
\end{tabular}

Table 1.3: OLS Estimates of General Bank Run Data

Model: OLS $(N=450)$

Dependent variable: $\log$ (Recovery Time)

Heteroskedasticity-robust standard errors

\begin{tabular}{ccccc}
\hline & \multicolumn{2}{c}{ Constant } & \multicolumn{2}{c}{$\log$ (Production) } \\
Model & Coefficient & p-value & Coefficient & p-value \\
\hline$\{\gamma=0.35 \wedge \theta=0.35\}$ & 6.3622 & 0.0007 & -0.3440 & 0.1616 \\
$\{\gamma=0.35 \wedge \theta=0.70\}$ & -3.7082 & 0.3988 & 1.0289 & 0.0974 \\
$\{\gamma=0.70 \wedge \theta=0.35\}$ & -6.8509 & 0.0844 & 1.4142 & 0.0063 \\
$\{\gamma=0.70 \wedge \theta=0.70\}$ & -5.3046 & 0.1206 & 1.2968 & 0.0142 \\
\hline
\end{tabular}



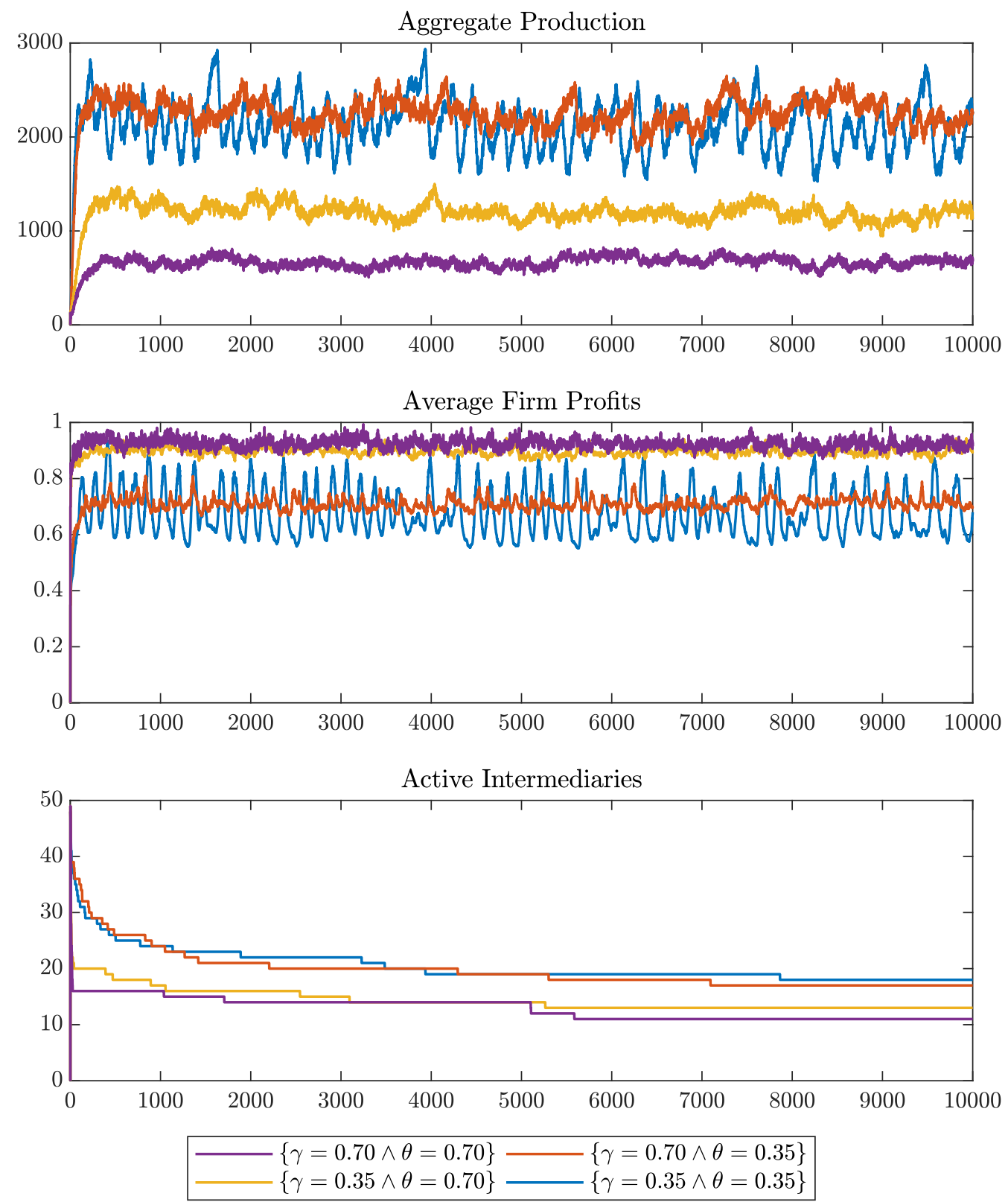

Figure 1.2: System Evolution 

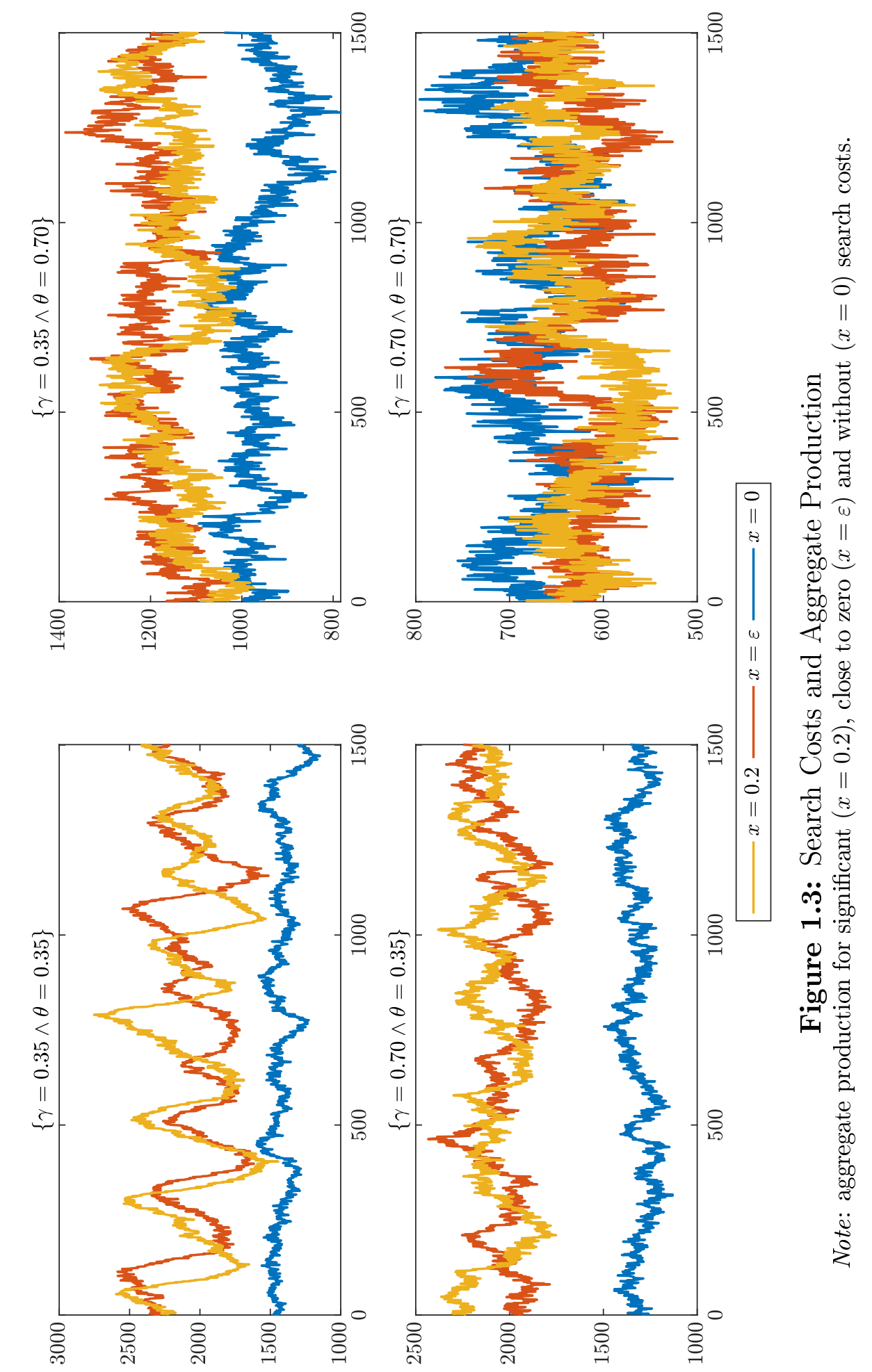


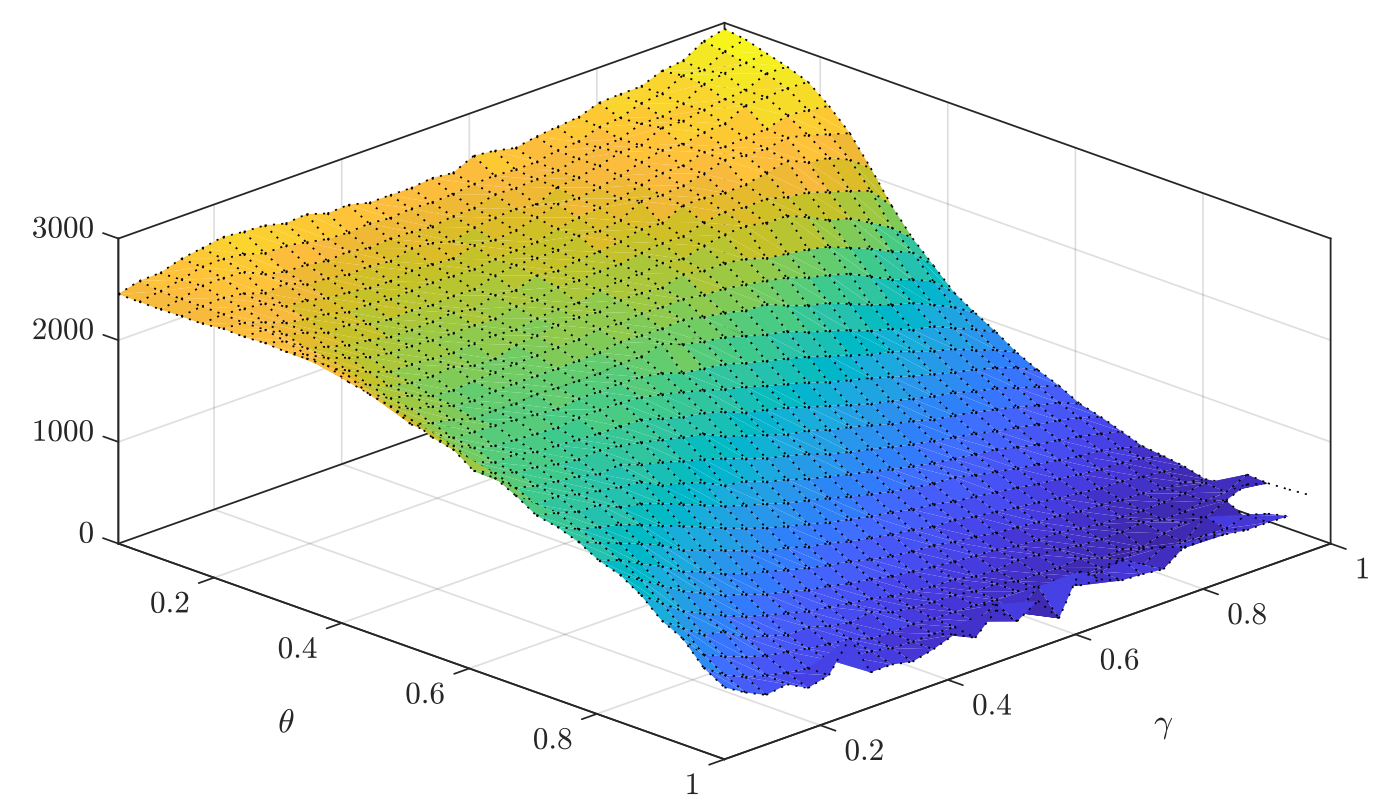

Figure 1.4: Expected Value of Aggregate Production

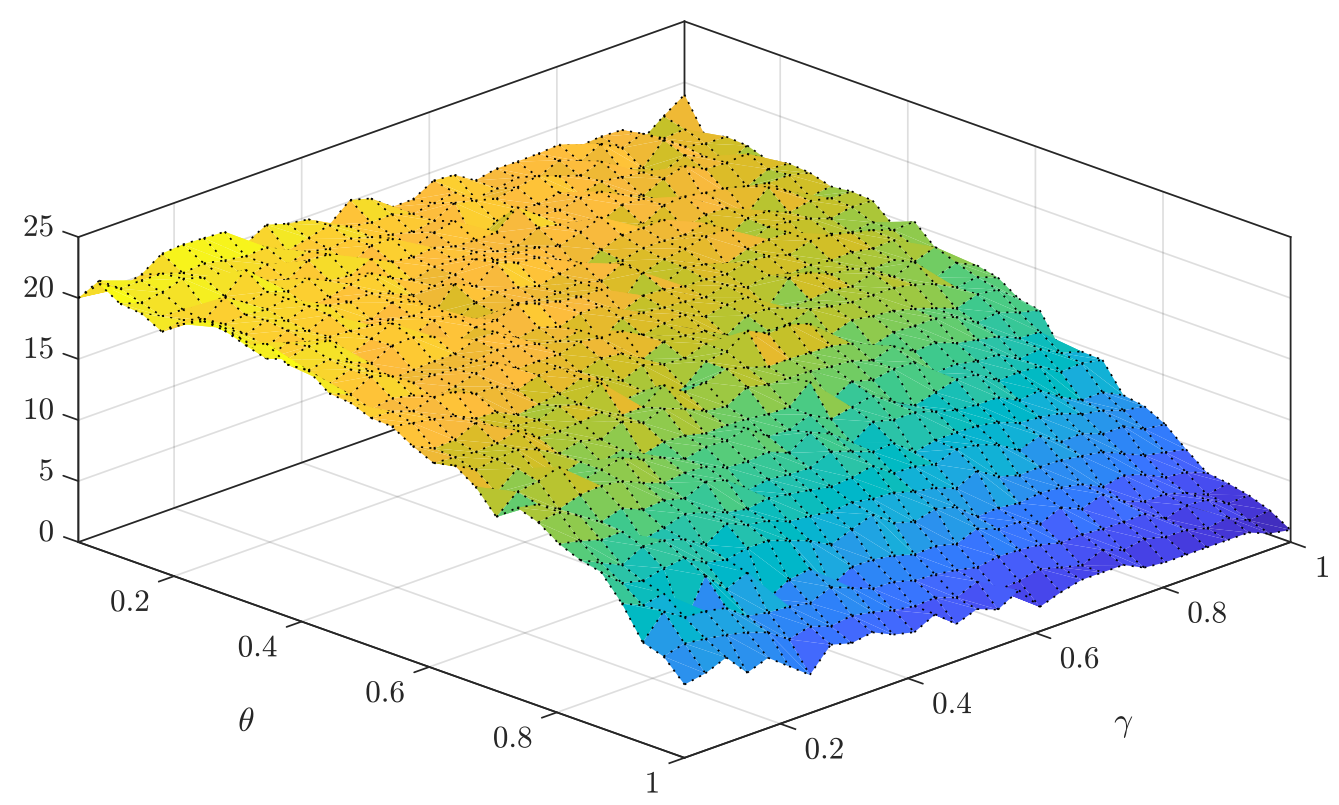

Figure 1.5: Average Number of Active Intermediaries 


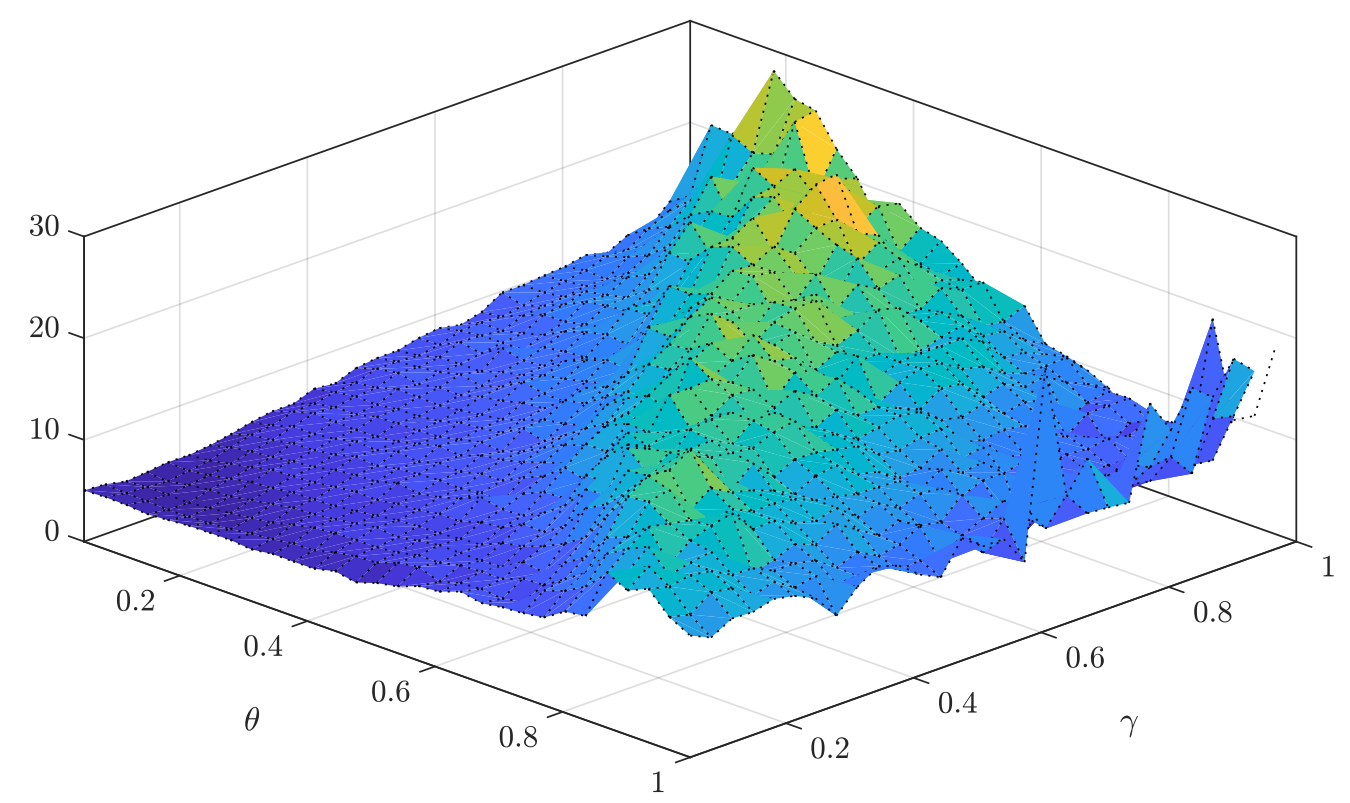

Figure 1.6: Expected Value of Production over Standard Deviation

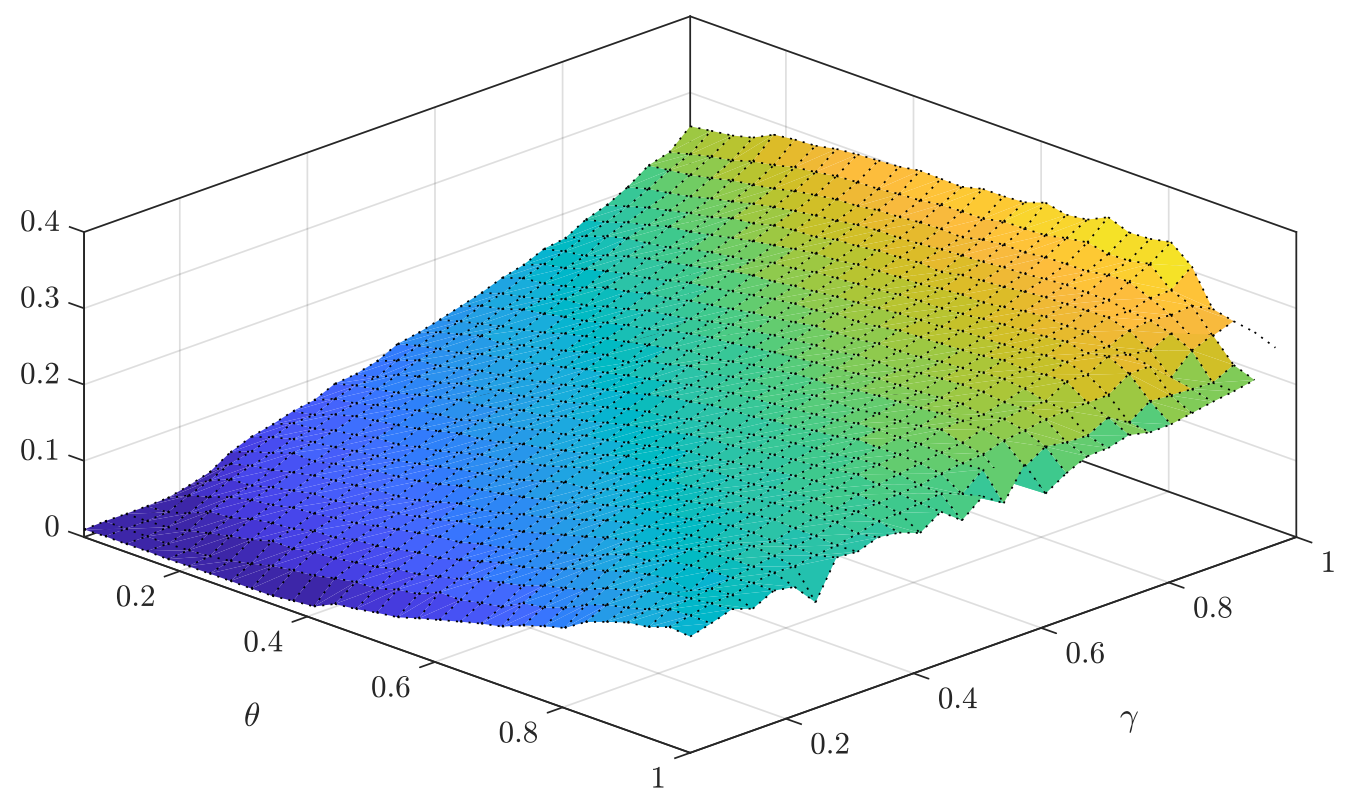

Figure 1.7: Expected Value of Unallocated Capital over Total Capital 


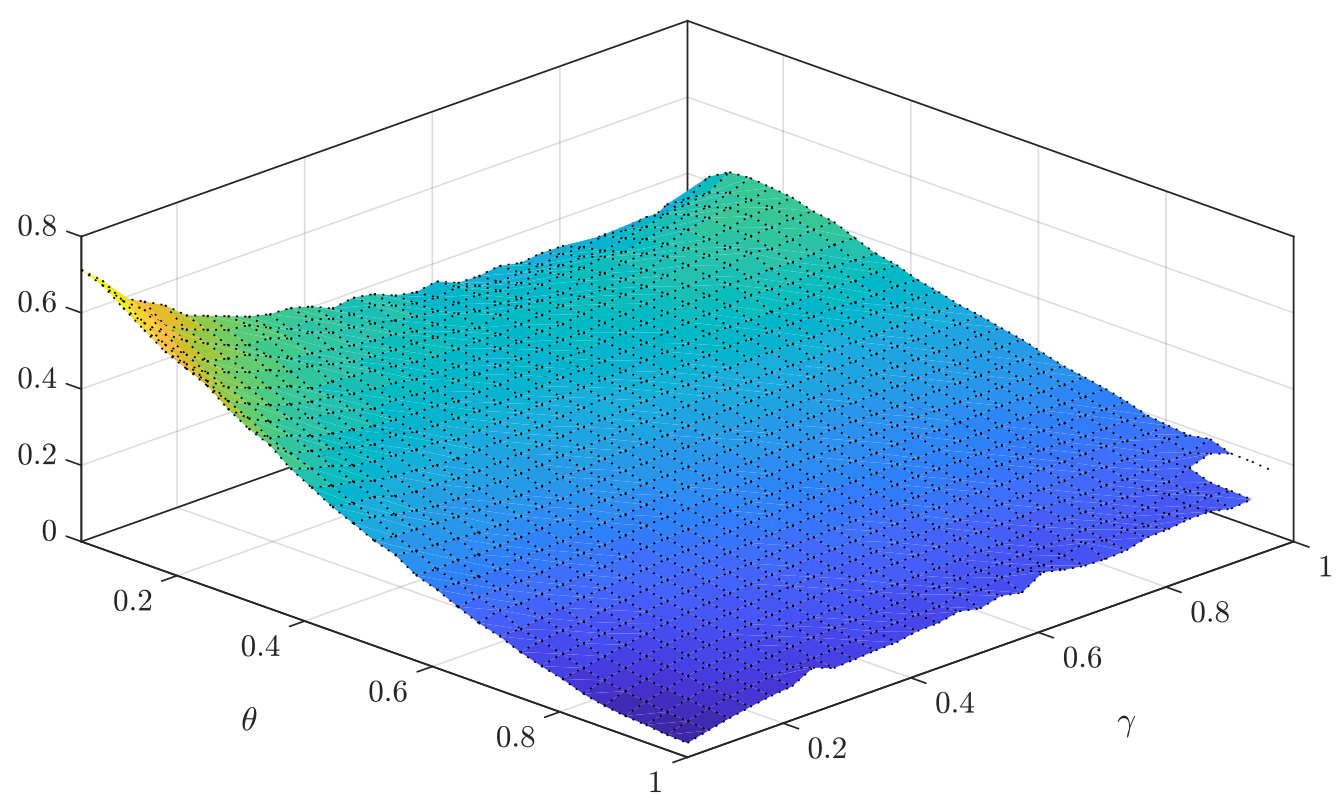

Figure 1.8: Expected Value of Excess Profits: $E[P]-\theta-x E[R]$

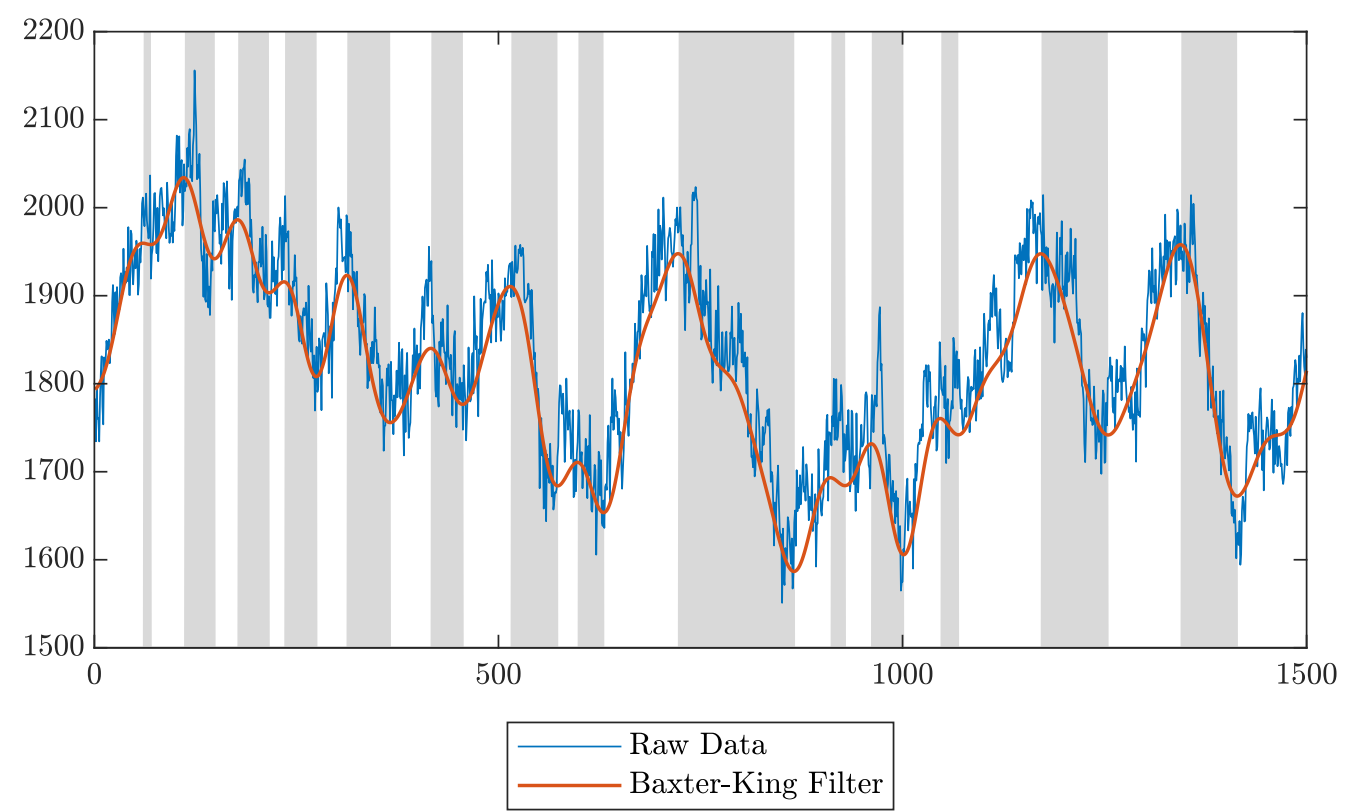

Figure 1.9: Production Cycle 


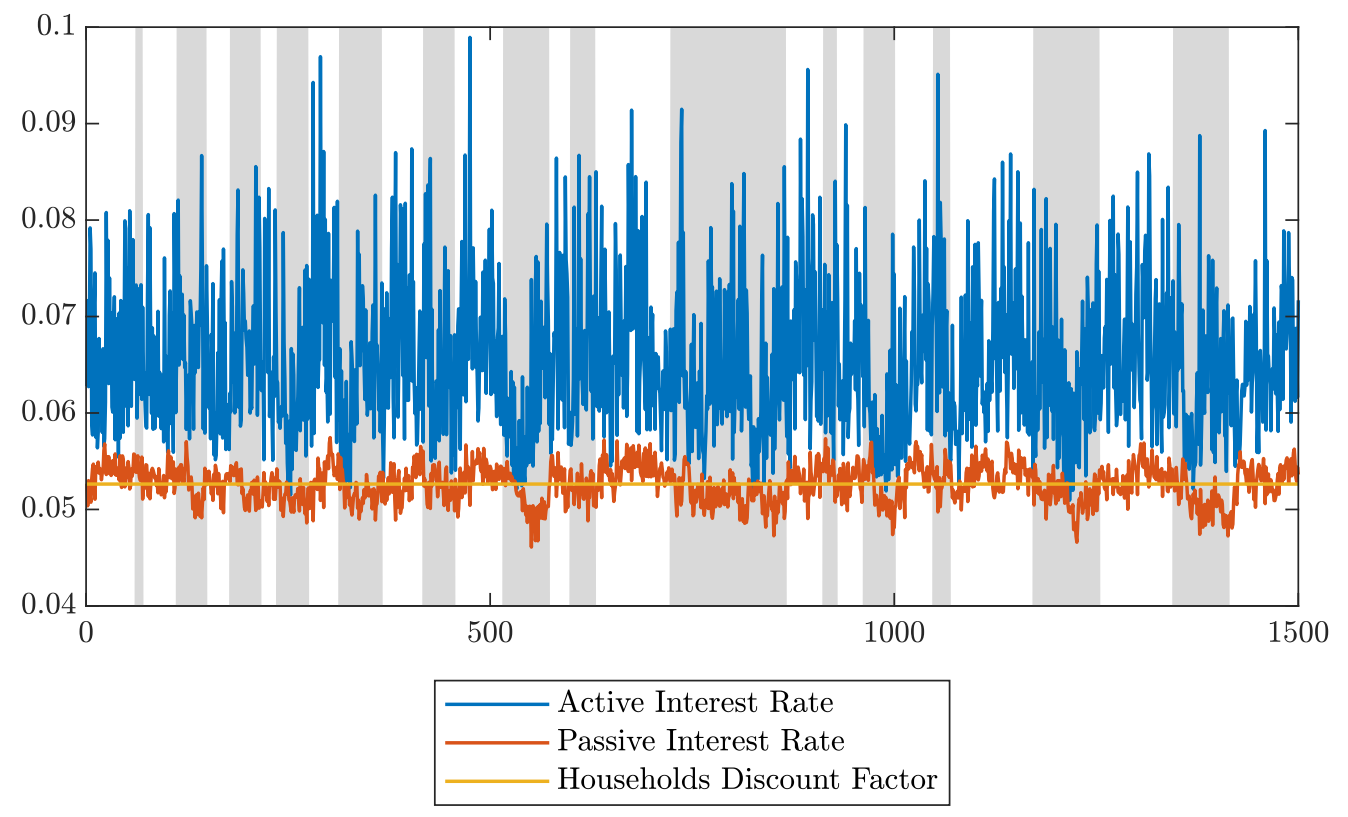

Figure 1.10: Average Interest Rates of the Intermediaries

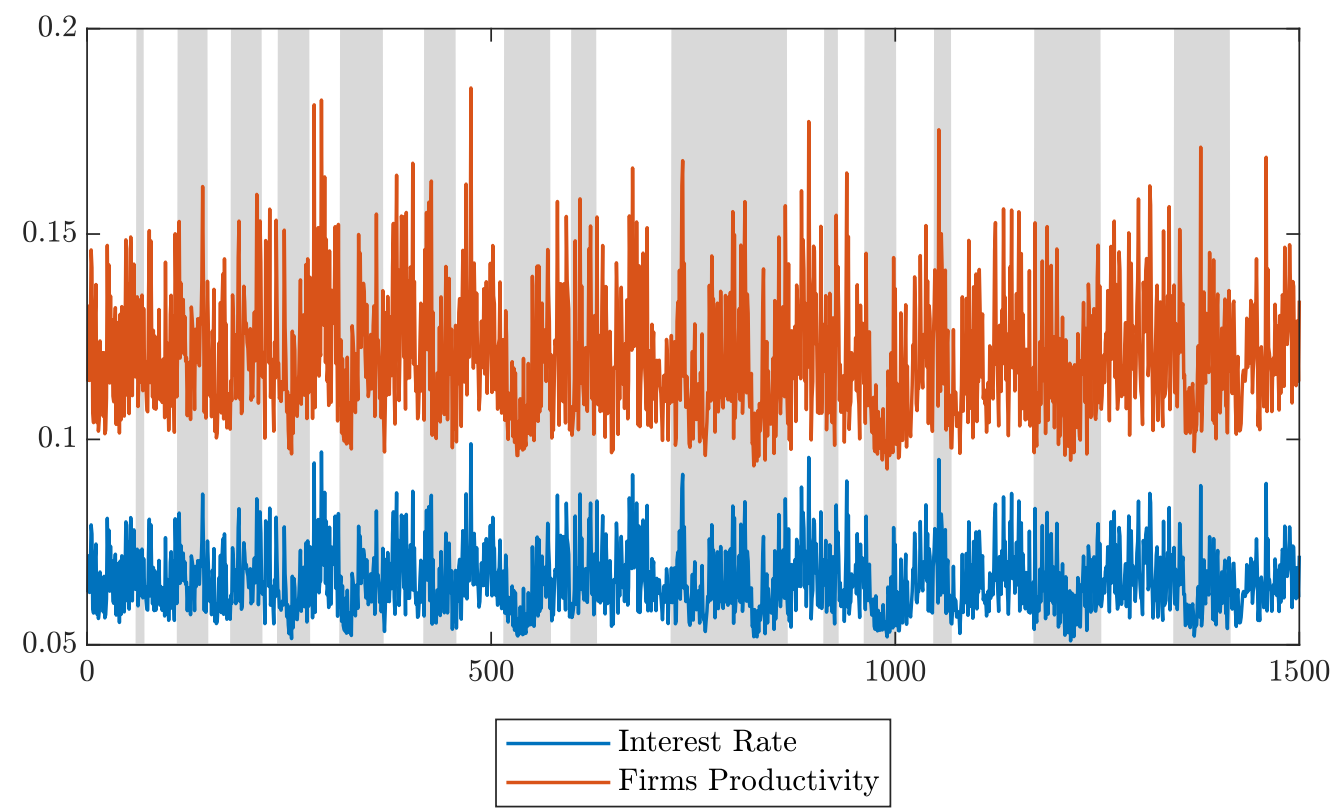

Figure 1.11: Average Interest Rates on Loans and Firms Productivity 


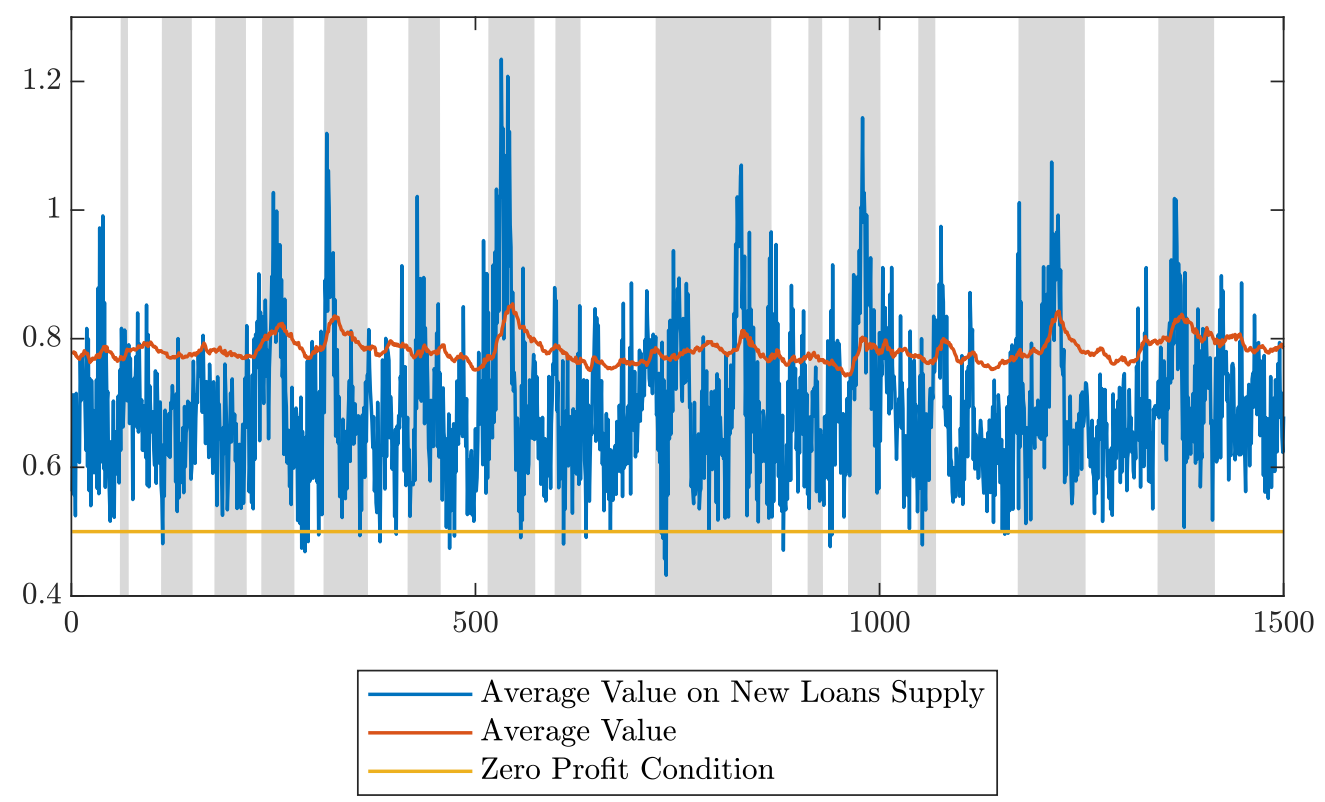

Figure 1.12: Average Contractual Profit

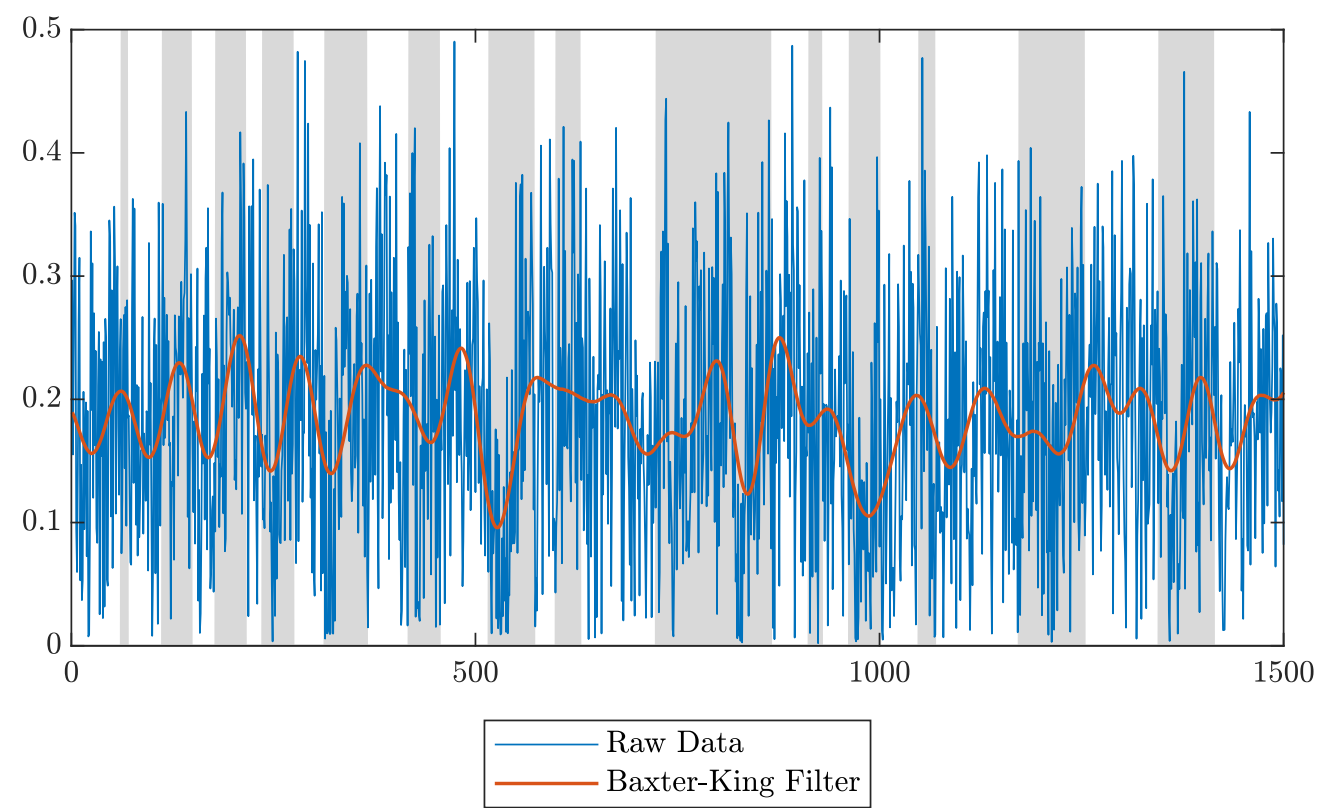

Figure 1.13: Average Unallocated Capital over Total Capital 


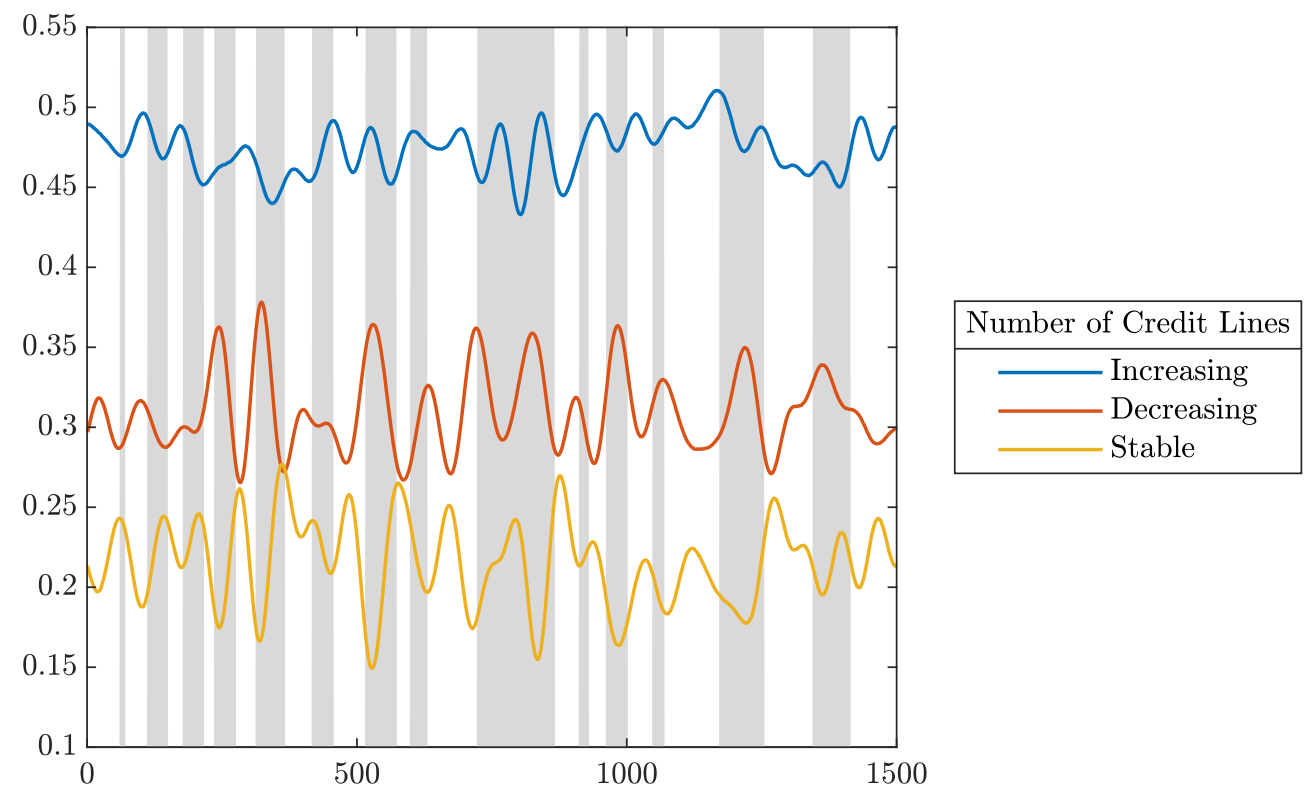

Figure 1.14: Intermediaries Behavior: Ratio over Total Active Intermediaries (Baxter-King Filter)

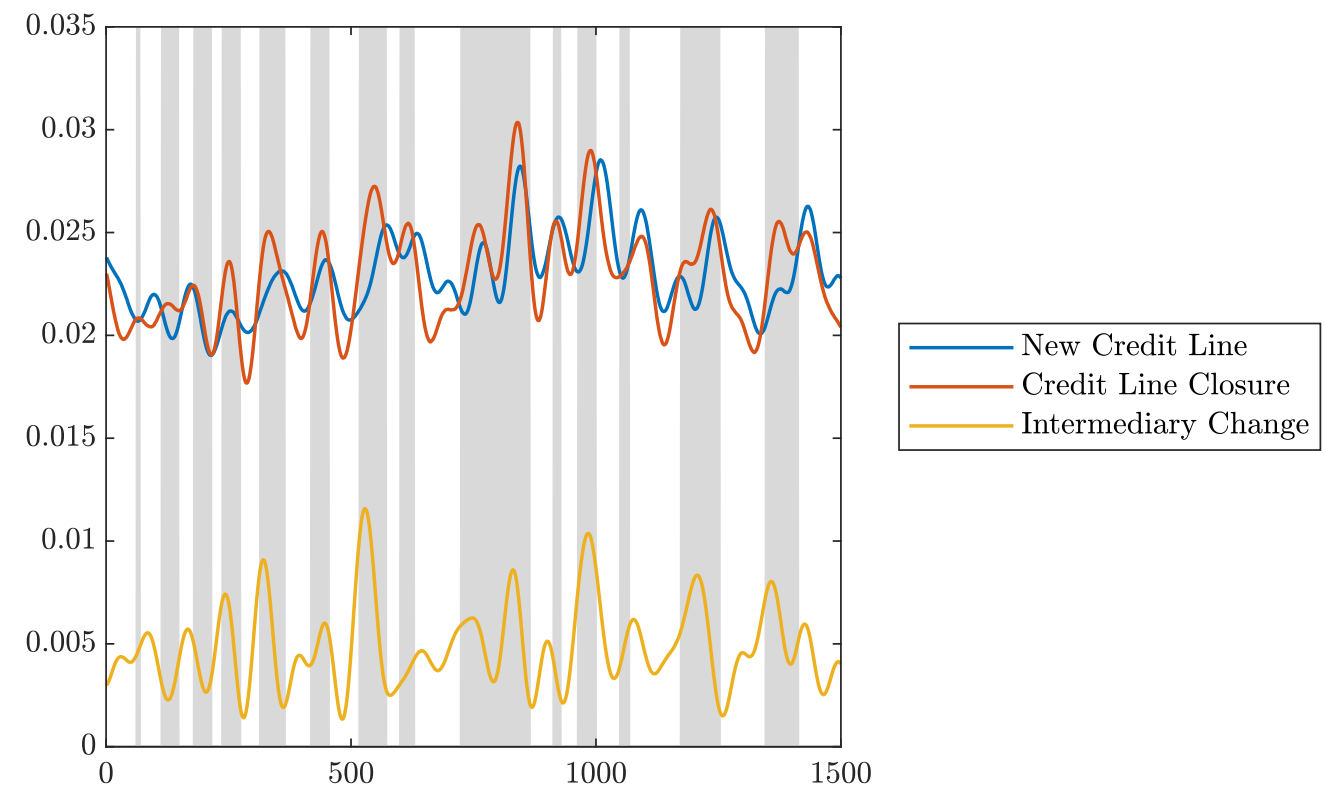

Figure 1.15: Firms Behavior: Ratio over Total Active Firms

(Baxter-King Filter) 

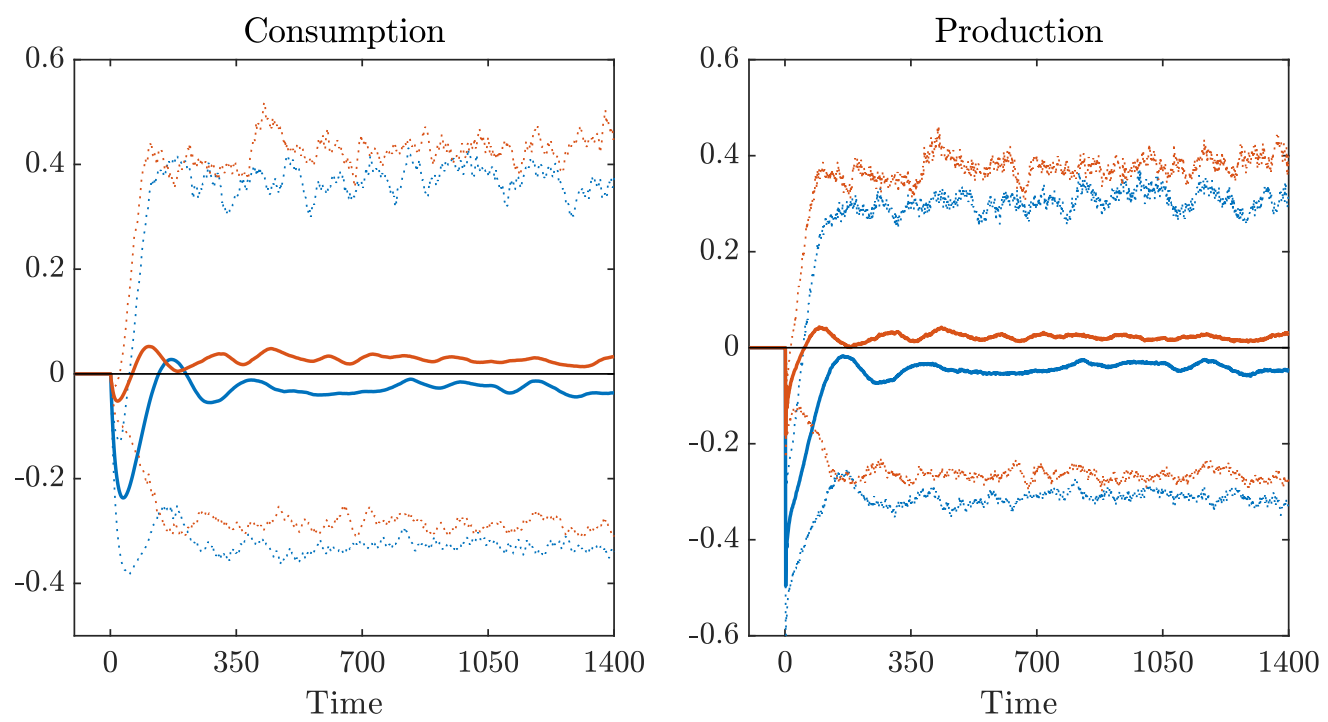

Contractual Profit

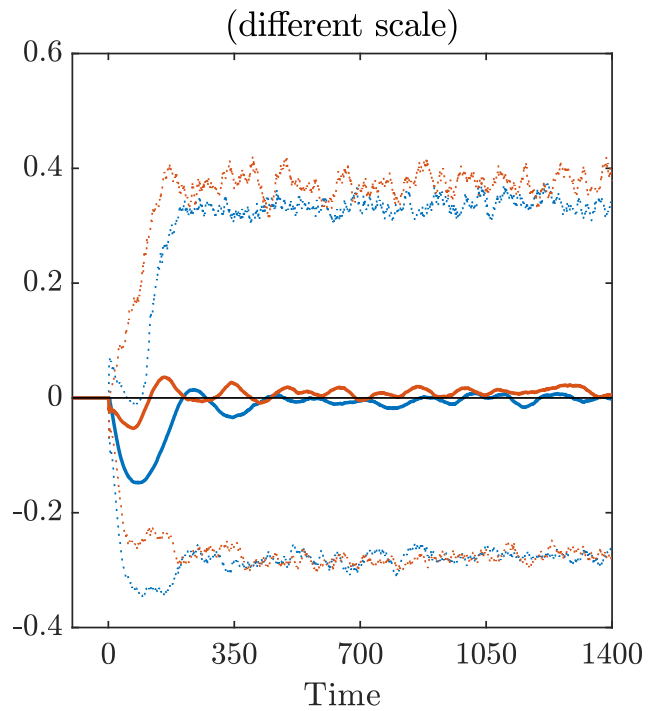

Unallocated/Total Capital

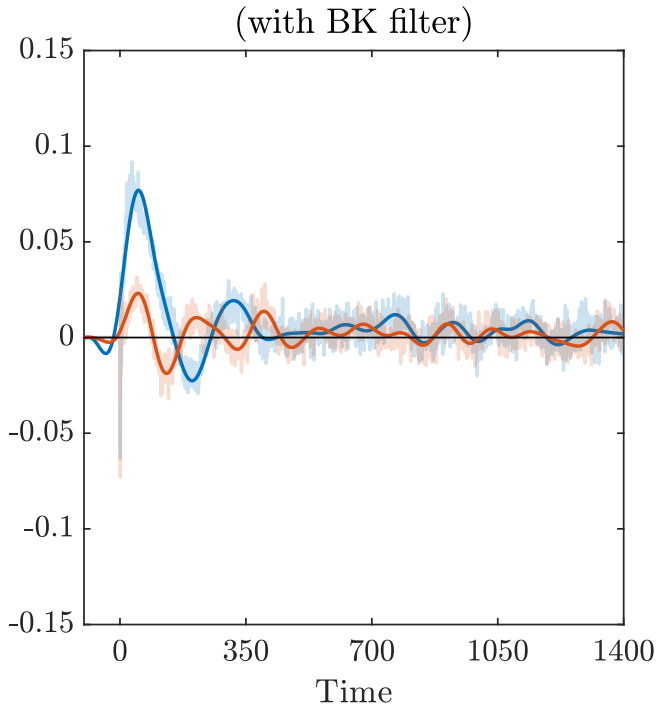

Targeted bank run

General bank run

$95 \%$ interval

$95 \%$ interval

Figure 1.16: Impulse Response Function: Percentage Deviation from the Baseline Simulation $\{\gamma=0.35 \wedge \theta=0.35\}$ 

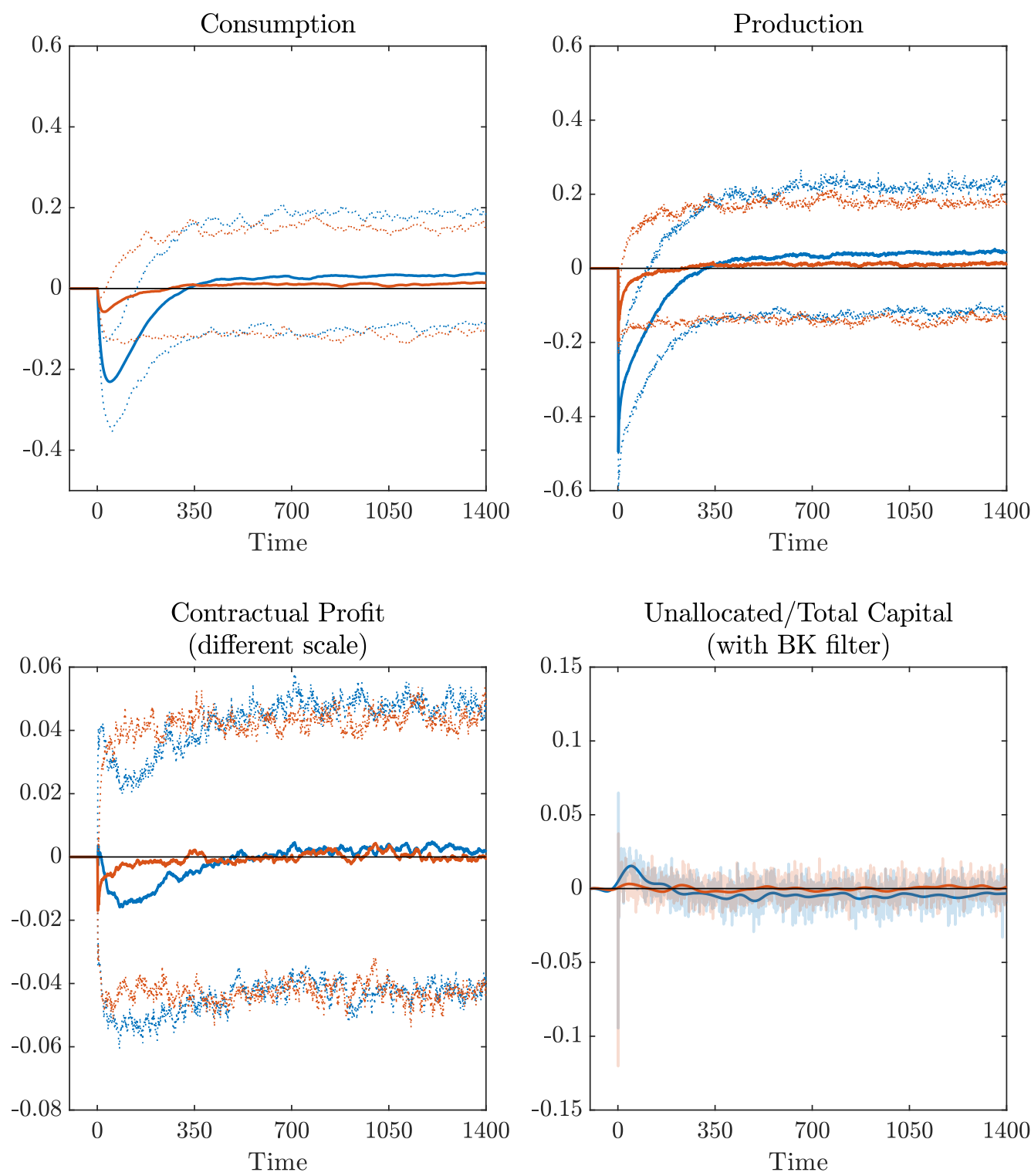

Targeted bank run

General bank run

$95 \%$ interval

$95 \%$ interval

Figure 1.17: Impulse Response Function: Percentage Deviation from the Baseline Simulation $\{\gamma=0.35 \wedge \theta=0.7\}$ 

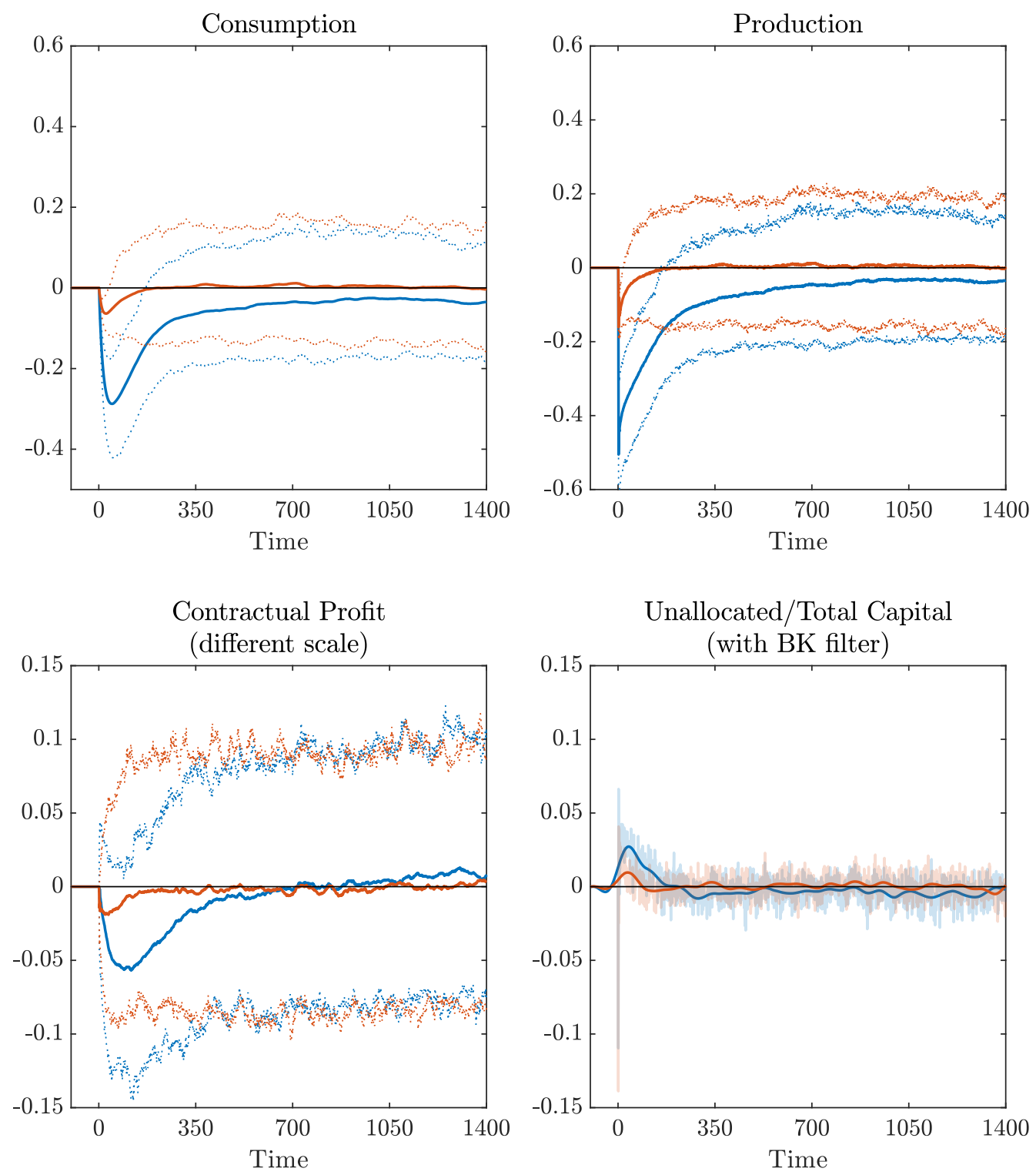

Targeted bank run

General bank run

$95 \%$ interval

$95 \%$ interval

Figure 1.18: Impulse Response Function: Percentage Deviation from the Baseline Simulation $\{\gamma=0.7 \wedge \theta=0.35\}$ 

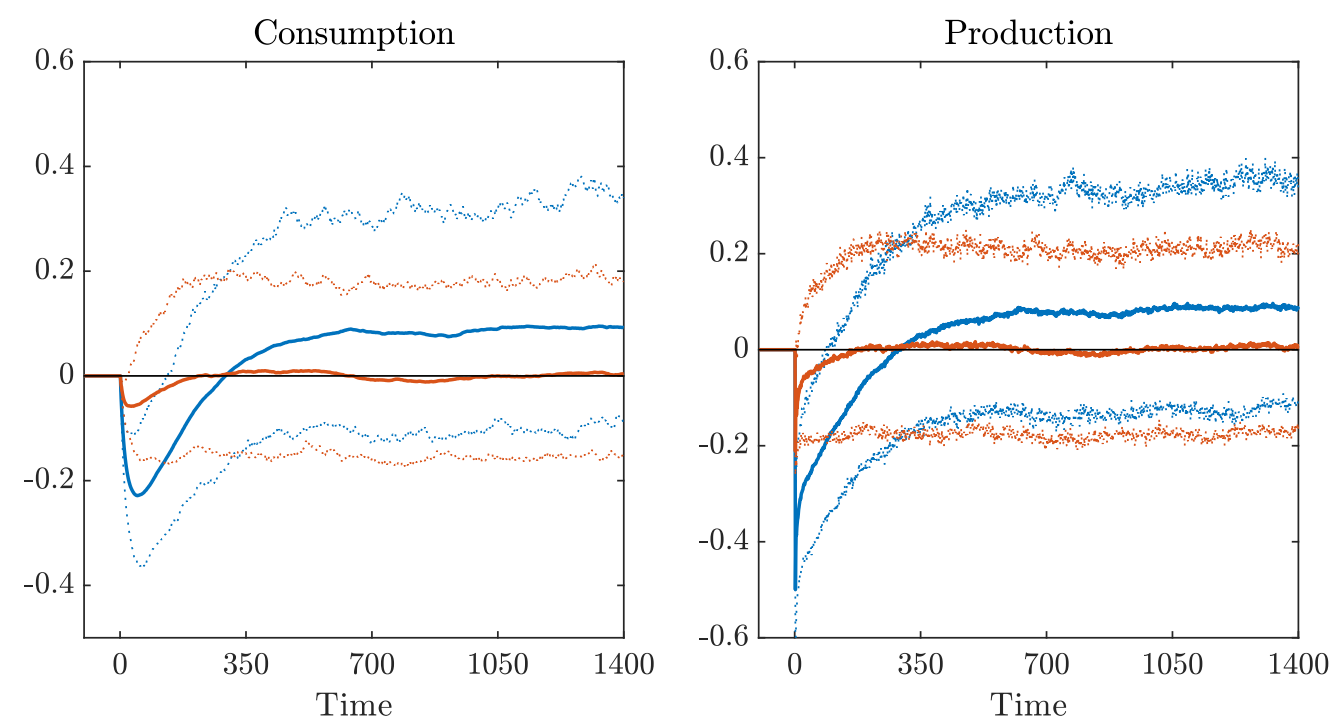

Contractual Profit
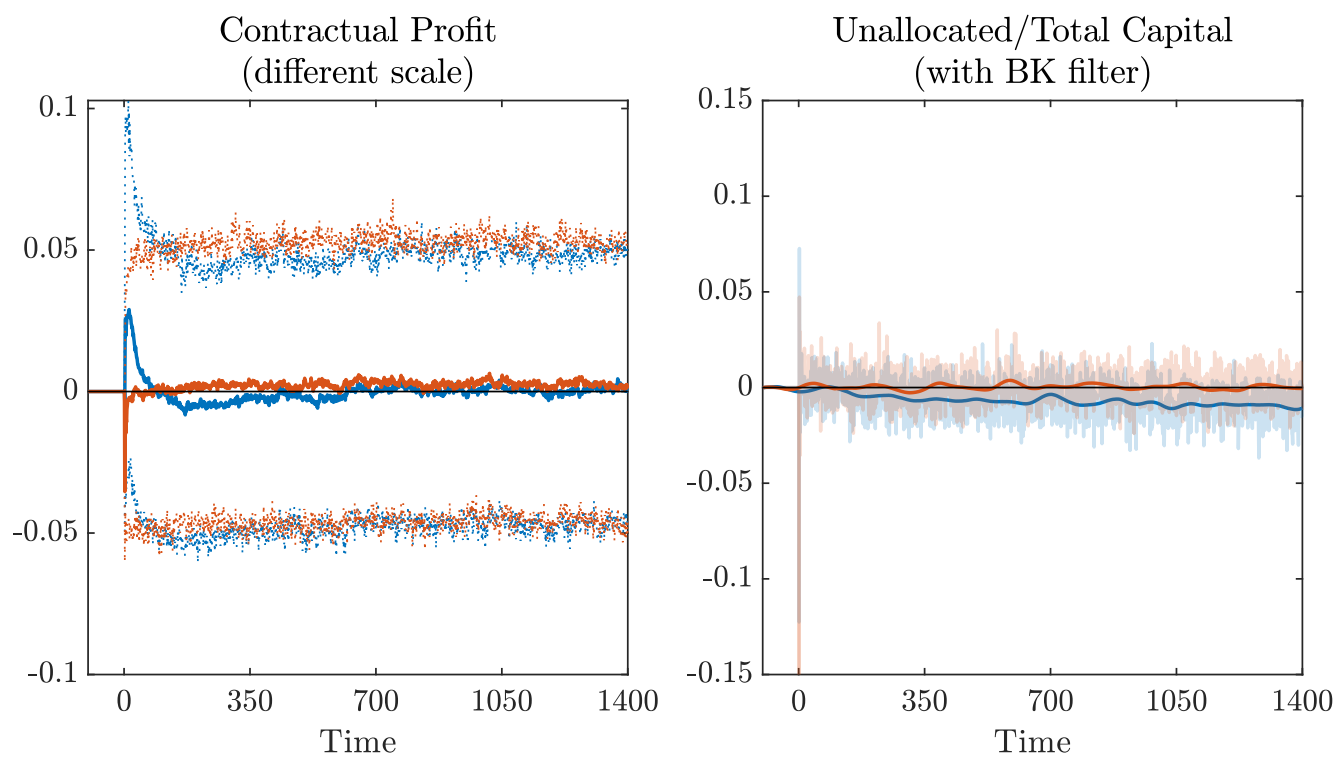

Targeted bank run

General bank run

$95 \%$ interval

$95 \%$ interval

Figure 1.19: Impulse Response Function: Percentage Deviation from the Baseline Simulation $\{\gamma=0.7 \wedge \theta=0.7\}$ 

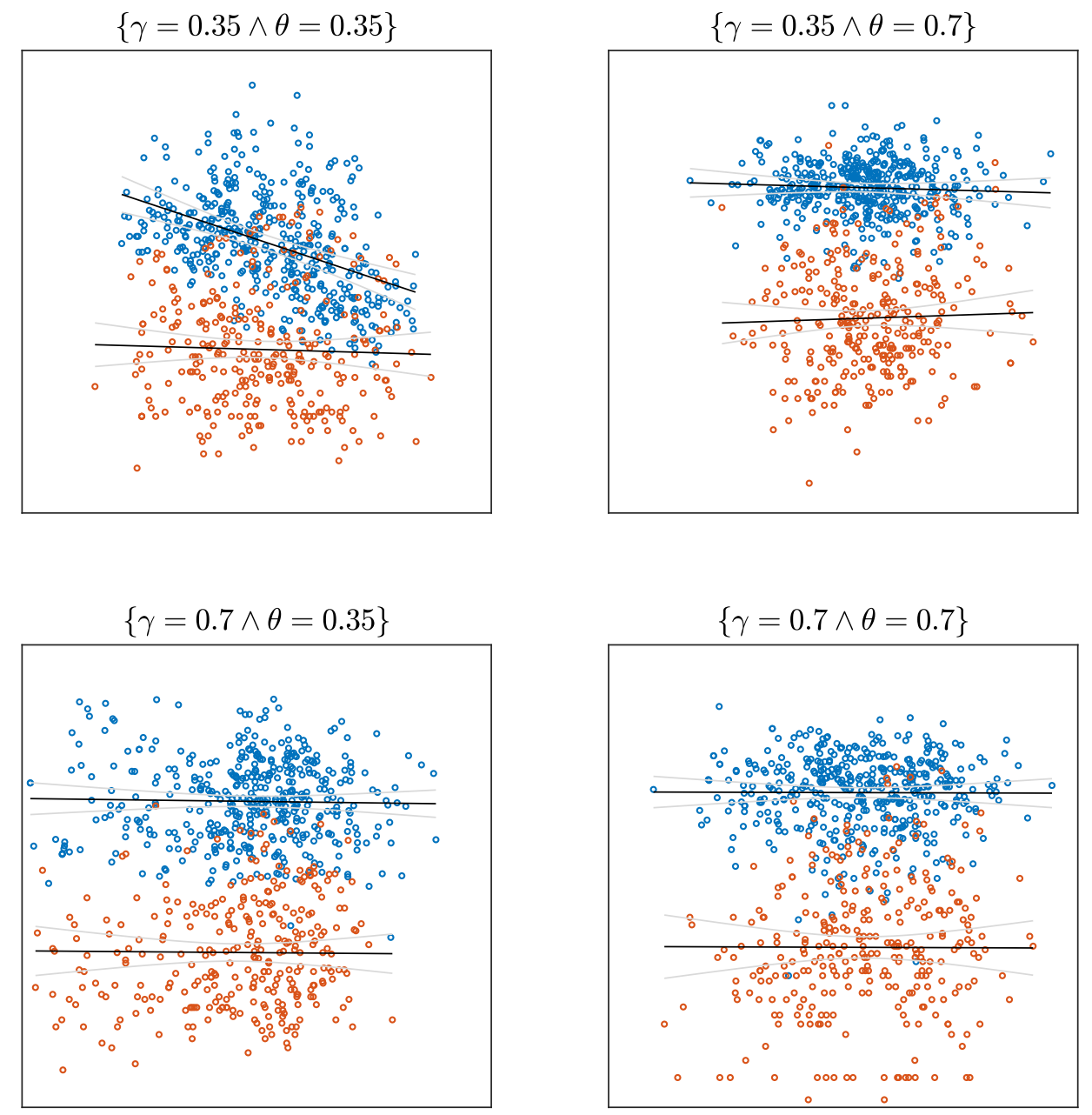

\begin{tabular}{|llll|}
\hline$\circ \quad$ Targeted bank run & $\bigcirc$ & General bank run \\
& OLS estimates & & $95 \%$ Prediction interval \\
\hline
\end{tabular}

Figure 1.20: Recovery Time and Production Level (Log Scale) 


\section{Chapter 2}

\section{$2.1 \quad$ Introduction}

The failure of Lehman Brothers in September 2008 was the tipping point of the financial crisis that had begun in the year before. Indeed, the refusal of the private sector to fund the unsustainable portfolio of this institution showed the extent of this event in all its dimension. Consequently, the response of the policymaker was to implement a comprehensive monetary and fiscal plan to save distressed intermediaries, recover the functionality of the financial sector and contain the subsequent recession.

The most peculiar characteristic of this event was its vast and uncontrollable diffusion throughout the financial sector. Indeed, the spread of the crisis through the complex network of interbank lending and borrowing relations led to a complete meltdown of the market. As a result, researchers have tried to understand the underlying mechanism of contagion and the reasons behind its amplification.

The role of market connectivity in the diffusion of idiosyncratic shocks is not a relatively new topic. Indeed, the seminal works of Allen and Gale (2000) and Freixas et al. (2000) showed how the structure of interbank claims can affect the stability of the system. However, the crisis led to the development of a new line of research which relies on network theory to investigate the propagation of shocks in the interbank market. Accordingly, scholars focused on the mechanism of financial contagion in different network topology both from a theoretical (Battiston et al., 2012b, $a$, Gai and Kapadia, 2010. Acemoglu et al., 2015) and an empirical point of view (see Upper (2011) for a review). Overall, these researches found a trade-off between idiosyncratic and systemic risk. Indeed, while a highly connected financial sector can easily compensate small shocks in single intermediaries, it is fully exposed to large events and bankruptcies cascades.

With regards to macroeconomic models, scholars studied the propagation of crises in the financial sector and their effects in the real economy in two main directions. Indeed, most of the research in this field analyzed the role 
of the financial accelerator (Bernanke and Gertler, 1989) in the amplification of idiosyncratic shocks in different topologies of the interbank network (Delli Gatti et al., 2010; Tedeschi et al., 2012; Riccetti et al., 2013; Grilli et al., 2014, 2015). Conversely, the remaining part of the authors focused on the effects of exogenous reductions in the intermediaries' liquidity on bankruptcies cascades (Iori et al., 2006, Lenzu and Tedeschi, 2012, Berardi and Tedeschi, 2017). Overall, these models studied how exogenous shocks in the productivity of the single investment or in the allocation of wealth can affect the aggregate dynamic of the economy. Specifically, individual defaults or fund reallocations can cause economy-wide changes through the amplification mechanisms of the financial accelerator and of bankruptcies cascades.

In this article, we follow the latter line of research. Indeed, the main aim of this work is to study how different network topologies of the interbank market can affect the reallocation of funds in the economy and the effect on the overall performance of the system. Specifically, we develop a macroeconomic agent-based model (ABM) in which movements in the asset and liability sides of banks' balance sheets are the result of a decentralized matching mechanism. In particular, we model the endogenous formation of deposit, credit and interbank relations through the preferential attachment mechanism developed by Bianconi and Barabási (2001). Indeed, agents move from their current financial institution to a new one on the basis of their fitness (see Delli Gatti et al. (2010); Riccetti et al. (2013); Lenzu and Tedeschi (2012) for different applications). In other words, households, firms and banks react to reductions in the attractiveness of their existing counterparty by switching to a new one. As a result, the dynamic of cycles and the topology of deposit, credit and interbank networks evolves endogenously.

Accordingly, our article extends the existing literature on macroeconomic and credit networks in two main directions. First, introducing households as active agents, we build a complete economic environment in which the response of depositors to changes in the overall state of the system plays a major role in the definition of final outcomes. Indeed, the existing literature on credit networks relegates the role of these agents to passive shock absorbers. However, it is clear that the end users of the financial sector are the households themselves. Consequently, our work fills this gap in the theoretical study of macroeconomic networks. Second, because we extend the preferential attachment mechanism also to depositors, we can obtain endogenous liquidity shocks. In other words, we do not need to assume a predefined mechanism of crisis formation because this event emerges as an intrinsic property of our model.

The article is organized as follows. In Section 2.2 we define the model. 
In Section 2.3 we study the dynamic of cycles and the long-run properties of the simulated economy for different network topologies. In Section 2.4 we calibrate our results on the empirical moments of United States data and we investigate the distributional characteristics of the system on the basis of the empirical results of previous researches. Lastly, Section 2.5 concludes and states some directions for future research.

\subsection{Sequence of Events}

The economy is composed of a fixed number of households $\left(h=1, \ldots, n_{h}\right)$, intermediaries $\left(i=1, \ldots, n_{i}\right)$ and firms $\left(f=1, \ldots, n_{f}\right)$. Households are the owners of financial capital, which we assume for simplicity as the only factor of production, while firms have no resources of their own and must raise funds in the credit market to start production.

Families deposit their wealth in only one intermediary at a time as demand deposits and cannot establish direct connections with producing firms. Here we are implicitly assuming that investment evaluation and ex-post verification are costly and intermediaries are more efficient than households in performing these tasks. In addition, we assume that the financial sector can supply credit without sustaining any additional effort or expense. On the other hand, households can always search a new counterparty and can move their wealth from an intermediary to another one without any constraint. Accordingly, we assume that at the beginning of every period families search and select the financial institutions which pay the highest interest rate.

The main source of income of intermediaries derives from the credit issued to enterprises. Specifically, as in Den Haan et al. (2003), financial institutions receive from borrowing firms the interest rate:

$$
r_{i, f, t}=\frac{\left(k_{i, f}\right)^{\alpha}-P_{i, t-1}}{k_{i, f}}
$$

where $(\cdot)^{\alpha}$ is a production function with decreasing marginal returns, $k_{i, f}$ the external finance supplied by the i-th intermediary to the $\mathrm{f}$-th firm and $P_{i, t-1}$ the profit left by the i-th bank to its borrowers at time $t$. Notice that the latter measures both the profitability $\left(P_{i, t-1}\right)$ and the cost of financing $\left(d r_{i, f, t} / d P_{i, t-1}<0\right)$ of the enterprise. Accordingly, entrepreneurs will search and select the banks paying the highest contractual profit.

We assume that intermediaries set their contractual profits $\left(P_{i, t-1}\right)$ before the start of production and update them every period taking into account both their demand for credit and the supply of deposits. Conversely, the size of each loan $\left(k_{i, f}\right)$ is defined at the beginning of the open-ended 
credit relation and is not modified through time. Specifically, intermediaries extract at random the value of new issuances from a predefined distribution. Indeed, the idea is to model the implicit informational capital of banks through this mechanism (Stiglitz, 2015b). In fact, we assume that financial institutions do not know the optimal size of loans. However, when they need additional money to repay their depositors, they reduce their assets starting from sub-optimal investments. Consequently, the efficiency of the intermediaries' portfolio increases over time because of this asymmetric mechanism of credit allocation?

As stated before, households observe the interest rate paid by financial institutions and move their wealth to the best-preforming intermediaries at the beginning of every period. Consequently, when banks experience an excessive withdrawal of funds, they must reduce lending to repay depositor: 10 . Financial institutions in that situation can avoid part of the process of credit liquidation by entering the interbank market. Specifically, illiquid banks can finance their deficit by borrowing from another intermediary at the required return, conditional to the availability of resources in the selected counterparty.

Lastly, after the allocation of funds in the interbank market, intermediaries supply credit and firms search and choose the banks offering the most attractive financing opportunities. As a result, if the enterprise has an existing credit line, the loan is closed and the capital returned to the original financial institution.

\subsubsection{Model Initialization}

At the beginning of the simulation families have an homogeneous quantity of capital $d_{h, 0}=K_{0}\left(\forall h=1, \ldots, n_{h}\right)$ which they deposit in a bank selected at random. We define the subset of households connected with the i-th intermediary at the end of time $t$ as $H_{i, t}$. Hence, at the time $t=0$ we have: $\operatorname{Pr}\left(h \in H_{i, 0}\right)=U\left(1, n_{i}\right)$, where $U(\cdot)$ is an uniform distribution.

Intermediaries set their initial contractual profit equal to the optimal distribution of incomes ${ }^{11}$ namely $P_{i, 0}=(1-\alpha)\left(K_{0}\right)^{\alpha}$, fix a minimum investment dimension $\bar{k}_{i, 0}$, evaluate the resources available for investments and generate

\footnotetext{
${ }^{9}$ In other words, new issuances can return both high and low interest rates, while the loans held in the portfolio are only the most profitable ones.

${ }^{10}$ We assume for the sake of simplicity that intermediaries calculate their financial needs on the basis of the net flow of capital. In other words, banks estimate their deficits after the complete reallocation of wealth by the households.

${ }^{11}$ The details of the optimal distribution of incomes and of the representative agent growth path are discussed in section 2.3 (Eq. 2.37 and 2.38).
} 
the new credit supply schedule.

The minimum investment dimension is the lowest value of capital which produces a non-negative interest rate: $\bar{k}_{i, t}=\left\{k \mid(k)^{\alpha}-P_{i, t}=0\right\}$. We set this constraint to avoid negative returns on new loans, which increase excessively the volatility of simulations and, because of that, occasionally produce degenerate equilibria in which only one intermediary remains in the market. However, from a theoretical point of view, this assumption allows us to define deposits as truly risk-free, in the sense that the capital quota is always repaid in the short term.

As stated before, the credit supply of every intermediary is computed according to a stochastic allocation process. The quantity of available resources is simply given by the sum of initial deposits $\left(D_{i, 0}=\sum_{h \in H_{i, 0}} d_{h, 0}\right)$, while the size of new loans is extracted from the distribution:

$$
k_{j}^{N} \sim U\left(\bar{k}_{i, 0}, D_{i, 0}\right)
$$

until the condition

$$
D_{i, 0}=\sum_{j \in F_{i}^{N}} k_{j}^{N}
$$

is satisfied, where $F_{i}^{N}$ is the set of new loans supplied by the i-th intermediary.

Lastly, firms demand funds. Given that all the intermediaries offer the same contractual profit at the beginning of the simulation, we allocate the credit across entrepreneurs at random. In other words, we extract the composition of the initial credit relations with probabilities: $\operatorname{Pr}\left(f \in F_{i, 0}\right)=$ $U\left(1, n_{i}\right) \cdot U\left(1, n_{f}\right)$, where $F_{i, t}$ is the set of firms connected with the i-th intermediary at the end of time $t$.

\subsubsection{Production and Interest Rates}

Given the set of credit relations inherited from the previous period:

$$
\left\{P_{i, t-1} ; k_{i, f}\right\} \text { with } f \in F_{i, t-1} \forall i=1, \ldots, n_{i}
$$

firms start production, retain profits and pay to their corresponding bank the interests on their loans, as defined in equation (2.1). On the other hand, intermediaries collect the aggregate flow of funds from their borrowing firms:

$$
y_{i, t}^{f}=\sum_{f \in F_{i, t-1}} r_{i, f, t} \cdot k_{i, f}
$$

and define the new temporary set of credit links: $F_{i, t}=F_{i, t-1}$. 
In the previous section, we introduce the possibility for intermediaries in financial distress to borrow in the interbank market to remedy the lack of funding ${ }^{12}$. Given that these loans pay a positive interest rate, they can have a considerable influence on the profitability of banks. We assume for the moment that there is an existing set of interbank relations:

$$
\left\{r_{i, j} ; k_{i, j}\right\} \text { with } j \in I_{i, t-1} \forall i=1, \ldots, n_{i}
$$

where $I_{i, t-1}$ is the set of intermediaries connected to the i-th bank at the end of time $t-1, r_{i, j}$ the interest rate received (paid) and $k_{i, j}$ the sum lent by the $\mathrm{i}$-th financial institution (borrowed by the $\mathrm{j}$-th bank, if negative). Therefore, intermediaries receive from their borrowers (pay to their lenders) the flow of incomes:

$$
y_{i, t}^{i}=\sum_{j \in I_{i, t-1}} r_{i, j} \cdot k_{i, j}
$$

Subsequently, under the assumption of an overnight interbank market, intermediaries return to their counterparties the capital borrowed in the previous period. Accordingly, the new set interbank links becomes:

$$
\left\{r_{i, j}=0 ; k_{i, j}=0\right\} \text { with } j \in I_{i, t} \forall i=1, \ldots, n_{i}
$$

with $I_{i, t}=I_{i, t-1}$.

Summing up, the net return paid to banks' depositors is equal to:

$$
r_{i, t}=\frac{y_{i, t}^{f}+y_{i, t}^{i}}{D_{i, t-1}}
$$

where $D_{i, t-1}=\sum_{h \in H_{i, t-1}} d_{h, t-1}$ are the aggregate deposits of the $\mathrm{i}$-th bank, such that:

$$
\left\{d_{h, t-1}\right\} \text { with } h \in H_{i, t} \forall i=1, \ldots, n_{i}
$$

where $H_{i, t}=H_{i, t-1}$ is the new temporary set of deposit links.

\subsubsection{Deposit Market}

At the beginning of each period families observe the interest rate paid by their corresponding intermediary, namely $r_{h, t}=r_{i, t}$ with $h \in H_{i, t}$ (see Eq. 2.9), and maximize the intertemporal problem:

$$
\max E_{t}\left[\sum_{s=0}^{\infty}\left(\beta^{1 / T_{y}}\right)^{s} \log \left(c_{h, t+s}\right)\right]
$$

\footnotetext{
${ }^{12}$ We provide the details of the interbank borrowing/lending mechanism in the next section.
} 


$$
\text { s.t. } d_{h, t+s}+c_{h, t+s}=\left(1+r_{h, t+s}\right) d_{h, t+s-1}
$$

where $c_{h, t+s}$ and $d_{h, t+s}$ are the consumption and savings of the h-th household at time $t+s$. In addition, to calibrate the model on real data, we assume that the length of one year is equal to $T_{y}$ periods. Accordingly, we set the one period discount factor equal to $\beta^{1 / T_{y}}{ }^{13}$

The optimal solution to the problem is given by the conditions:

$$
\begin{gathered}
c_{h, t}=\left(1-\beta^{1 / T_{y}}\right)\left(1+r_{h, t}\right) d_{h, t-1} \\
d_{h, t}=\beta^{1 / T_{y}}\left(1+r_{h, t}\right) d_{h, t-1}
\end{gathered}
$$

Subsequently, households search at random another intermediary and move their funds to the new location if the latter has a higher fit:

$$
\eta_{i}=\frac{r_{i, t}}{\max \left(r_{z, t}\right)}
$$

for $z=1, \ldots, n_{i}$. In other words, the set of deposit relations between banks and households changes according to the rule:

$$
\left\{d_{h, t}\right\} \text { with } \begin{cases}h \notin H_{\text {old }, t} \wedge h \in H_{\text {new }, t} & \text { if } \eta_{\text {new }} \geq \eta_{\text {old }} \\ h \in H_{\text {old }, t} & \text { otherwise }\end{cases}
$$

\subsubsection{Intermediaries Behavior and Interbank Market}

After the reallocation of wealth by the households, intermediaries modify their contractual profits, evaluate liquidity, enter the interbank market and supply credit.

Banks react to movements in the market modifying their contractual profits. In particular, they follow the rule:

$$
\begin{aligned}
& P_{i, t}= \begin{cases}P_{i, t-1} \\
{[1+\gamma \cdot \mathbb{1} \cdot U(0,1)] \cdot P_{i, t-1}} & \text { if } D_{i, t} \geq D_{i, t-1}\end{cases} \\
& \text { with } \mathbb{1}= \begin{cases}+1 & \text { if } C_{i, t-1} \geq \bar{k}_{i, t-1} \\
-1 & \text { otherwise }\end{cases}
\end{aligned}
$$

where

$$
C_{i, t-1}=D_{i, t-1}-A_{i, t-1}-\sum_{j \in I_{i, t-1}} k_{i, j}
$$

\footnotetext{
${ }^{13}$ Therefore, the yearly value is given by the cumulative product: $\beta=\prod_{t=1}^{T_{y}} \beta^{1 / T_{y}}$.
} 
is the amount of unallocated capital at the end of the previous period. Moreover, $D_{i, t-1}=\sum_{h \in H_{i, t-1}} d_{h, t-1}$ and $A_{i, t-1}=\sum_{f \in F_{i, t-1}} k_{i, f}$ are the past aggregate deposits and credits to firms, while $\sum_{j \in I_{i, t-1}} k_{i, j}$ is the net interbank position of the i-th bank.

When an intermediary observes an increase in the total amount of deposits $\left(D_{i, t} \geq D_{i, t-1}\right)$, it keeps the contractual profit at the level of the previous period. In fact, it recognizes that its interest rate is higher than the rest of the economy and that it is optimal to not modify the conditions which ensured the achievement of that result.

Conversely, when banks experience a withdrawal of deposits, they must understand the reasons behind the sub-optimal interest rate paid to their investors. The main driver of this decision is the amount of unallocated capital accrued in the preceding period. Indeed, due to the minimum investment dimension $\left(\bar{k}_{i, t-1}\right)$, it is always optimal for the single intermediary to invest all the available resources to obtain a non-negative interest rate. Hence, an excess of uninvested funds - defined here as a positive difference between the overall quantity of cash reserves and the minimum investment dimension $\left(C_{i, t-1} \geq \bar{k}_{i, t-1}\right)$ - indicates that the bank it is not offering a sufficiently competitive contractual profit to the firms. In the opposite situation, the intermediary recognizes that it is leaving an excessively high quota of production to the entrepreneurs and that it is obtaining a sub-optimal return from its investments.

Subsequently, given the new contractual profit $P_{i, t}$, banks compute the new minimum investment dimension $\bar{k}_{i, t}$, update the expected future return of their credits:

$$
E\left[r_{i, f, t+1}\right]=\left[\left(k_{i, f}\right)^{\alpha}-P_{i, t}\right] / k_{i, f}
$$

with $f \in F_{i, t}$ and evaluate their liquidity:

$$
L_{i, t}=D_{i, t}-A_{i, t-1}
$$

where $\left(D_{i, t}\right)$ is the current level of deposits and $\left(A_{i, t-1}\right)$ the portfolio of credits inherited from the preceding period. Indeed, this process is necessary for the intermediaries to assess their financial needs and, in case of liquidity shortage, which loans bear the minimum opportunity cost of closure. Specifically, with the term liquidity $\left(L_{i, t}\right)$ we indicate the amount of unallocated resources available for lending in each bank at the beginning of every period. As stated before, we assume that investments in the interbank market last only one period and are repaid together with their interest rates. Therefore, liquidity is simply given by the difference between the current level of deposits and the portfolio of credits inherited from the preceding period. 
Notice that the equations of liquidity (2.20) and unallocated capital (2.18) seem to represent the same economic dimension. However, by rewriting them in terms of their past values, we obtain:

$$
\begin{gathered}
L_{i, t}=D_{i, t}-D_{i, t-1}+C_{i, t-1} \\
U_{i, t}=A_{t-1}-A_{t}+L_{i, t}
\end{gathered}
$$

where we removed for simplicity the interbank market.

The new versions of the two equations put under the light the main drivers of the underlying economic dynamic. Specifically, with regards to the unallocated capital $\left(U_{i, t}\right)$, it emerges that, given the current level of liquidity, entrepreneurs' movements between intermediaries determine the overall amount of uninvested funds left in banks $\left(F_{i, t-1} \rightarrow F_{i, t}\right)$. Conversely, the resources available for supplying new credit $\left(L_{i, t}\right)$ are the result of the households' investment decisions $\left(H_{i, t-1} \rightarrow H_{i, t}\right)$. In other words, the movements in the level of unallocated capital $\left(U_{i, t}\right)$ capture the changes in the asset side of the intermediaries' balance sheets, while the adjustments in the liquidity $\left(L_{i, t}\right)$ provide a proxy for the evolution of banks' liabilities.

\section{Interbank Market}

As stated before, when intermediaries experience an excessive withdrawal of funds, namely when $L_{i, t}<0$, they must reduce lending to repay their depositors or they can try to meet their financial needs by borrowing in the interbank market. On the contrary, banks with positive resources $\left(L_{i, t} \geq 0\right)$ must decide whether to lend them to other financial institutions or supply credit to firms.

To being with, intermediaries compute their reserve/ask interest rate:

$$
r_{i, t}^{I}= \begin{cases}\infty & \text { if } L_{i, t} \leq 0 \\ \varepsilon & \text { if } L_{i, t} \in\left(0, \bar{k}_{i, t}\right] \\ E\left[r_{t+1}^{p} \mid L_{i, t} ; \bar{k}_{i, t}\right] & \text { if } L_{i, t}>\bar{k}_{i, t}\end{cases}
$$

where

$$
E\left[r_{t+1}^{p} \mid L_{i, t} ; \bar{k}_{i, t}\right]=\left[\frac{\left(L_{i, t}\right)^{\alpha+1}-\left(\bar{k}_{i, t}\right)^{\alpha+1}}{(1+\alpha)\left(L_{i, t}-\bar{k}_{i, t}\right)}-P_{i, t}\right] \frac{2}{L_{i, t}+\bar{k}_{i, t}}
$$

is the expected return of lending the amount $L_{i, t}$ to firms. In other words, $E\left[r_{t+1}^{p} \mid L_{i, t} ; \bar{k}_{i, t}\right]$ is the opportunity cost of investing $L_{i, t}$ in the interbank market rather than in credit to enterprises. Accordingly, banks with positive resources will accept any request of borrowing in the interbank market at the required interest rate $E\left[r_{t+1}^{p} \mid L_{i, t} ; \bar{k}_{i, t}\right]$ up to the amount $L_{i, t}$. 
Conversely, when the liquidity of the financial institution is positive but lower than the minimum investment dimension $\bar{k}_{i, t}$, it is not sufficient to supply credit to firms. Accordingly, the intermediary demand only a minimum interest rate 14

Lastly, when the bank has no resources to invest in the interbank market or is in liquidity distress, it requires an infinite interest rate to supply credit. In other words, the financial institution demands an infinite reserve price to obtain a positive return from investing a null quantity of capital in the interbank market.

Subsequently, financial distressed intermediaries observe the expected interest rate of each investment $\left(E\left[r_{i, f, t+1}\right]\right)$ and evaluate the opportunity of closing the credit contracts with the lowest returns, until the condition:

$$
\sum_{f \in F_{i, t}^{d e f}} k_{i, f}+L_{i, t} \geq 0
$$

is satisfied, where $F_{i, t}^{\text {def }} \subseteq F_{i, t}$ is the smallest subset of investments with minimum profitability respecting this constraint 15 .

Lastly, banks in liquidity distress $\left(L_{i, t} \leq 0\right)$ enter in sequence the interbank market ${ }^{16}$, evaluate the benefit of borrowing from a new intermediary and calculate the optimal size of the loan:

1. The intermediary in deficit looks for a new counterparty in the interbank market and moves to the new location if the latter has a higher fit, where:

$$
\eta_{i}=(1-\omega) \frac{\min \left(r_{z, t}^{I}\right)}{r_{i, t}^{I}}+\omega \frac{D_{i, t}}{\max \left(D_{z, t}\right)}
$$

is the fit of the $\mathrm{i}$-th bank, for $z=1, \ldots, n_{i}$. Accordingly, interbank links become:

$$
\begin{gathered}
\left.\begin{array}{c}
i \notin I_{\text {old }, t} \wedge i \in I_{\text {new }, t} \\
\text { old } \notin I_{i, t} \wedge \text { new } \in I_{i, t}
\end{array}\right\} \quad \text { if } \eta_{\text {new }} \geq \eta_{\text {old }} \\
i \in I_{\text {old }, t} \wedge \text { old } \in I_{i, t}
\end{gathered} \quad \text { otherwise }
$$

Notice that, as in Berardi and Tedeschi (2017), banks select their counterparties in the interbank market on the basis of their ask interest rate $\left(r_{i, t}^{I}\right)$ and size $\left(D_{i, t}\right)$. Indeed, the largest financial institutions may have

${ }^{14} \varepsilon=2.22 \times 10^{-16}$ is the machine epsilon.

${ }^{15}$ In other words, $E\left[r_{i, f, t+1}\right] \geq E\left[r_{i, f^{\text {def }}, t+1}\right] \forall f \in\left\{F_{i, t} \backslash F_{i, t}^{\text {def }}\right\} \wedge f^{\text {def }} \in F_{i, t}^{\text {def }}$

${ }^{16}$ The order of entrance is extracted at random. 
at their disposition more resources to lend but can ask a higher return. Therefore, we model this trade-off by changing the weight $\omega$ of the intermediaries' fit.

2. To maximize its future profitability, the bank chooses to finance the credits whose expected returns are higher than the interest rate required by its counterparty. In addition, the total amount demanded must be lower than the quantity supplied by the other financial institution. Specifically, whenever a bank borrows from an intermediary, the available resources of the latter decrease. Consequently, the intermediaries entering the interbank first find more capital to support their financial needs.

The bank evaluates the potential liquidity it would obtain if it had not the possibility to finance itself in the interbank market:

$$
L_{i, t}^{T}=\sum_{f \in F_{i, t}^{d e f}} k_{i, f}+L_{i, t}
$$

and chooses to finance that part of its portfolio of credits in deficit $F_{i, t}^{f i n} \subseteq F_{i, t}^{d e f}$ respecting the conditions:

$$
\begin{aligned}
k_{i, f} & \in F_{i, t}^{f i n}: \\
& \left\{E\left[r_{i, f, t+1}\right] \geq r_{S, t}^{I}\right\} \wedge\left\{\sum_{f \in F_{i, t}^{f i n}} k_{i, f} \leq L_{i, t}^{T}+L_{S, t}\right\}
\end{aligned}
$$

where $L_{S, t}$ and $r_{S, t}^{I}$ are the liquidity and the interest rate of the intermediary selected $(S)$ in the interbank market ${ }^{17}$.

3. The amount financed, the interest rate and the interbank links are thus updated accordingly:

$$
\begin{aligned}
& \left\{r_{i, S}=r_{S, t}^{I} ; k_{i, S}=L_{i, t}^{T}-\sum_{f \in F_{i, t}^{f i n}} k_{i, f}\right\} \text { with } S \in I_{i, t} \\
& \left\{r_{S, i}=r_{S, t}^{I} ; k_{S, i}=\sum_{f \in F_{i, t}^{f i n}} k_{i, f}-L_{i, t}^{T}\right\} \text { with } i \in I_{S, t}
\end{aligned}
$$

\footnotetext{
${ }^{17}$ We adopt this notation because the selected intermediary can be both the old or the new one.
} 
4. Lastly, the liquidity constrained bank closes the credit lines which are not financed through the interbank market:

$$
\left\{f \in F_{i, t}^{\text {def }}\right\} \wedge\left\{f \notin F_{i, t}^{f i n}\right\} \Rightarrow\left\{f \notin F_{i, t}\right\} \wedge\left\{k_{i, f}=0\right\}
$$

and both the intermediaries update their available resources:

$$
\begin{aligned}
L_{S, t} & =L_{S, t}-k_{S, i} \\
L_{i, t} & =L_{i, t}+k_{i, S}+\sum_{f \notin F_{i, t}} k_{i, f}
\end{aligned}
$$

After this process of interbank financing and credit closure, intermediaries observe the quantity of resources available for investment $\left(L_{i, t}\right)$ and generate their new credit supply schedule as in the initialization phase of the system (see Eq. 2.2 and 2.3 with available resources equal to $L_{i, t}$ instead of $D_{i, 0}$ ).

\subsubsection{Credit market}

Given the supply of loans, firms search at random a new counterparty and move to the new location if the latter has a higher fit:

$$
\eta_{i}=\frac{P_{i, t}}{\max \left(P_{z, t}\right)}
$$

and a new credit relation starts:

$$
\left\{P_{\text {new }, t}, k_{\text {new }, f}=k_{j}^{N}\right\} \text { with } f \in F_{\text {new }, t} \text { if }\left\{\eta_{\text {new }} \geq \eta_{\text {old }} \mid \text { credit supply }\right\}
$$

where $k_{j}^{N} \in F_{\text {new }}^{N}$ is the size of a new loan supplied by the new intermediary. Consequently, the preexisting credit line is closed:

$$
\left\{f \notin F_{\text {old }, t}\right\} \wedge\left\{k_{\text {old }, f}=0\right\}
$$

Notice that not all firms are connected with an intermediary and have an active credit line. In that situation we assume that: $\eta_{\text {old }}=\eta_{\text {not connected }}=0$. In addition, entrepreneurs can move to a new financial institution conditional to an effective supply of credit. Therefore, the firm can switch to the new location only in this case.

Lastly, when the credit supply is completely depleted or there is no more demand for new loans, intermediaries evaluate the final amount of unallocated resources/cash reserves:

$$
C_{i, t}=D_{i, t}-A_{i, t}-\sum_{j \in I_{i, t}} k_{i, j}
$$




\subsection{Network Topology, Steady State and Cy- cles}

In the previous section we describe the mechanism behind the formation of borrowing and lending relations. These links can be easily interpreted as the building blocks of a financial network. Indeed, agents (households, banks and firms) are the nodes of a directed graph in which the weights of the edges are equal to the size of the deposit, interbank and credit relations. Accordingly, the direction of the links goes from borrowers to lenders.

In this section we examine the characteristics of the system for different values of the parameter governing the behavior of banks $(\omega)$. Specifically, we study two extreme cases in which financial institutions select their counterparties in the interbank market only on the basis of their size $(\omega=1)$ and interest rate $(\omega=0)$. Furthermore, we examine an intermediate situation, namely a mid-point between these two frameworks $(\omega=0.6)$.

We perform this analysis in two main directions. First, we study the topology of the network for individual simulations. Indeed, even if different replications of the model produce dissimilar results, the main properties of the network remain the same. Second, we analyze both the characteristics of cycles and the long-run steady-state of the economy on the basis of 200 simulations. Indeed, we can study the empirical moments of each variable through this method and we can compare the different frameworks in detail.

Lastly, notice that in the previous section we introduce the length of the year $T_{y}$ as a parameter of the model. Here we perform the analysis on the data transformed in a quarterly basis. Specifically, we collect every time series $y_{s}$ in its corresponding quarterly form $y_{t}^{q}$ :

$$
y_{t}^{q}=\sum_{s=t \cdot T_{y} / 4}^{(t+1) \cdot T_{y} / 4-1} y_{s}
$$

The set of parameters employed in the simulations, the calibration of the model and the micro properties of the system are then discussed in the next section.

\subsubsection{Network Topology}

In the previous section we introduce the possibility of different network topologies to emerge depending on the behavior of banks. Specifically, we assume that intermediaries can select their counterparties in the interbank market according to their interest rate and size. In fact, the largest banks 
may have more resources to lend but can demand a higher return. For this reason, a trade-off can exist between the amount financed and the required interest rate. As a result, intermediaries' behavior can affect the topology of the deposit, interbank and credit networks. In particular, the system can converge to a highly centralized network for two main reasons.

First, when intermediaries borrow in the interbank market they bear an additional risk: while the credit line between two banks is fixed, the underlying assets are not. Indeed, financial institutions must always pay interests on the debt contracted in the interbank market. On the contrary, firms are free to move to other banks and can close the existing loan. In that situation, intermediaries must pay a fixed interest rate on their interbank loans even if they are receiving a reduced income stream from their credit issued to entrepreneurs. In other words, borrowers in the interbank market can suffer additional losses because the real activities underlying the interbank credit may not cover it anymore.

Second, when banks select their counterparties on the basis of their size, by construction, they do so regardless of the ask interest rate. Consequently, when the return required by the hub increases, intermediaries in deficit can finance a smaller share of their portfolio and must liquidate a larger quota of their credits. For this reason, also optimal investments, which could have been founded by other banks, are closed and the productivity of liquidity constrained institutions decreases.

Summing up, these two effects can generate a competitive advantage for lenders in the interbank market. In particular, only the hub can exploit these mechanisms in a highly centralized context and can pay, on average, a higher return to its investors. In this way, it can attract more households and can reinforce its position in all three markets (deposit, interbank and, because of the large availability of funds, credit market).

A visual inspection of the graphs representing the two extreme cases confirms this idea. When intermediaries select their counterparties in the interbank market on the basis of their relative size $(\omega=1)$, the system converges to a highly centralized network (Fig. 2.1). Indeed, most of the households deposits in the hub and also a large part of the firm borrows from it. Moreover, all the transactions carried in the interbank market flow through the largest bank. On the contrary, intermediaries are almost equal in the decentralized context $(\omega=0)$, without a clear hub emerging in the market (Fig. 2.2).

The time series representing the ID of the hubl 18 and its degree confirm

\footnotetext{
${ }^{18}$ Each bank has an unique identifier from 1 to $n_{i}$. The ID is equal to the normalized identifier between $1 / n_{i}$ to 1 .
} 
these results. When intermediaries select their counterparties in the interbank market on the basis of their relative size $(\omega=1)$, the system converges to a highly centralized network. As a consequence, nearly one third of the resources flows through a single financial institution in all three markets and the hub remains the same throughout the simulation (Fig. 2.3, 2.4 and 2.5).

On the contrary, when the interest rate is the key determinant of intermediaries' decisions $(\omega=0)$, no hub emerges in the market (Fig. 2.6, 2.7 and 2.8). Indeed, by searching the financial institutions asking the lowest interest rates, banks in deficit can achieve a higher margin of intermediation 19 . As a result, these extra profits more than compensate for the risk of idiosyncratic credit closures by firms. Overall, banks in financial distress exploit the interbank market in this context and pay, on average, a higher return to its investors. The result is then a continuous reallocation of wealth by the households.

Lastly, the hub emerges only for a limited time in the intermediate situation $(\omega=0.6)$ (Fig. 2.9, 2.10 and 2.11). In fact, as in the centralized framework, the largest bank can exploit other intermediaries because of its size and can reinforce its market position. However, when it starts demanding an excessively high interest rate, the rest of the system stop borrowing from it. Therefore, the hub loses the additional profits coming from the interbank market and pays a lower return to its depositors. Overall, households start to withdraw their resources and the bank loses its privileged state.

Finally, with regards to the correlation coefficient between the degree of the hub and its fit, this value is always positive (see boxes from Fig. 2.3 to Fig. 2.11). Furthermore, the strength of the relationship in the deposit and interbank markets is always higher than in the credit sector. Indeed, the availability of funds in banks determines the issuance of new loans to firms. Consequently, the deposit and interbank networks dominate the credit one. Nevertheless, the correlation coefficient of the interbank market is close to zero in the centralized framework (see Fig. 2.5). Indeed, the fit of the hub is constant and equal to its maximum value in that context, while its degree fluctuates according to the availability of funds and the market demand. As a result, the correlation coefficient is equal to zero.

\subsubsection{Credit Cycles}

Cycles show different dynamics in three network topologies. In particular, aggregate fluctuations in the centralized framework are more persistent (Fig.

\footnotetext{
${ }^{19}$ Indeed, the difference between the interest rate obtained from credit to firms and the return paid to intermediaries increases.
} 
2.12) and exhibit a larger amplitude (Fig. 2.13).

To begin with, the three network topologies follow a similar pattern in the allocation of funds during different phases of the cycle (see Fig. 2.14, 2.15 and 2.16). In fact, an exogenous increase in the aggregate production produces a subsequent rise in the centrality of the deposit and credit markets in all the specifications of the model. Hence, positive shocks are mainly due to a better allocation of funds by the single institution. Indeed, only a more efficient bank can attract a larger number of households and lend the additional resources to a broader number of firms. Accordingly, also the interest rates in the deposit and interbank markets increase, thus leading to the observed reduction in the centrality of the latter. Nevertheless, the size of this reallocation of funds is larger and more persistent in the centralized network. Similarly, the interbank market has a statistically positive effect on future production only in this framework 20 . Indeed, all banks rely on the single hub to finance their deficits in this context. For this reason, the state of the economy highly depends on the overall efficiency of the core bank and vice-versa.

To confirm these results, we estimate a vector autoregressive model of order one for all the network topologies and we simulate the impulse response functions of a positive shock in the aggregate production and an exogenous reduction in the volume of the interbank market21.

With regards to the positive shock in the aggregate production, this produces a reallocation of funds and credits from the periphery to the hub (Fig. 2.17, 2.18 and 2.19). This confirms the idea of a temporary rise in the productivity of a single intermediary. Accordingly, also interest rates hike in both the deposit and interbank market in the short-run. However, this positive shock, raising the quantity of resources available in the system, increases the amount of unallocated capital as well. Consequently, the average contractual profit starts growing in the medium term, reducing the interest rates and moving the economy back to the long-run equilibrium.

This dynamic is particularly pronounced in the centralized model, with a large reallocation of funds from the periphery to the hub in the shortrun, followed by a small reversal during the medium-term transition phase.

\footnotetext{
${ }^{20}$ Also the interbank market in the intermediate context follows this pattern, but it is not statistically significant.

${ }^{21}$ The time series included in the estimations are: aggregate production, interest rate of deposits, volume of deposits in the hub and in the periphery, average contractual profit, interbank volume and interest rate, liquidity, volume of credit in the hub and in the periphery, unallocated capital. Lag selection is based on the Akaike (AIC), Schwarz Bayesian (BIC) and Hannan-Quinn (HQC) information criterions. The orthogonal errors of the impulse response function follow the actual order of the model.
} 
The cause is the different response of the interbank market in the three specifications. Even if the interbank interest rate rises in all the network topologies, this movement is larger in the centralized framework. Indeed, in this context, banks choose to finance their deficits only from the hub, which requires a higher return because of its increased efficiency. Consequently, the volume and the degree centrality of the interbank market decrease and the intermediaries of the periphery close a larger number of credit lines. As a result, the implicit loss of informational capital, reducing the overall productivity of the periphery, cause a vaster reallocation of funds toward the core bank.

Conversely, when banks finance their deficit on the basis of the interest rate, the increase in the interbank market returns is lower. Indeed, the intermediaries can switch to those institutions which offer a better price, thus reducing the degree centrality of the interbank market. In addition, the increased efficiency of the system provides a vaster quantity of resources. Hence, the overall effect is a rise in the interbank market volume.

These results are confirmed by the impulse response function of an exogenous reduction in the volume of the interbank market (Fig. 2.20, 2.21 and 2.22). Indeed, in the centralized specification, the hub is not able to compensate the contraction of optimal investments in the periphery. Indeed, new loans issuances from the core bank are not as efficient as the seized ones. For this reason, the interest rate of the hub decreases and it suffers a sudden withdrawal of resources. In addition, the interbank market cannot counterbalance this outflow of funds because of the dimension of the largest bank. Indeed, the single intermediary of the periphery is too small to provide enough resources to the core bank. Consequently, also the hub must close a large portion of its portfolio, including optimal investments as well. Therefore, the outcome is a temporary recession.

In view of that, is not surprising that a negative shock in the interbank market has no effects in the decentralized and intermediate frameworks. In fact, there are no banks which benefit more from this mechanism in these contexts. Consequently, new loans issuances can easily compensate the seized ones. In addition, even if new credits were not as profitable as the old ones, the rest of the market would be able to counterbalance the subsequent outflow of funds in the hub. This confirms the idea that a large part of the recession in the centralized specification is due to the inability of the periphery to finance the deficit of the hub. In fact, the asymmetric properties of the network would require a perfect coordination between the intermediaries in the rest of the market to finance the core bank. 


\subsubsection{Steady State}

In this section we study the long-term properties of aggregate production for the three network topologies. In addition, we compare our results with the neoclassical solution of the model and a benchmark situation without the interbank market.

To obtain the neoclassical optimal growth path, we assume a perfectly competitive environment in which all the entrepreneurs maximize their profits $P_{f, t}$ given the current interest rate $r_{t}$ :

$$
\max _{\left\{k_{f, t}\right\}} P_{f, t}=\left(k_{f, t}\right)^{\alpha}-r_{t} k_{f, t} \Rightarrow r_{t}=\alpha\left(k_{f, t}\right)^{\alpha-1}
$$

Subsequently, by assuming a one-to-one relation between firms and households $\left(k_{f, t}=d_{h, t}=k_{t}\right)$ and by substituting (2.36) into (2.14), we obtain the optimal growth path:

$$
k_{t+1}=\beta\left(1+r_{t}\right) k_{t}=\beta\left(\alpha\left(k_{t}\right)^{\alpha}+k_{t}\right)
$$

and the equilibrium contractual profits:

$$
P_{t}=(1-\alpha)\left(k_{t}\right)^{\alpha}
$$

On the one hand, all the specifications of the model converge to a pseudo steady-state level in the long-term (Fig. 2.23). This outcome is a direct consequence of the capital accumulation rule of the households (Eq. 2.14), combined with the decreasing marginal returns of the production function. Indeed, an excess of capital, reducing the interest rate paid to depositors, decreases their incentive to save and vice-versa. As a result, the system converges to a long-term steady-state level. In addition, aggregate production in the neoclassical solution outperforms the results obtained in our agent-based setting. Indeed, the mechanism of decentralized matching, through the continuous creation and destruction of deposit and credit relations, maintains the system below the optimal allocation of wealth. Nevertheless, this outcome is line with the existing literature on search and matching models for the credit market (Den Haan et al., 2003; Wasmer and Weil, 2004, Becsi et al., 2013) and fully confirms their results.

On the other hand, the interbank market has a positive effect on the longrun aggregate production (Fig. 2.23). Indeed, when intermediaries suffer a withdrawal of deposits, they can finance the most profitable investments through this market. Consequently, the implicit loss of informational capital decreases and the overall productivity of the economy rises. For this reason, banks can provide funds to a vaster number of firms, thus leading to an additional increase in the aggregate production. 
Lastly, all the three specification of the model achieve a similar level of production in the long-term. However, their distributional properties are quite different (Fig. 2.24). Firstly, the centralized and intermediate frameworks seem to have similar moments, with the exception of the mean. Indeed, the continuous formation and destruction of different hubs in the intermediate case does not allow them to reach a critical mass. As a result, cycles follow a similar dynamic in these two contexts (see the duration and depth of expansions and recessions in Fig. 2.12 and 2.13). However, the large number of credit closures by the hub during recessions produces a large loss of informational capital, with a consequent reduction in the overall productivity of the system (see, for example, the evolution of the degree of the hub in Fig. 2.10). Conversely, aggregate production in the centralized framework ranges between the two extremes of the previous distributions. Consequently, the centralized framework outperforms the intermediate context on average, but at the cost of a higher volatility (see Fig. 2.12 and 2.13). Indeed, even if the loss of informational capital is lower during recessions, the state of the economy is highly dependent on the performance of the hub and vice-versa.

In summary, the interbank market has a positive effect on the economy. Indeed, counterbalancing depositors movements, it reduces the implicit loss of banks' informational capital and increases the overall efficiency of the system. Nevertheless, a highly centralized interbank market amplifies the effects of an exogenous shock in the economy. Indeed, the state of the system heavily depends on the overall efficiency of the core bank and vice-versa.

\subsection{Calibration Analysis}

ABMs rely on the assumption that economies are complex systems, in which a large number of heterogeneous agents interact with each other without any central planner coordinating their actions. The natural corollary to this idea is that both the dynamics and the distributional properties of the time series observed in the real world are the outcome of this process of decentralized interactions (Delli Gatti et al. 2005). As a consequence, this approach to the study of economics has both the potential and the necessity to validate its results not only from an aggregate point of view but also from a micro level.

In this section, we analyze the performance of our model in reproducing some of the stylized facts characterizing modern economies. We take United States data as a reference point for the aggregate analysis, while we rely on the empirical results of previous researches to study the distributional properties of the system at the micro level. Specifically, we analyze both 
the macro and micro attributes of the simulations under the three different network topologies.

The set of parameters employed in the process of validation are chosen to minimize the degree of subjectivity in the decisional process and to control for computational times. In particular, we use some common values for the production function $(\alpha=0.3)$ and for the one-year discount factor ( $\beta=$ $0.99)$, while we limit the number of households $\left(n_{h}=1000\right)$, firms $\left(n_{f}=\right.$ 1000) and financial intermediaries $\left(n_{i}=20\right)$ for reasons of computational tractability. As stated in the previous section, the three network topologies are obtained by simply setting the weight $\omega$, which influences the measure of fit in the interbank market through equation (2.26), equal to 0 in the decentralized case, 0.6 in the intermediate context and to 1 in the centralized one. Subsequently, to let the system converge to the pseudo steady-state, we run 200 simulations of $T=30000$ periods, starting from the same initial value for the households capital $\left(k_{0}=0.001\right)$, and we study the dynamics of the last 15000 observations. Lastly, we calibrate the model by setting the intermediaries sensitivity $\gamma=0.015$ and the one year time scale $T_{y}=160$. Indeed, these value best fit the real time series at the aggregate level.

\subsubsection{Macro Properties}

The time series included in the analysis of the aggregate properties of the simulations are the annual growth rates of real consumption and production and the one-year real interest rate. In addition, we study also the cyclical behavior of aggregate production by detrending the logarithm of the time series in levels through the Hodrick-Prescott filter. Finally, notice that the real data is available only at a quarterly frequency. Consequently, we perform the analysis on the quarterly transformation of the simulated data (see Eq. 2.35 .

To begin with the analysis of standard deviations, the model produces a good replication of the observed values on the real aggregate consumption and production growth rates, while the volatility of the interest rate is significantly lower than the observed one (Table 2.1). With regards to the correlations among these variables (Tables 2.2, 2.4, 2.5 and 2.6), the direction of the co-movements is generally correct in all the specifications. However, the model overestimates the strength of the relation between production and interest rates.

The situation is different when we focus on autocorrelations (Tables 2.3 , 2.7, 2.8 and 2.9p: with the exception of interest rates, all the other variables have an autocorrelation coefficient lower than the observed one. This departure from the real data is particularly pronounced in the decentralized 
specification of the model. At the same time, all the simulations overestimate the effect of past values of production on current returns. On the contrary, the three specifications of the model underestimate the correlation coefficients between interest rates and the past growth rates of production and consumption. To end with, aggregate returns display a large persistence as in the real data.

In the last two decades, researchers focused also on the asymmetric behavior of business cycles. Sichel (1993) studied the coefficient of skewness of the detrended time series ${ }^{22}$ of the real aggregate production in the US economy. The author found a negative value for both these parameters, indicating some deepness and steepness characteristics of the time series. All the simulations reproduce these aspects, with the centralized specification being closer to the real data (Table 2.10).

In summary, the two specifications reproduce some of the stylized facts characterizing real-world aggregate time series. In particular, the centralized simulation seems to be closer to the actual data. Conversely, the major problems of the model come from the excess reactivity of the system to changes in the aggregate return and from the low autocorrelation coefficient of consumption and production. The first issue is due to the lack of other forms of household income beyond interest rates. As a result, relatively small changes in investment returns produce large fluctuations in savings. In addition, real world interest rates are affected not only by business cycles, but also by long-term trends in the technological component of production. The second point can be addressed by taking into account that we are assuming a strong process of capital reallocation in the model. A more sticky mechanism would return more realistic results and reduce most of the noise producing this outcome. Nevertheless, we believe that this would return only second order improvements, at the cost of increasing excessively the parametrization of the model.

\subsubsection{Micro Properties}

In this section we analyze the micro properties of the system. First, we focus on the characteristics of the distribution of financial capital and incomes of households and firms. Second, we investigate the dynamics of interest rates at the level of the single intermediary.

Notice that in this analysis we rely on the data of individual simulations in their original form. In other words, as for the network topology, even if dif-

\footnotetext{
${ }^{22}$ Deviations from the trend are obtained by applying the Hodrick-Prescott filter to the logarithm of the original time series.
} 
ferent replication of the model produce dissimilar results, the main properties of the time series remain the same. In addition, the quarterly transformation employed in the previous sections (Eq. 2.35) is not necessary here because we study the cross-sectional characteristics of the data.

A well-known feature of natural and social phenomena is their power law distribution (Gabaix, 2016). In particular, largest firms follow a power law statistics, while the remaining part of the system is distributed according to a log-normal function. This feature has been observed both in terms of production/revenues (Axtell, 2001; Ramsden and Kiss-Haypál, 2000, Okuyama et al. 1999) and of capital employed (Gaffeo et al. 2003). This characteristic is fully reflected in our simulations and it holds for all the specifications of the model (Fig. from 2.25 to 2.30). Furthermore, the scale parameter is not stable over time, but increases during expansions (Gaffeo et al., 2003). To test this feature, we estimate the power law scale factor of the 95th percentile of the distribution of firms' capital for every time period and we regress it on the level of production. Given the well-known problem of heteroskedasticity in estimated dependent variable models and the strong autocorrelation in our observations, we employ the Newey-West estimator to overcome this issue in our ordinary least squares regressions. The results (Table 2.11) confirm this additional stylized fact: the distribution of firms size is less skewed during expansions than during recessions.

Since the seminal work of Pareto (1986) (see Persky (1992) for an analysis) similar patterns have been found also in the distributive properties of the households wealth and incomes (Clementi and Gallegati, 2005; Clementi et al. 2006). Also in this case the model replicates these findings (Fig. from 2.31 to 2.36, with the centralized specification returning a clear confirmation of this fact. In addition, households incomes are more homogeneous than distribution of wealth (Gabaix, 2016). In this case the decentralized framework outperforms the centralized and intermediate specifications: even if the tail of the wealth distribution follows a power law, incomes are closer to a log-normal function (see Fig. 2.33 and 2.36).

Lastly, with regards to investments returns, we plot in Figures 2.37, 2.38 and 2.39 the interest rates paid by the three largest intermediaries in terms of invested capital. From these graphs emerges clearly that the variance of aggregate returns is lower than the volatility of the single asset, a standard behavior of financial markets. Furthermore, aggregate returns follow the same path of the largest intermediary in the centralized framework (see the correlation coefficients in the graphs). This result highlights that in this context exists a market maker which moves all the system and bears most of the systemic risk.

In addition, interest rates display volatility clustering at the individual 
level (see Cont (2001, 2007) for a discussion on the topic). This feature is particularly pronounced in the decentralized case, where no agents in the system have a significant market power. In view of that, we can consider the economy in this context closer to a first best equilibrium. Indeed, intermediaries are quite homogeneous in this case. Consequently, they can not influence market prices excessively, bringing the financial system closer to a perfectly competitive environment. Therefore, even if the single investment is more volatile, the aggregate dynamics is smoother. On the contrary, it is not possible to edge completely idiosyncratic risk in the centralized framework because one asset in the market contains most of the systemic risk. In other words, the optimal portfolio (the market portfolio) does not exits in this situation because individual and aggregate risks overlap in the single investment.

\subsection{Concluding Remarks}

In this article, we develop a macroeconomic ABM to study the effects of different topologies of the interbank market on the overall performance of the economy. Specifically, we implement a decentralized matching mechanism to obtain an endogenous evolution of deposit, credit and interbank relations.

Overall, our model confirms the importance of the interbank market as an indisputable source of economic development. Indeed, counterbalancing depositors movements, it reduces the implicit loss of banks' informational capital and increases the overall efficiency of the system. Nevertheless, a highly centralized network amplifies the effects of exogenous shocks in the economy, a result confirmed also by other researches (Iori et al., 2006, Lenzu and Tedeschi, 2012, Tedeschi et al., 2012). Indeed, the state of the system depends heavily on the overall efficiency of the core bank and vice-versa. In particular, the single intermediary in the periphery does not have sufficient resources to sustain a distressed hub in a centralized context. In other words, the bailout of a core bank would require a perfect coordination of all the other actors of the market or the direct intervention of the government. In view of that, a more homogeneous financial system would be more sustainable and less subject to large banking crises.

The model can be extended in a number of directions to consider important issues. First, we have not included the labor market in this framework to maintain our analysis as simple as possible. Nevertheless, researchers show that the mechanism of decentralized matching in the credit sector can have a large impact also on the level of employment (see Wasmer and Weil (2004) for a representative agent analysis and Riccetti et al. $(2015)$ for an ABM). 
Accordingly, an extension of our model in this direction would enrich our economic environment with a fundamental factor of production and would complete our analysis of welfare. Second, most of the research on interbank and credit networks focused on the role of the financial accelerator as an amplifier of exogenous shocks (Delli Gatti et al., 2010, Tedeschi et al. 2012, Riccetti et al., 2013; Grilli et al. 2014, 2015). In view of that, the introduction of this mechanism in our model would test those results in a complete economic system in which banks' liabilities are not fixed but follow depositors' behavior. 


\subsection{Tables and Figures}

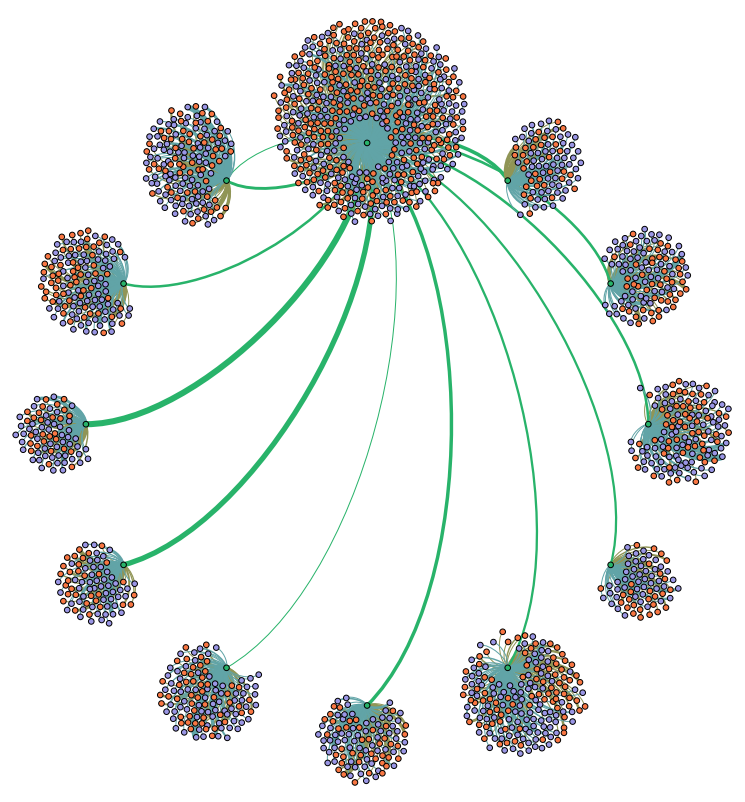

Figure 2.1: Network: Centralized Topology

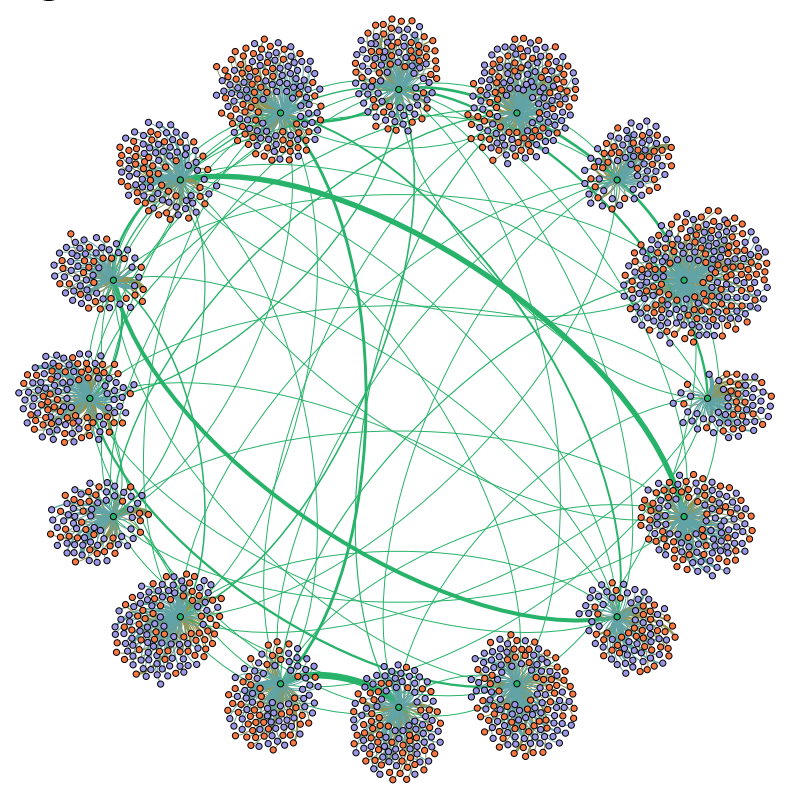

Figure 2.2: Network: Decentralized Topology

Note: weighted edges (size equal to invested amount). Color Palette: Blue $\rightarrow$ Households, Green $\rightarrow$ Banks, Red $\rightarrow$ Firms. 


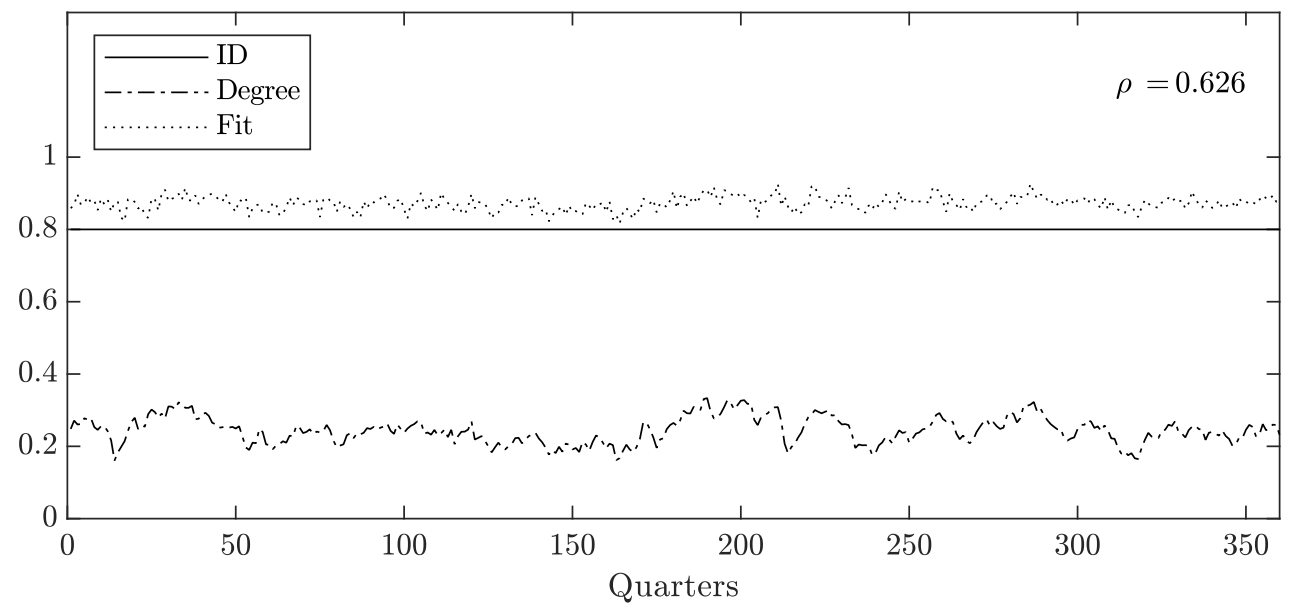

Figure 2.3: Hub of Deposits Market (Centralized)

Note: Normalized ID, in-degree and fitness of deposits market hub. Box indicates the correlation coefficient between hub in-degree and fit.

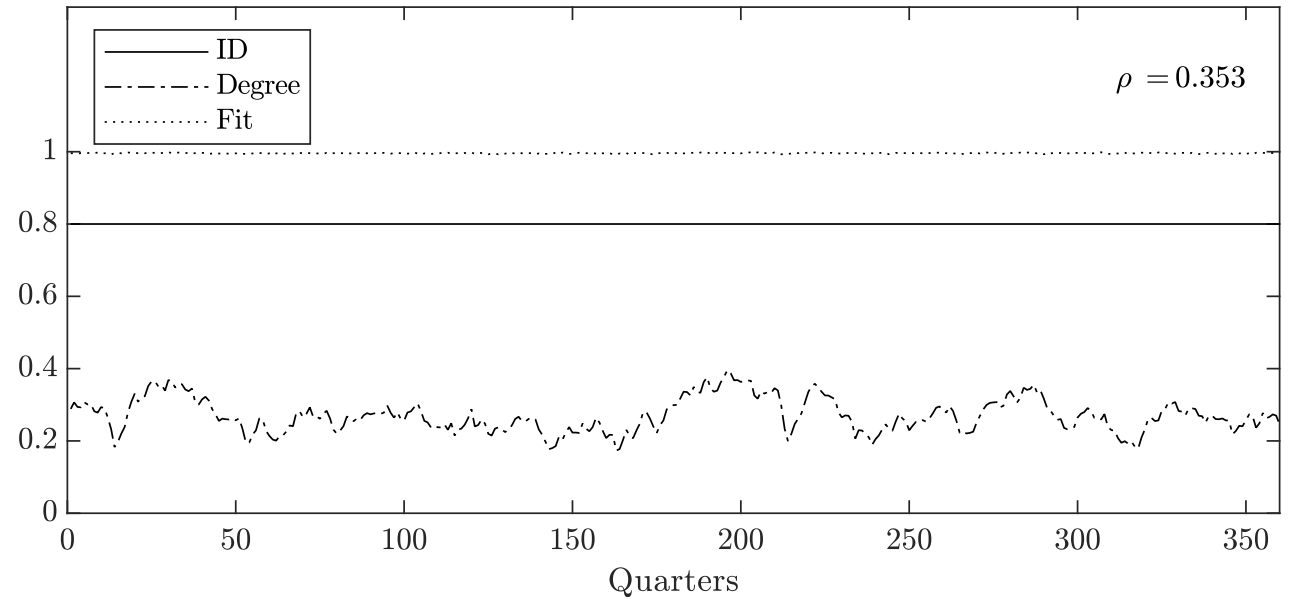

Figure 2.4: Hub of Credit Market (Centralized)

Note: Normalized ID, in-degree and fitness of credit market hub. Box indicates the correlation coefficient between hub in-degree and fit. 


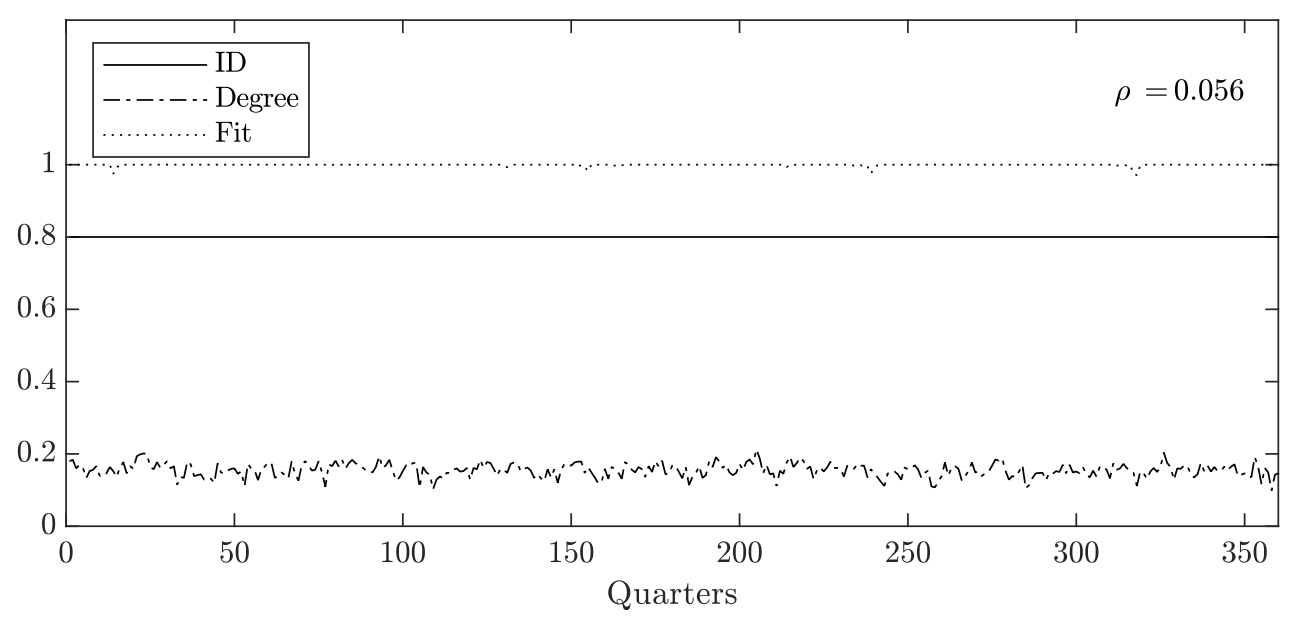

Figure 2.5: Hub of Interbank Market (Centralized)

Note: Normalized ID, in-degree and fitness of interbank market hub. Box indicates the correlation coefficient between hub in-degree and fit.

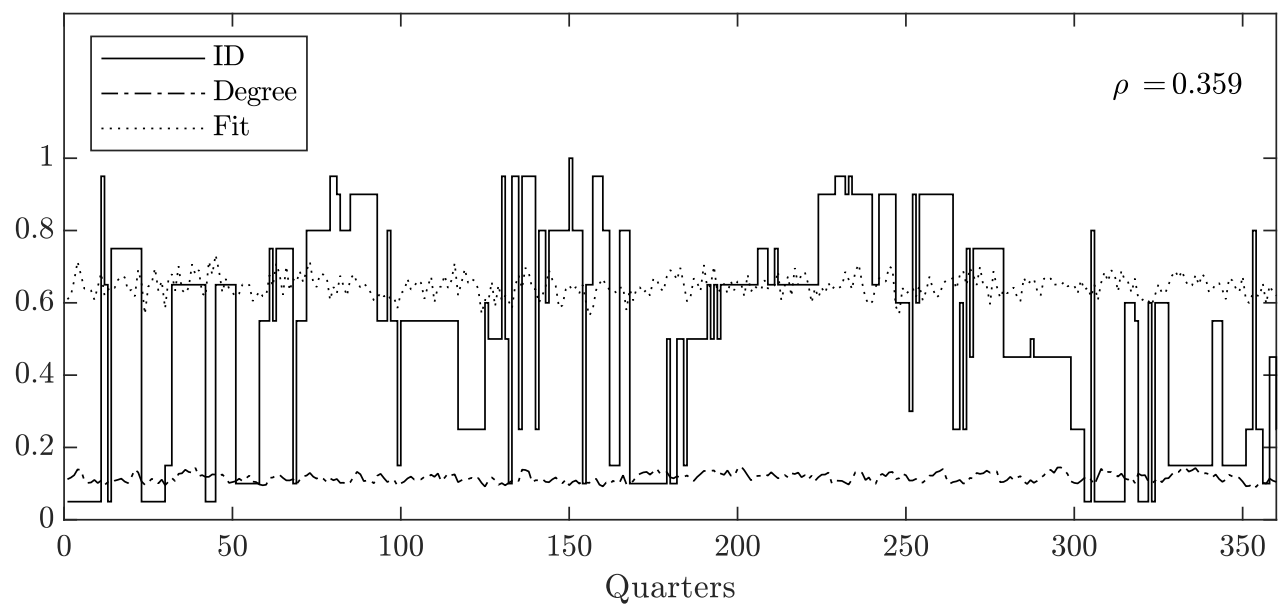

Figure 2.6: Hub of Deposits Market (Decentralized)

Note: Normalized ID, in-degree and fitness of deposits market hub. Box indicates the correlation coefficient between hub in-degree and fit. 


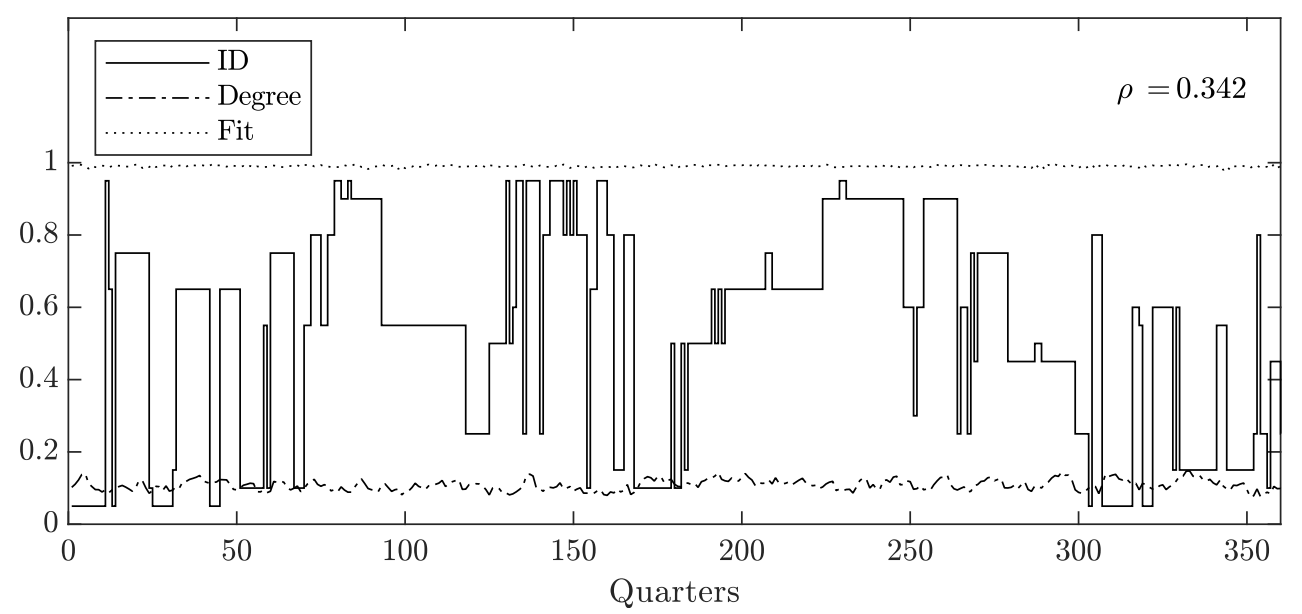

Figure 2.7: Hub of Credit Market (Decentralized)

Note: Normalized ID, in-degree and fitness of credit market hub. Box indicates the correlation coefficient between hub in-degree and fit.

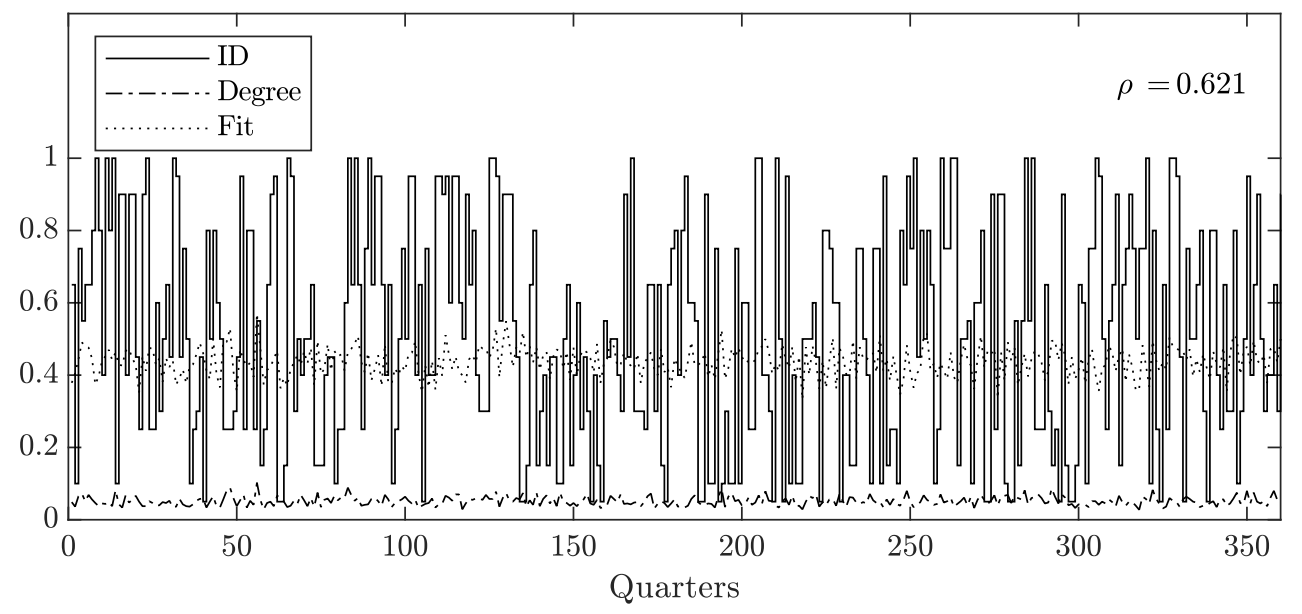

Figure 2.8: Hub of Interbank Market (Decentralized)

Note: Normalized ID, in-degree and fitness of interbank market hub. Box indicates the correlation coefficient between hub in-degree and fit. 


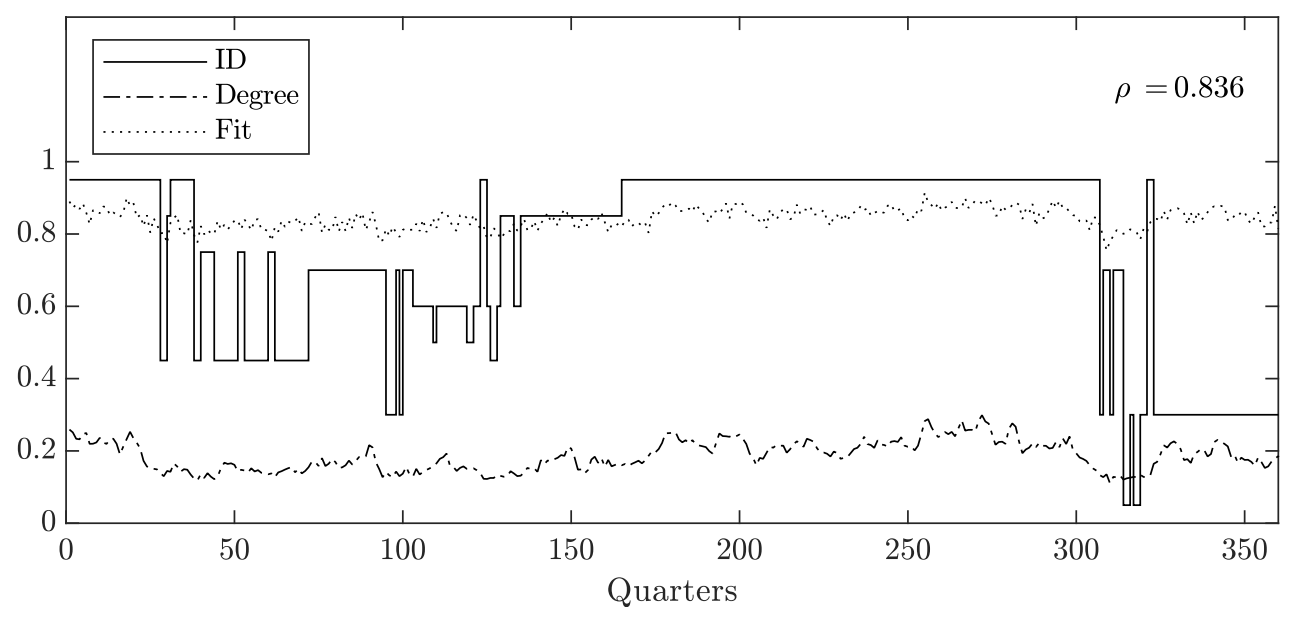

Figure 2.9: Hub of Deposits Market (Intermediate)

Note: Normalized ID, in-degree and fitness of deposits market hub. Box indicates the correlation coefficient between hub in-degree and fit.

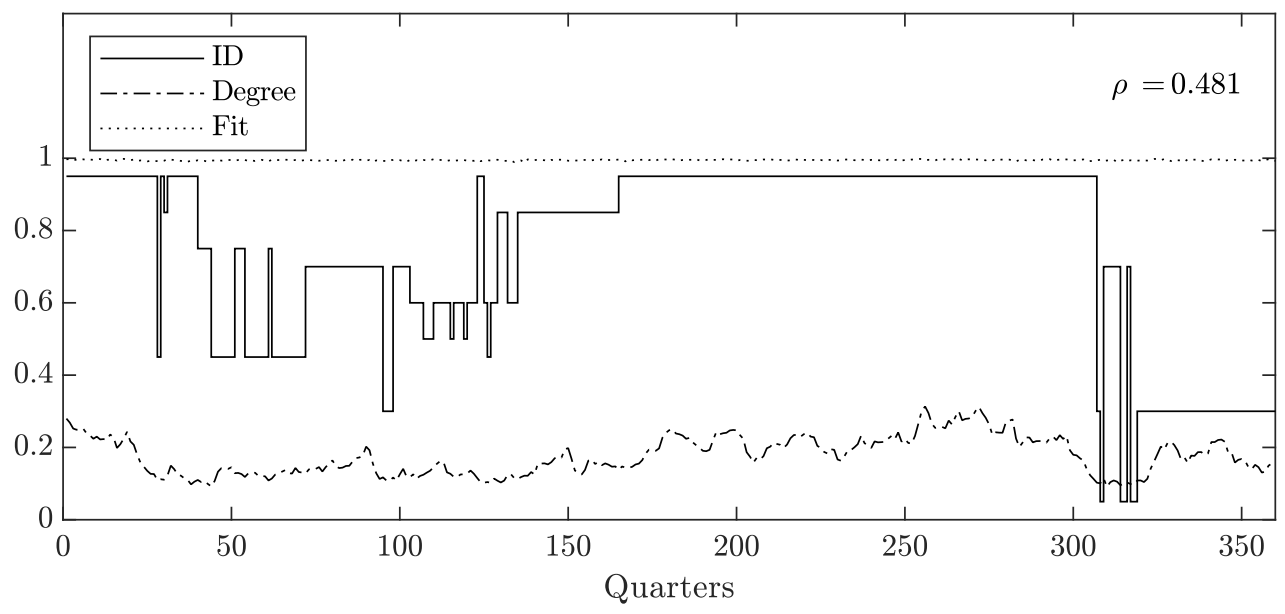

Figure 2.10: Hub of Credit Market (Intermediate)

Note: Normalized ID, in-degree and fitness of credit market hub. Box indicates the correlation coefficient between hub in-degree and fit. 


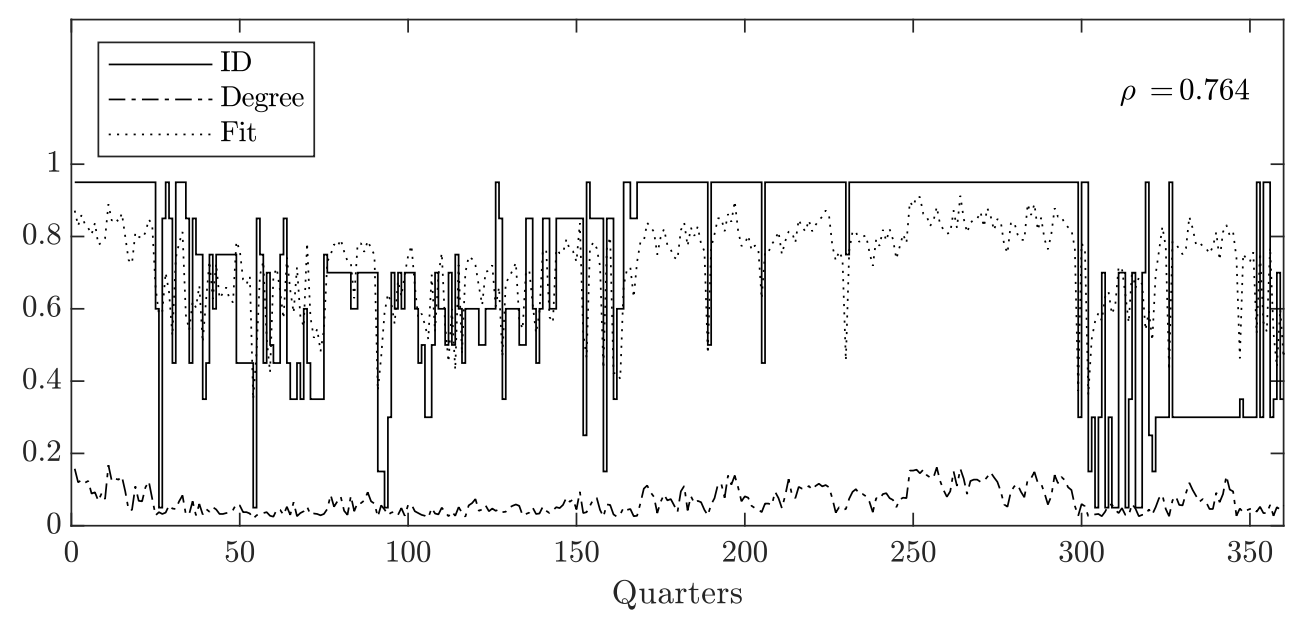

Figure 2.11: Hub of Interbank Market (Intermediate)

Note: Normalized ID, in-degree and fitness of interbank market hub. Box indicates the correlation coefficient between hub in-degree and fit.

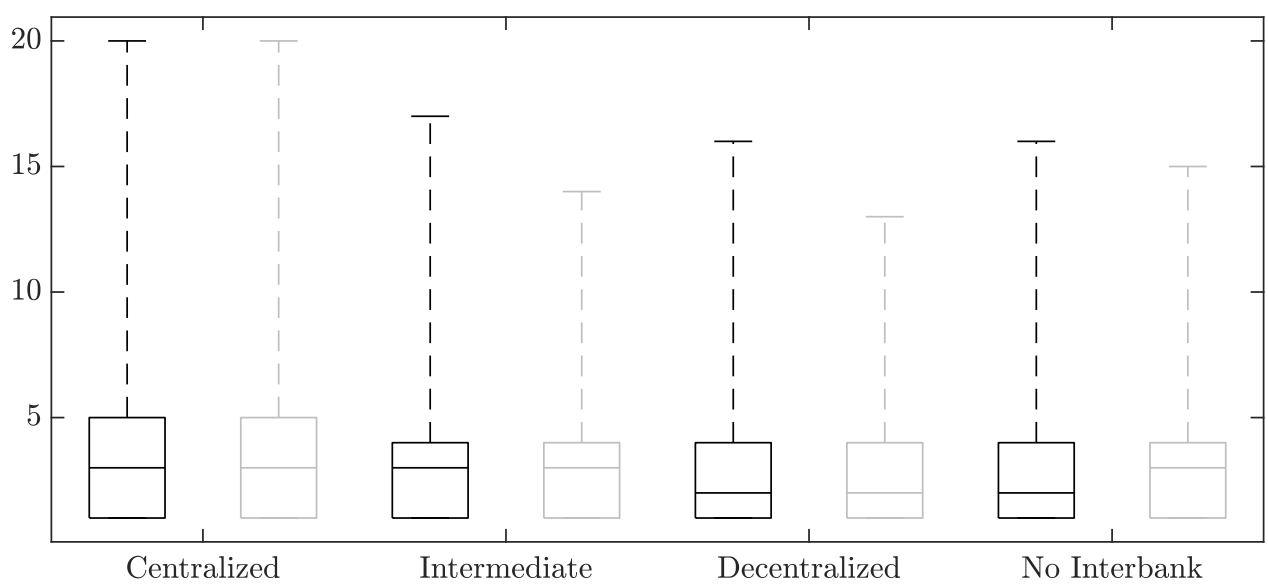

Figure 2.12: Duration of Expansions and Recessions

Note: length of periods with positive (black) and negative (gray) growth rates. Box plots based on 200 simulations. 


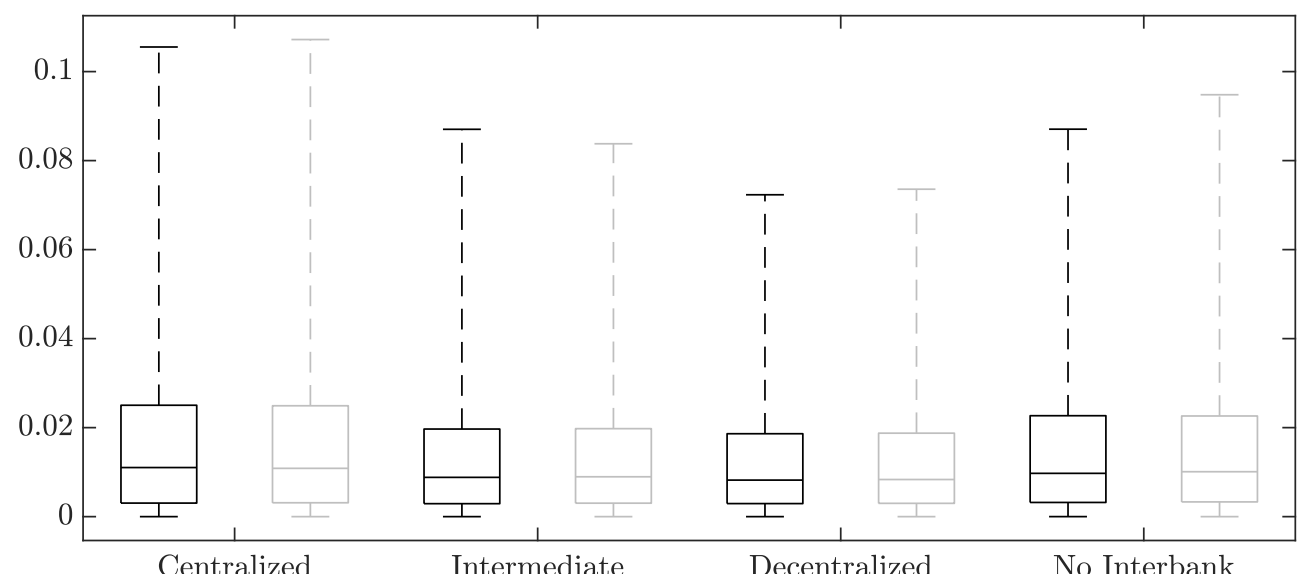

Figure 2.13: Depth of Expansions and Recessions

Note: cumulative growth rates of expansions (black) and recessions (gray). Box plots of absolute values based on 200 simulations.

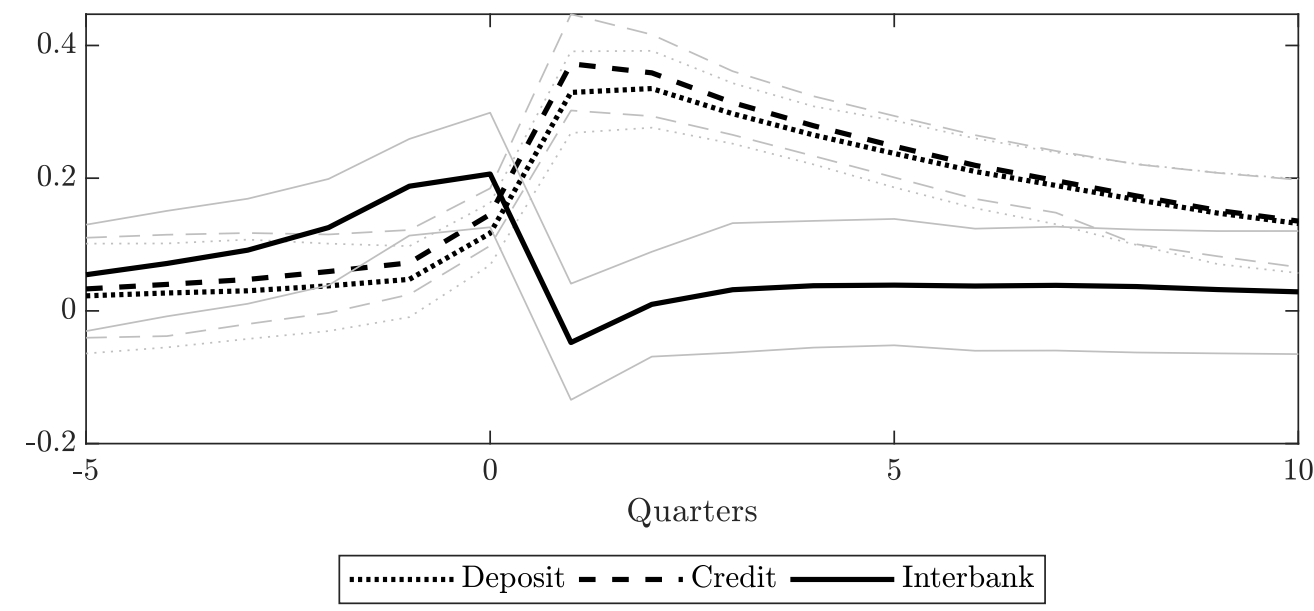

Figure 2.14: Cross-Correlation of Production and Centrality (Centralized)

Note: cross-correlation between aggregate production and the centrality of deposit, credit and interbank markets. Average (black lines) and $90 \%$ confidence intervals (gray lines) of 200 simulations. 


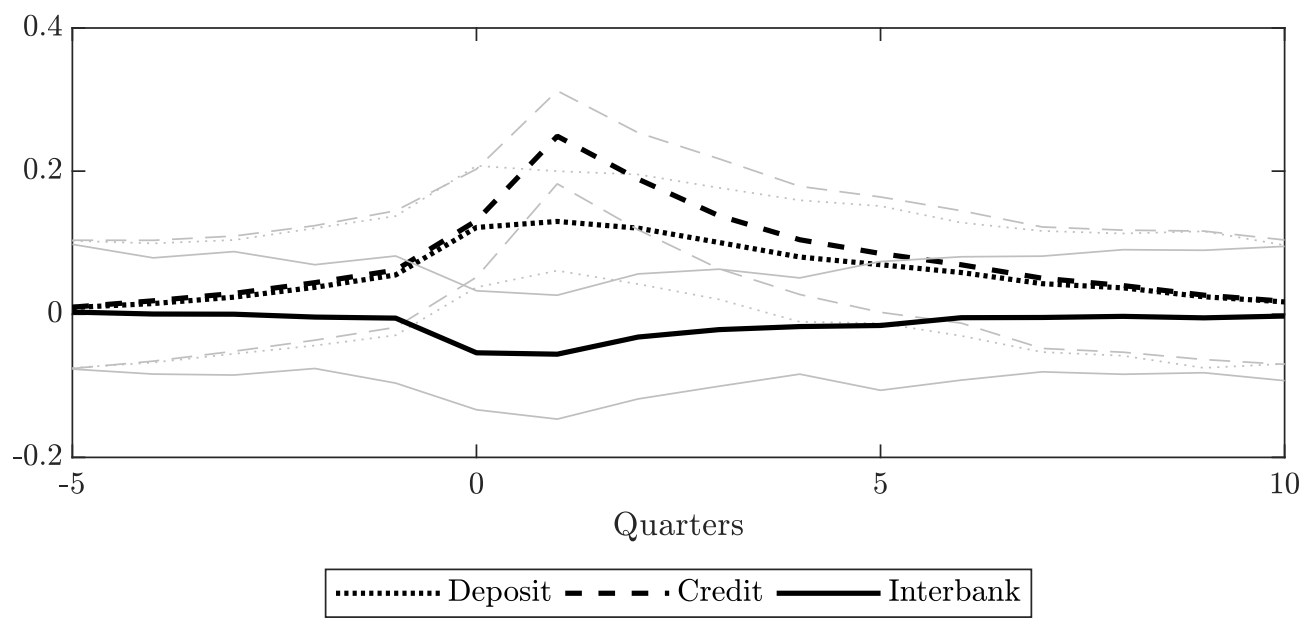

Figure 2.15: Cross-Correlation of Production and Centrality (Decentralized)

Note: cross-correlation between aggregate production and the centrality of deposit, credit and interbank markets. Average (black lines) and 90\% confidence intervals (gray lines) of 200 simulations.

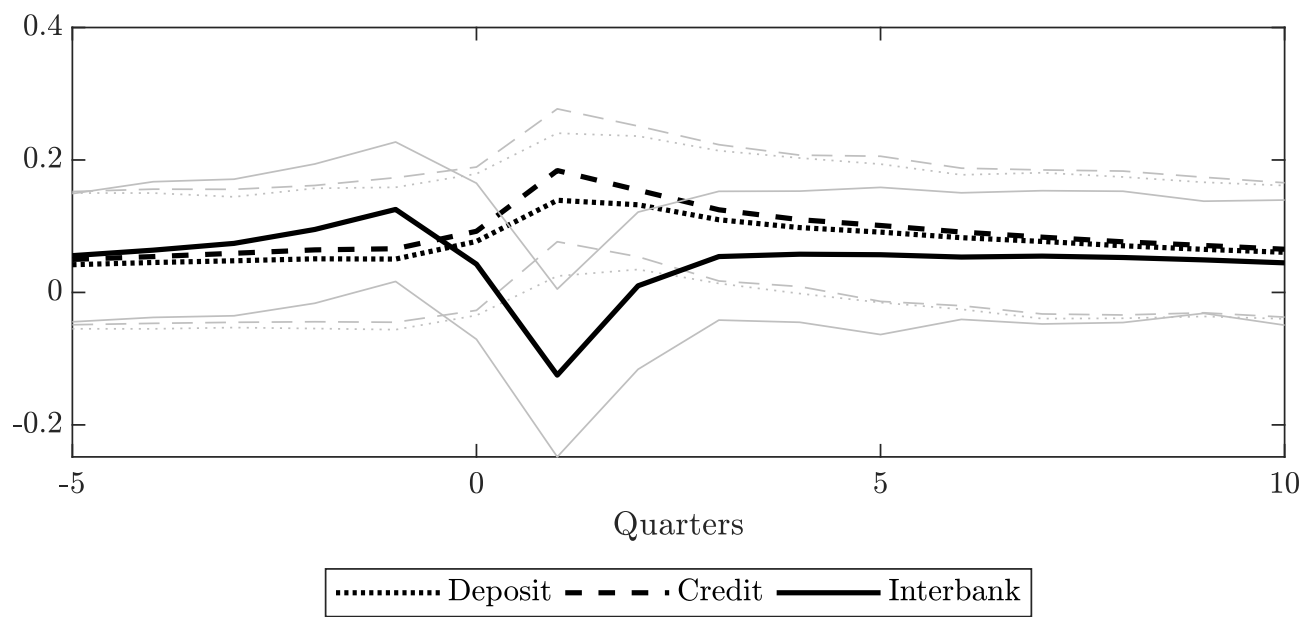

Figure 2.16: Cross-Correlation of Production and Centrality (Intermediate)

Note: cross-correlation between aggregate production and the centrality of deposit, credit and interbank markets. Average (black lines) and 90\% confidence intervals (gray lines) of 200 simulations. 

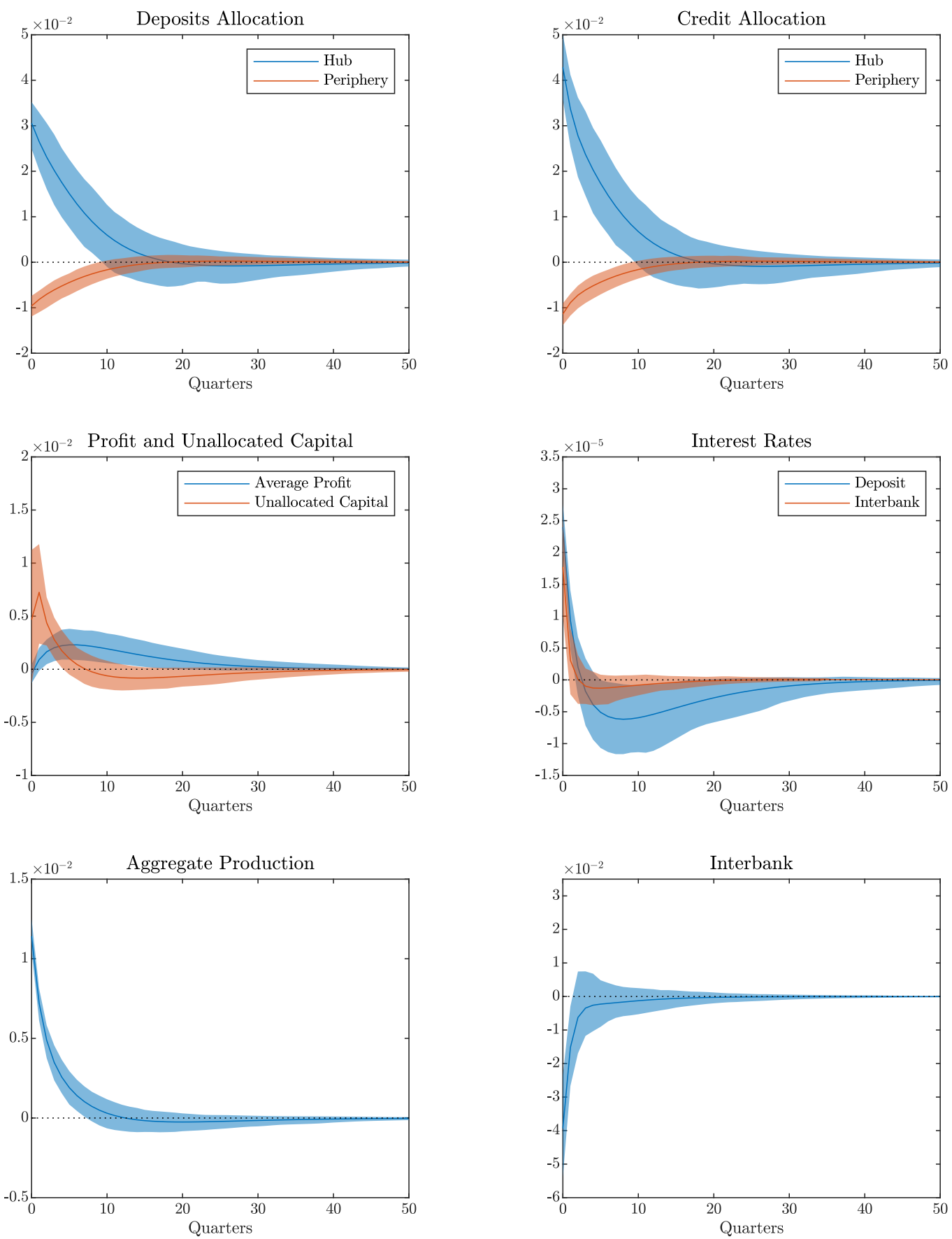

Figure 2.17: Positive Shock in Aggregate Production (Centralized)

Note: impulse-response function of a positive shock in aggregate production. Average (solid lines) and $90 \%$ confidence intervals (shaded areas) of 200 simulations. 

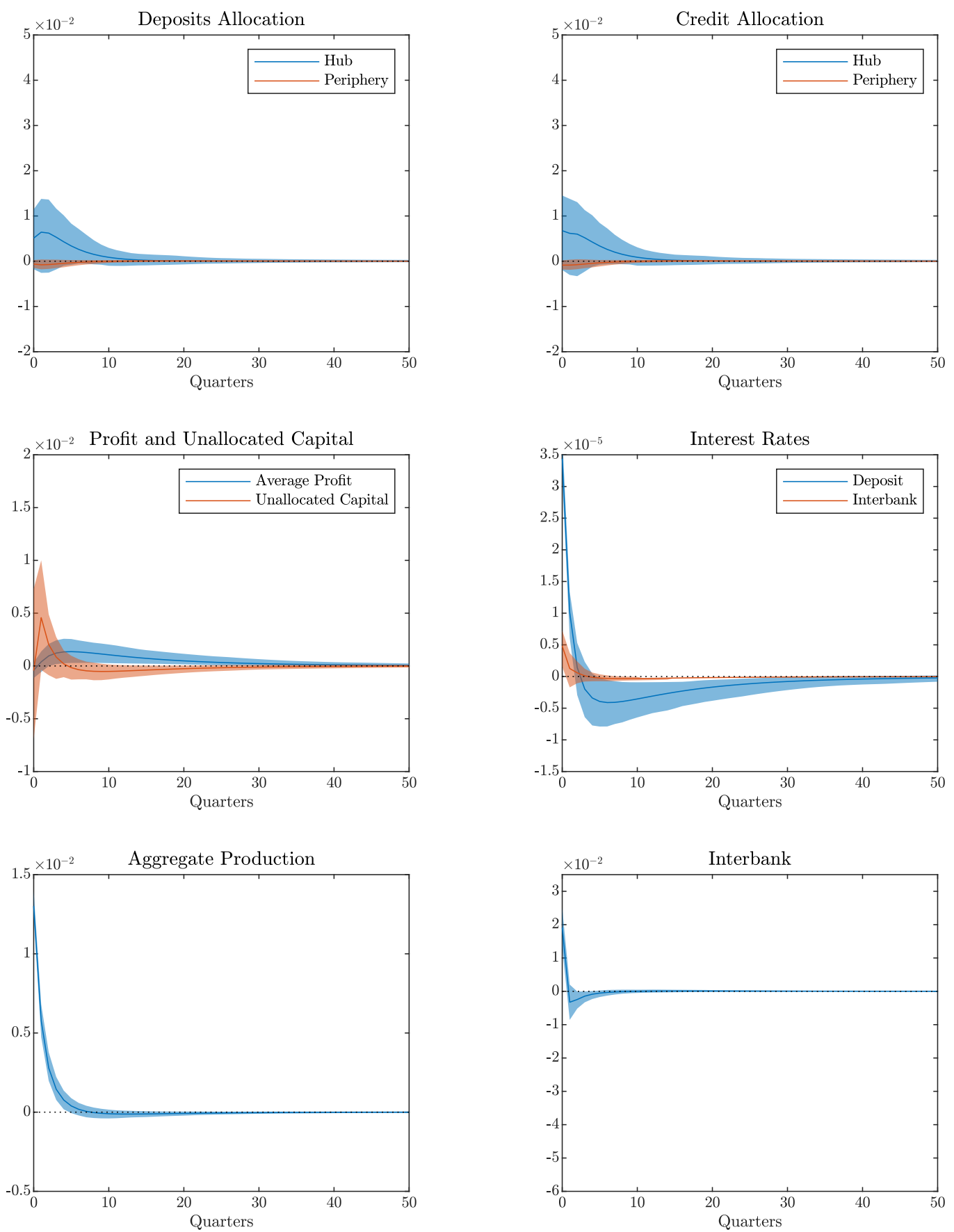

Figure 2.18: Positive Shock in Aggregate Production (Decentralized)

Note: impulse-response function of a positive shock in aggregate production. Average (solid lines) and $90 \%$ confidence intervals (shaded areas) of 200 simulations. 

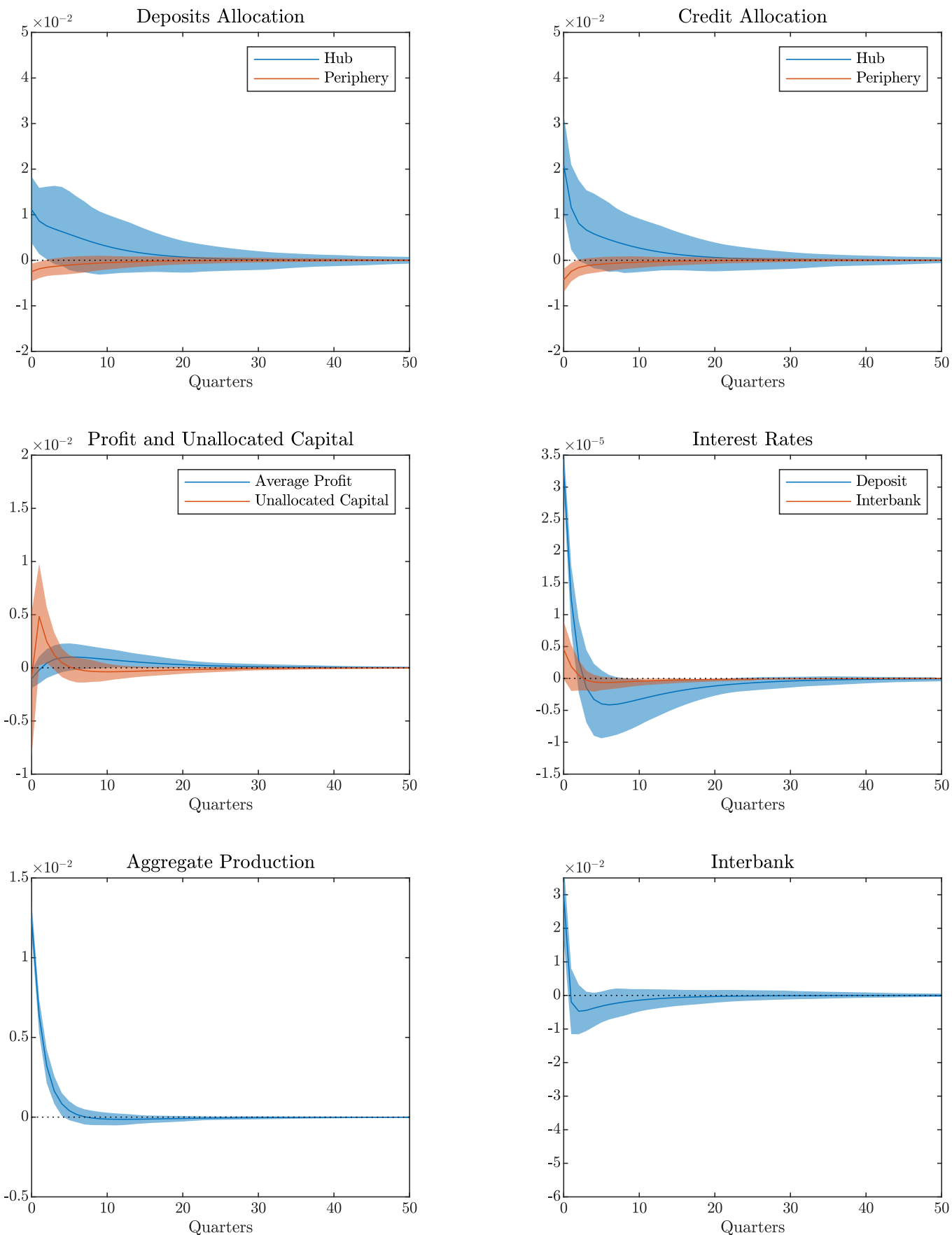

Figure 2.19: Positive Shock in Aggregate Production (Intermediate)

Note: impulse-response function of a positive shock in aggregate production. Average (solid lines) and 90\% confidence intervals (shaded areas) of 200 simulations. 

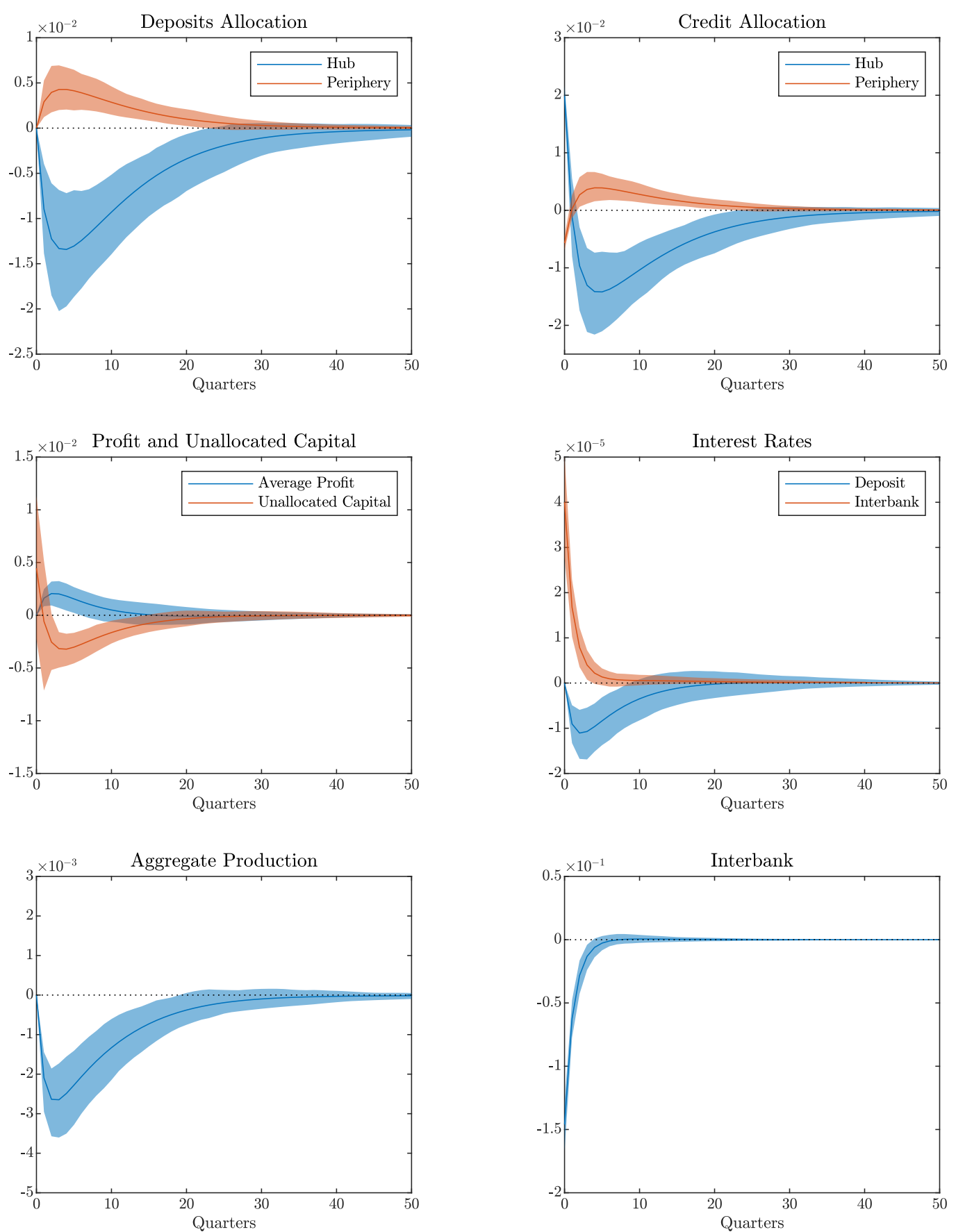

Figure 2.20: Reduction in the Interbank Market Volume (Centralized)

Note: impulse-response function of a negative shock in the interbank market volume. Average (solid lines) and 90\% confidence intervals (shaded areas) of 200 simulations. 

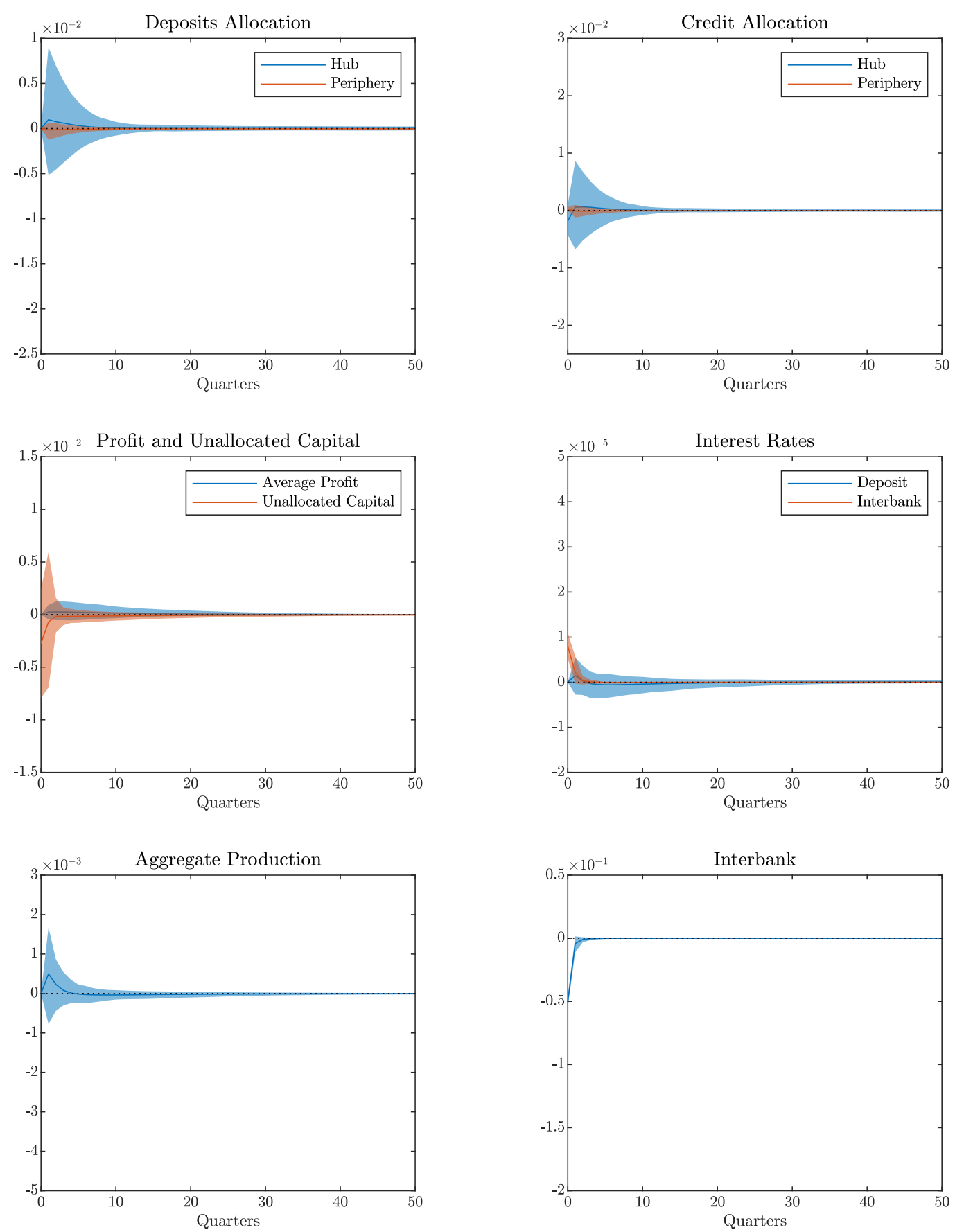

Figure 2.21: Reduction in the Interbank Market Volume (Decentralized)

Note: impulse-response function of a negative shock in the interbank market volume. Average (solid lines) and 90\% confidence intervals (shaded areas) of 200 simulations. 

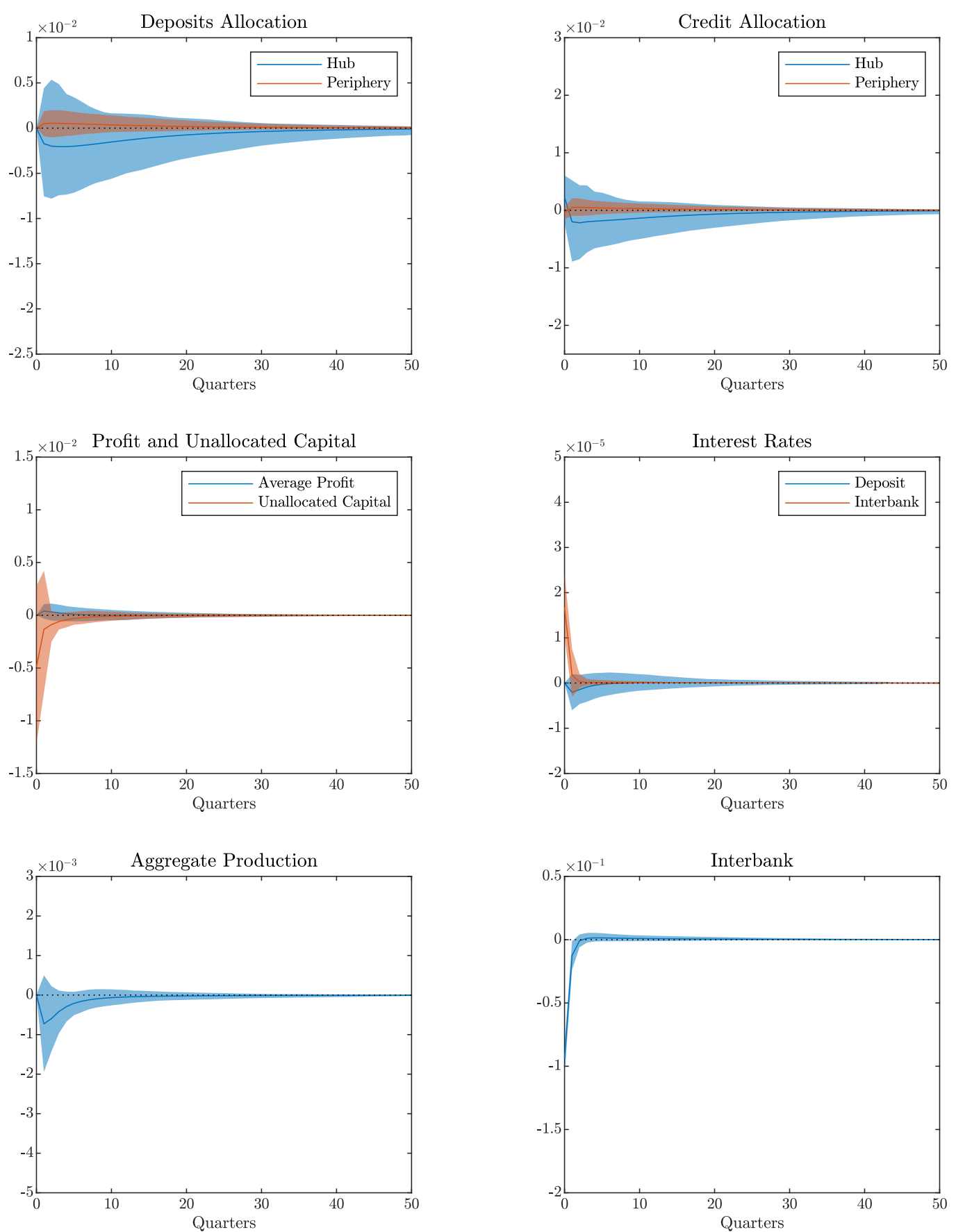

Figure 2.22: Reduction in the Interbank Market Volume (Intermediate)

Note: impulse-response function of a negative shock in the interbank market volume. Average (solid lines) and 90\% confidence intervals (shaded areas) of 200 simulations. 


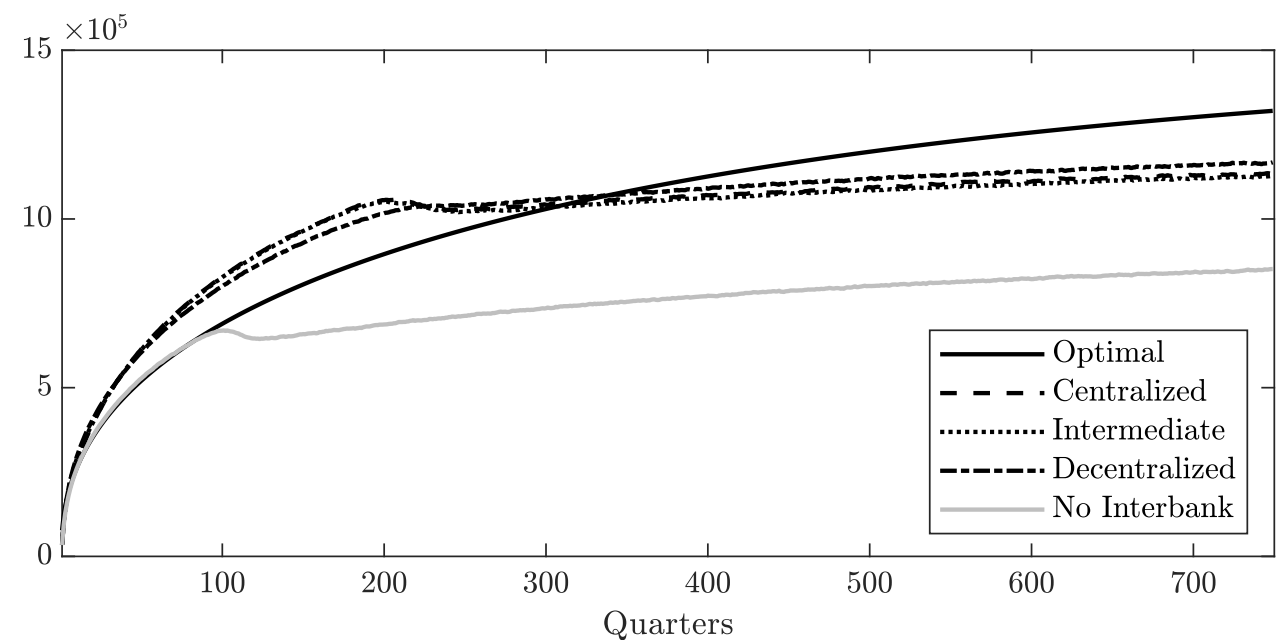

Figure 2.23: Long-Run Dynamic: Aggregate Production Average value of 200 simulations.

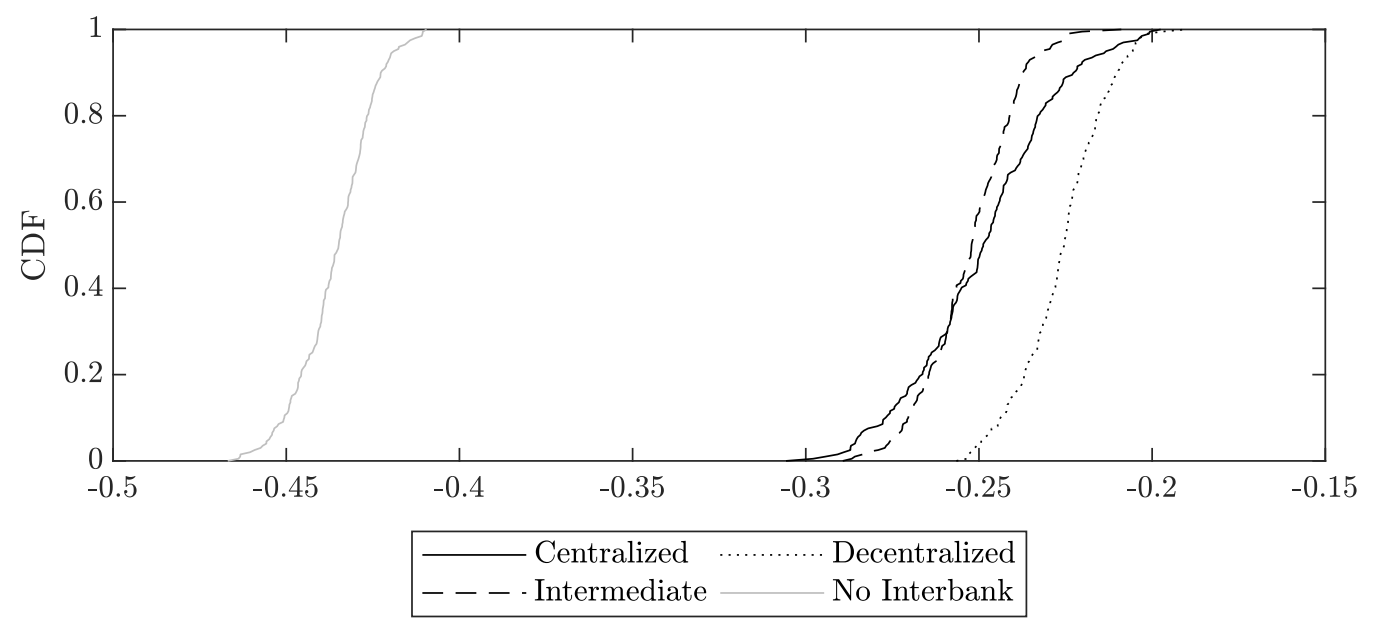

Figure 2.24: Percentage Deviations from Optimal Steady-State:

Aggregate Production

(Cumulative Distribution Function of Final Observations) 
Table 2.1: Standard Deviations

\begin{tabular}{|c|c|c|c|c|}
\hline & US Data & Centralized & Intermediate & Decentralized \\
\hline \multirow{2}{*}{$\sigma_{\hat{y}}$} & \multirow{2}{*}{0.0239} & 0.0227 & 0.0212 & 0.0214 \\
\hline & & $(0.0201-0.0256)$ & $(0.0189-0.0239)$ & $(0.0195-0.0235)$ \\
\hline \multirow{2}{*}{$\sigma_{\hat{c}}$} & \multirow{2}{*}{0.0196} & 0.0198 & 0.0173 & 0.0173 \\
\hline & & $(0.0176-0.0218)$ & $(0.0151-0.0199)$ & $(0.0154-0.0192)$ \\
\hline \multirow{2}{*}{$\sigma_{\hat{c}} / \sigma_{\hat{y}}$} & \multirow{2}{*}{0.8197} & 0.8714 & 0.8153 & 0.8113 \\
\hline & & $(0.7952-0.9461)$ & $(0.7470-0.8791)$ & $(0.7560-0.8793)$ \\
\hline \multirow{2}{*}{$\sigma_{r}$} & \multirow{2}{*}{0.0249} & 0.0007 & 0.0006 & 0.0007 \\
\hline & & $(0.0005-0.0009)$ & $(0.0005-0.0008)$ & $(0.0006-0.0009)$ \\
\hline
\end{tabular}

Note: average standard deviations of 200 simulations for different network topologies ( $95 \%$ confidence intervals in brackets).

Table 2.2: Correlation Matrix: US Data

\begin{tabular}{c|ccc} 
& $\hat{y}_{t}$ & $\hat{c}_{t}$ & $r_{t}$ \\
\hline$\hat{y}_{t}$ & 1 & 0.877 & 0.017 \\
$\hat{c}_{t}$ & 0.877 & 1 & 0.126 \\
$r_{t}$ & 0.017 & 0.126 & 1
\end{tabular}

Table 2.3: Autocorrelation Matrix: US Data

\begin{tabular}{c|ccc} 
& $\hat{y}_{t-1}$ & $\hat{c}_{t-1}$ & $r_{t-1}$ \\
\hline$\hat{y}_{t}$ & 0.856 & 0.834 & 0.067 \\
$\hat{c}_{t}$ & 0.742 & 0.880 & 0.172 \\
$r_{t}$ & 0.002 & 0.097 & 0.956
\end{tabular}

Note: correlation and autocorrelation of United States annual real interest rates (GS1 less CPI annual growth rate), real aggregate consumption (PCECC96) and production (GDPC1) growth rates. Data on quarterly frequency from 1953-Q1 to 2018-Q2. Data retrieved from FRED, Federal Reserve Bank of St. Louis. 
Table 2.4: Correlation Matrix: Centralized Simulation

\begin{tabular}{c|ccc} 
& $\hat{y}_{t}$ & $\hat{c}_{t}$ & $r_{t}$ \\
\hline \multirow{2}{*}{$\hat{y}_{t}$} & 1 & 0.824 & 0.162 \\
$\hat{c}_{t}$ & 0.824 & $(0.753-0.883)$ & $(0.081-0.237)$ \\
& $(0.753-0.883)$ & 1 & 0.156 \\
$r_{t}$ & 0.162 & 0.156 & $(0.066-0.241)$ \\
& $(0.081-0.237)$ & $(0.066-0.241)$ & 1
\end{tabular}

Note: average correlation of 200 simulations (95\% confidence intervals in brackets).

Table 2.5: Correlation Matrix: Intermediate Simulation

\begin{tabular}{c|ccc} 
& $\hat{y}_{t}$ & $\hat{c}_{t}$ & $r_{t}$ \\
\hline \multirow{2}{*}{$\hat{y}_{t}$} & 1 & 0.811 & 0.113 \\
\multirow{2}{*}{$\hat{c}_{t}$} & 0.811 & $(0.745-0.869)$ & $(0.063-0.165)$ \\
& $(0.745-0.869)$ & 1 & 0.101 \\
$r_{t}$ & 0.113 & 0.101 & $(0.046-0.163)$ \\
& $(0.063-0.165)$ & $(0.046-0.163)$ & 1
\end{tabular}

Note: average correlation of 200 simulations ( $95 \%$ confidence intervals in brackets).

Table 2.6: Correlation Matrix: Decentralized Simulation

\begin{tabular}{|c|c|c|c|}
\hline & $\hat{y}_{t}$ & $\hat{c}_{t}$ & $r_{t}$ \\
\hline \multirow[b]{2}{*}{$\hat{y}_{t}$} & \multirow[b]{2}{*}{1} & 0.846 & 0.089 \\
\hline & & $(0.800-0.882)$ & $(0.046-0.128)$ \\
\hline \multirow{2}{*}{$\hat{c}_{t}$} & 0.846 & \multirow{2}{*}{1} & 0.087 \\
\hline & & & $(0.033-0.145)$ \\
\hline \multirow{2}{*}{$r_{t}$} & 0.089 & 0.087 & \multirow{2}{*}{1} \\
\hline & $(0.046-0.128)$ & $(0.033-0.145)$ & \\
\hline
\end{tabular}

Note: average correlation of 200 simulations (95\% confidence intervals in brackets). 
Table 2.7: Autocorrelation Matrix: Centralized Simulation

\begin{tabular}{c|ccc} 
& $\hat{y}_{t-1}$ & $\hat{c}_{t-1}$ & $r_{t-1}$ \\
\hline$\hat{y}_{t}$ & 0.639 & 0.424 & 0.080 \\
& $(0.566-0.702)$ & $(0.312-0.506)$ & $(-0.003-0.142)$ \\
$\hat{c}_{t}$ & 0.606 & 0.655 & 0.150 \\
& $(0.524-0.681)$ & $(0.585-0.712)$ & $(0.055-0.243)$ \\
$r_{t}$ & 0.200 & 0.132 & 0.990 \\
& $(0.113-0.288)$ & $(0.052-0.216)$ & $(0.984-0.995)$
\end{tabular}

Note: average autocorrelation of 200 simulations (95\% confidence intervals in brackets).

Table 2.8: Autocorrelation Matrix: Intermediate Simulation

\begin{tabular}{c|ccc} 
& $\hat{y}_{t-1}$ & $\hat{c}_{t-1}$ & $r_{t-1}$ \\
\hline$\hat{y}_{t}$ & 0.503 & 0.320 & 0.017 \\
& $(0.415-0.585)$ & $(0.204-0.429)$ & $(-0.028-0.072)$ \\
$\hat{c}_{t}$ & 0.471 & 0.557 & 0.085 \\
& $(0.349-0.560)$ & $(0.468-0.632)$ & $(0.024-0.154)$ \\
$r_{t}$ & 0.151 & 0.078 & 0.990 \\
& $(0.101-0.219)$ & $(0.022-0.146)$ & $(0.982-0.994)$
\end{tabular}

Note: average autocorrelation of 200 simulations (95\% confidence intervals in brackets).

Table 2.9: Autocorrelation Matrix: Decentralized Simulation

\begin{tabular}{c|ccc} 
& $\hat{y}_{t-1}$ & $\hat{c}_{t-1}$ & $r_{t-1}$ \\
\hline \multirow{2}{*}{$\hat{y}_{t}$} & 0.444 & 0.336 & 0.011 \\
& $(0.358-0.530)$ & $(0.249-0.430)$ & $(-0.035-0.053)$ \\
$\hat{c}_{t}$ & 0.445 & 0.548 & 0.063 \\
& $(0.356-0.546)$ & $(0.473-0.621)$ & $(0.009-0.124)$ \\
$r_{t}$ & 0.113 & 0.073 & 0.994 \\
& $(0.069-0.161)$ & $(0.015-0.129)$ & $(0.990-0.996)$
\end{tabular}

Note: average autocorrelation of 200 simulations (95\% confidence intervals in brackets). 
Table 2.10: Deepness and Steepness of Aggregate Production

\begin{tabular}{ccccc}
\hline & US Data & Centralized & Intermediate & Decentralized \\
\hline \multirow{2}{*}{ Deepness } & -0.39 & $\begin{array}{c}-0.11 \\
(-0.40-0.19)\end{array}$ & $\begin{array}{c}-0.09 \\
-0.43-0.16)\end{array}$ & $(-0.39-0.14)$ \\
\hline \multirow{2}{*}{ Steepness } & -0.46 & -0.09 & -0.01 & -0.01 \\
& & $(-0.38-0.25)$ & $(-0.32-0.28)$ & $(-0.29-0.22)$ \\
\hline
\end{tabular}

Note: average coefficient of skewness of detrended time series (deepness) and growth rates (steepness). Average of 200 simulations (95\% confidence intervals in brackets).

Table 2.11: Power Law and Aggregate Production

Model: OLS $(T=15000)$

Dependent variable: Power Law Scale Parameter (95th Percentile)

HAC standard errors, bandwidth 18 (Bartlett kernel)

Centralized

\begin{tabular}{ccccc}
\hline & Coefficient & Std. Error & t-ratio & p-value \\
\hline Intercept & 0.9118 & 0.1392 & 6.546 & $<0.0001$ \\
Production & $6.1740 \mathrm{e}-05$ & $4.8906 \mathrm{e}-06$ & 12.62 & $<0.0001$ \\
\hline \multicolumn{5}{c}{ Intermediate } \\
\hline Intercept & 0.2371 & 0.2688 & 0.8822 & 0.3777 \\
Production & $9.0495 \mathrm{e}-05$ & $9.3877 \mathrm{e}-06$ & 9.640 & $<0.0001$ \\
\hline
\end{tabular}

Decentralized

\begin{tabular}{ccccc}
\hline & Coefficient & Std. Error & t-ratio & p-value \\
\hline Intercept & 0.6461 & 0.1773 & 3.645 & 0.0003 \\
Production & $7.9350 \mathrm{e}-05$ & $6.4643 \mathrm{e}-06$ & 12.28 & $<0.0001$ \\
\hline
\end{tabular}




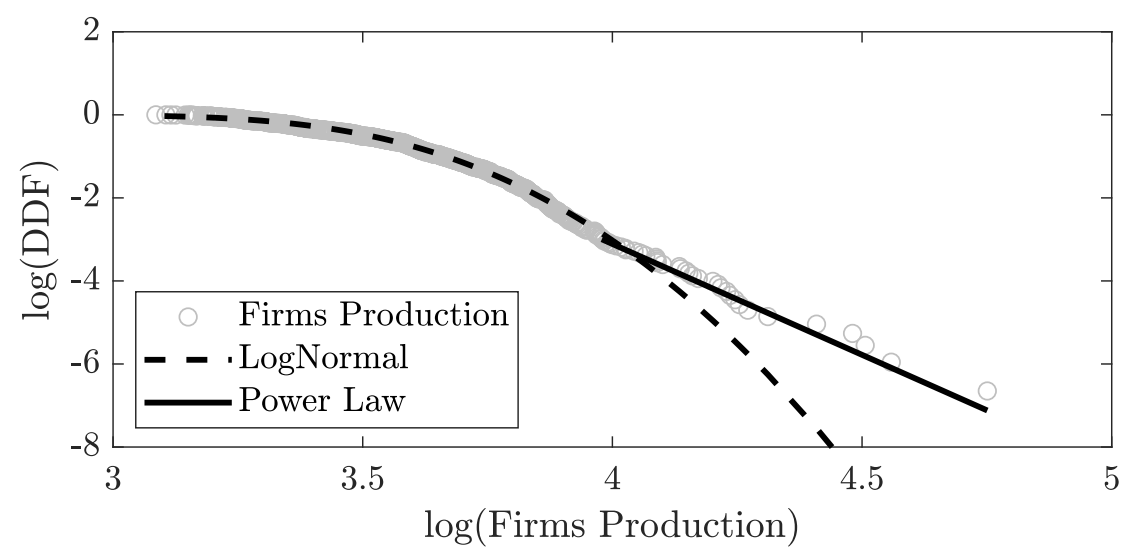

Figure 2.25: Distribution of Firms Production (Centralized)

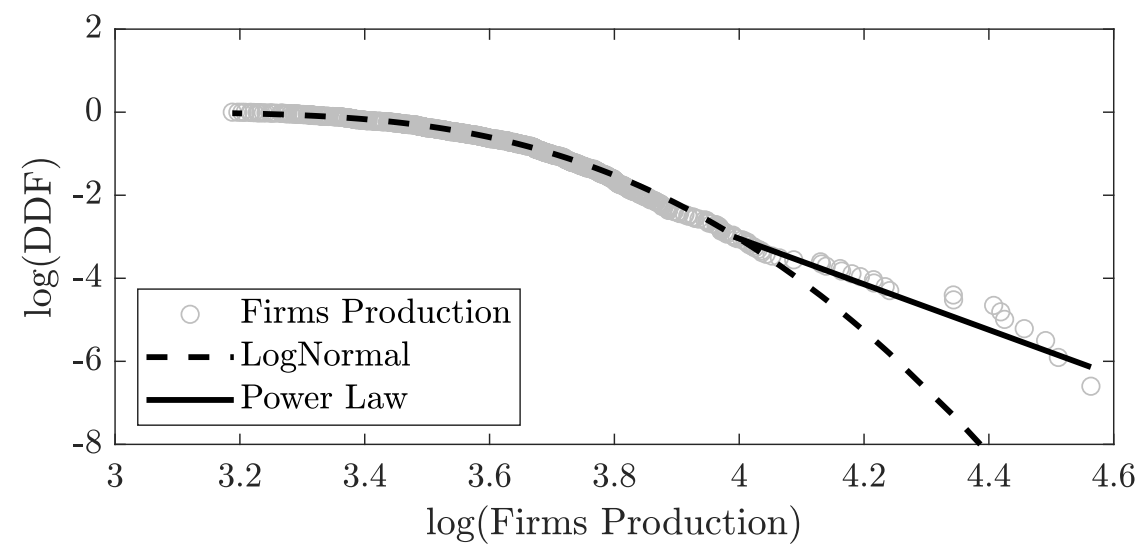

Figure 2.26: Distribution of Firms Production (Intermediate)

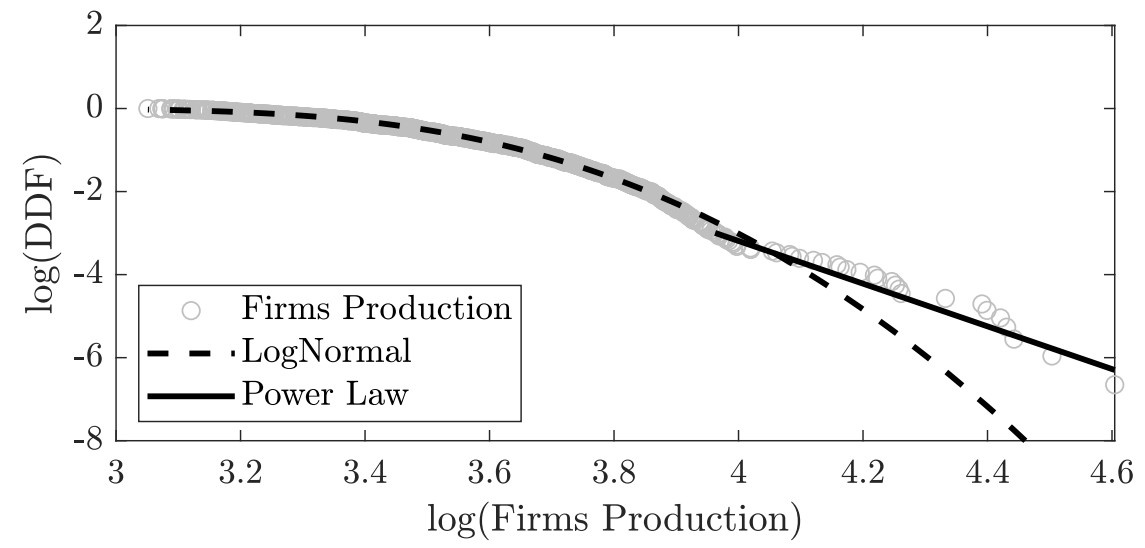

Figure 2.27: Distribution of Firms Production (Decentralized) 


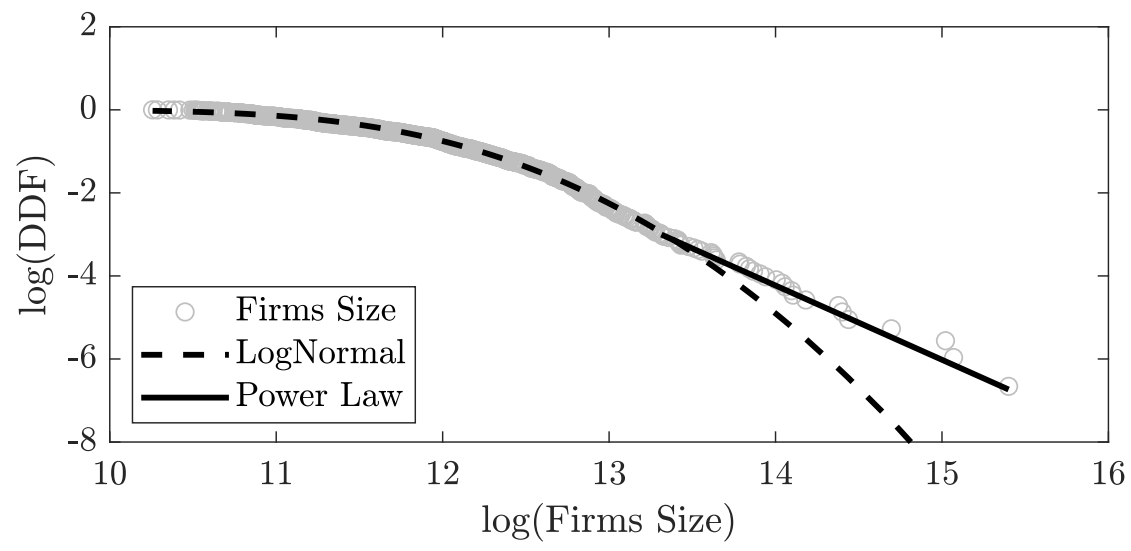

Figure 2.28: Distribution of Firms Capital (Centralized)

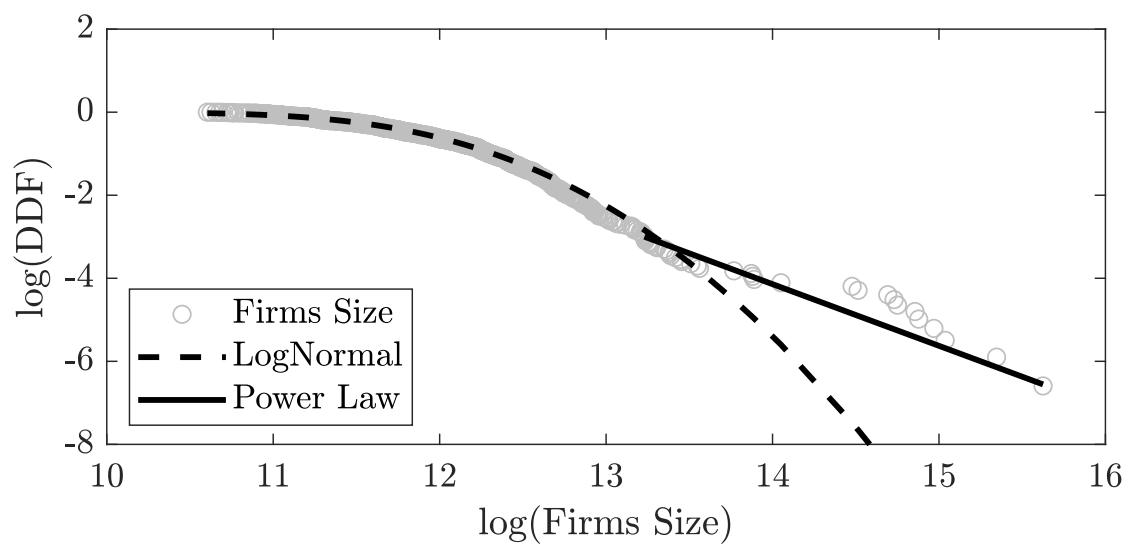

Figure 2.29: Distribution of Firms Capital (Intermediate)

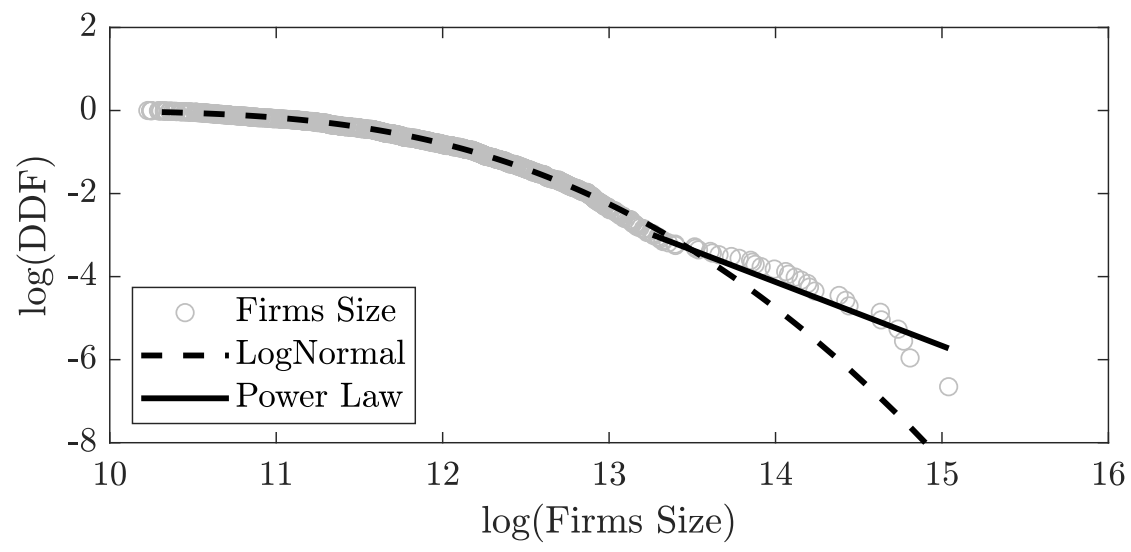

Figure 2.30: Distribution of Firms Capital (Decentralized) 


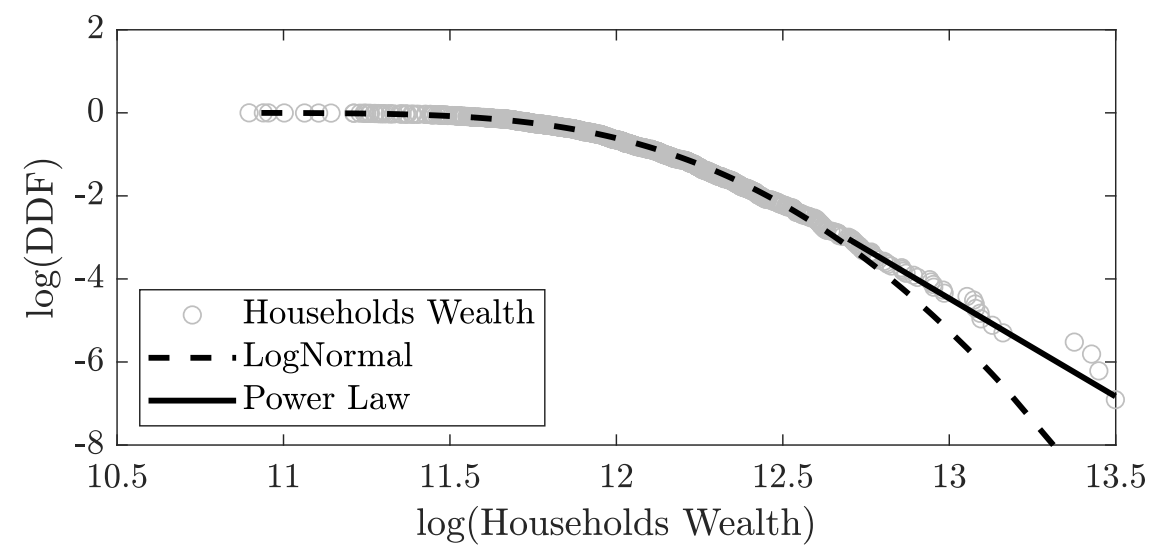

Figure 2.31: Distribution of Households Wealth (Centralized)

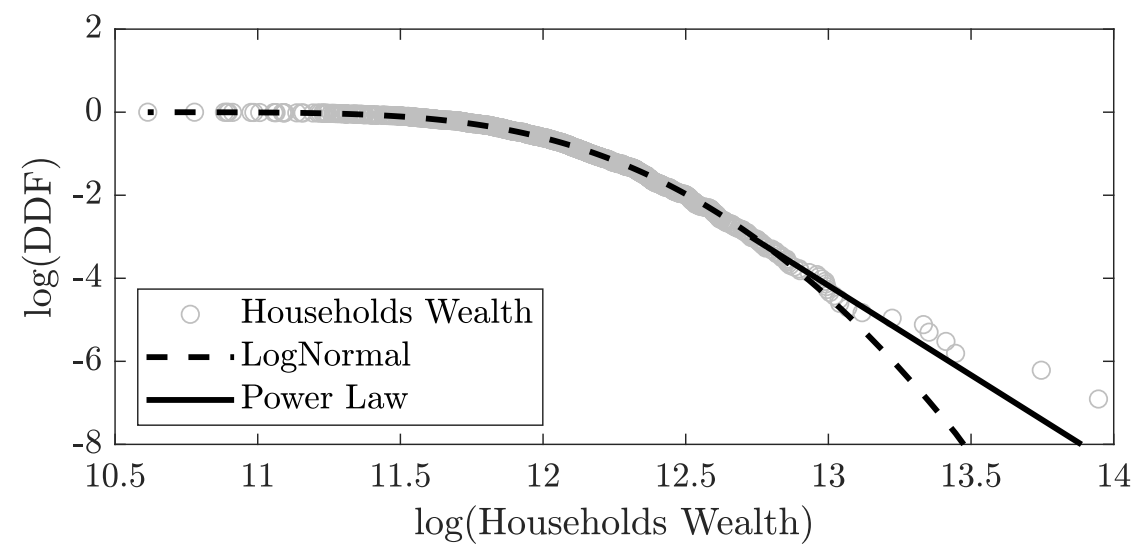

Figure 2.32: Distribution of Households Wealth (Intermediate)

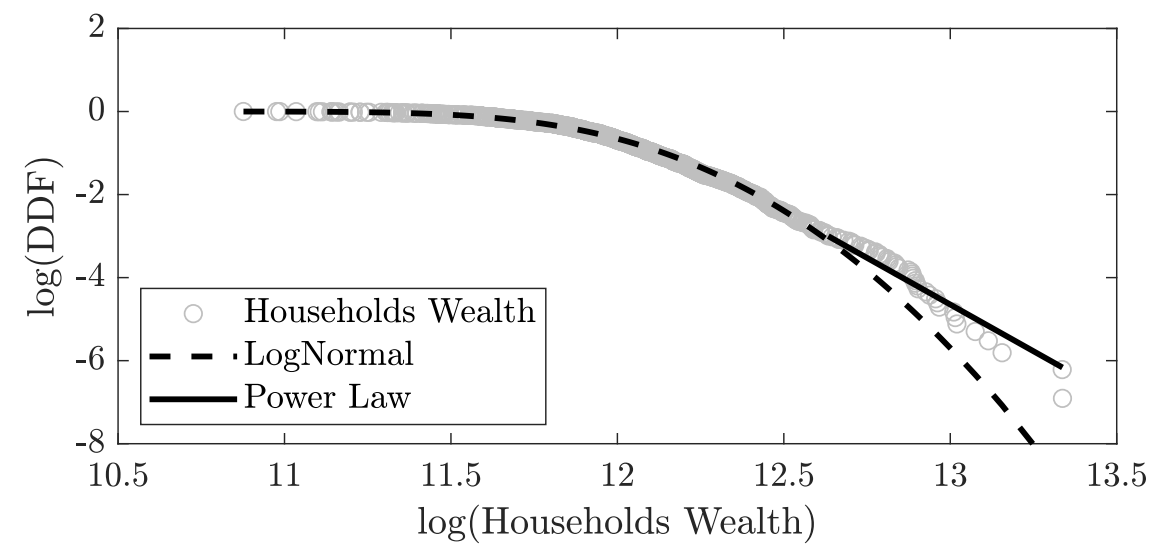

Figure 2.33: Distribution of Households Wealth (Decentralized) 


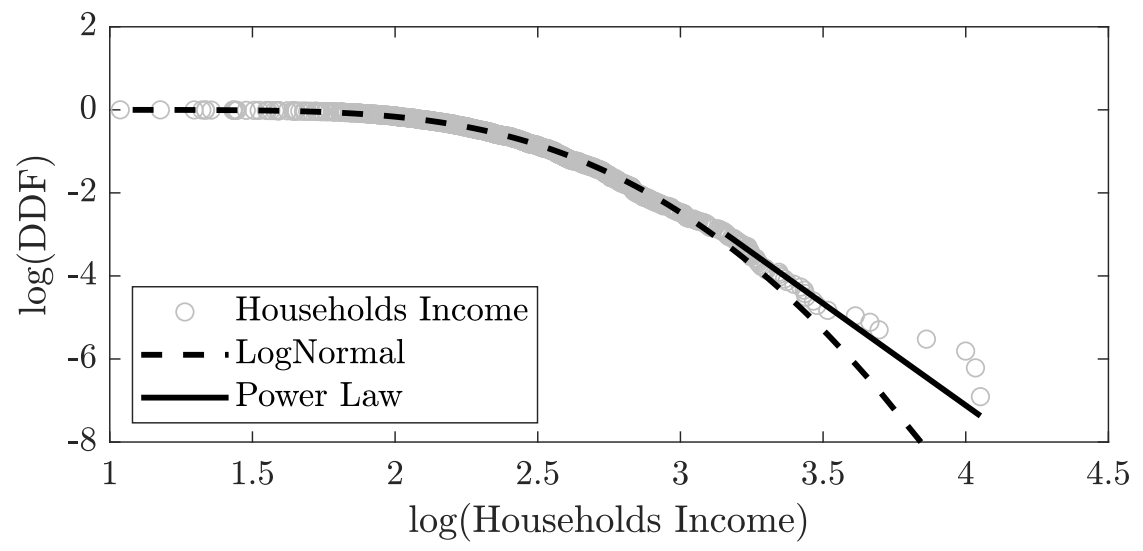

Figure 2.34: Distribution of Households Income (Centralized)

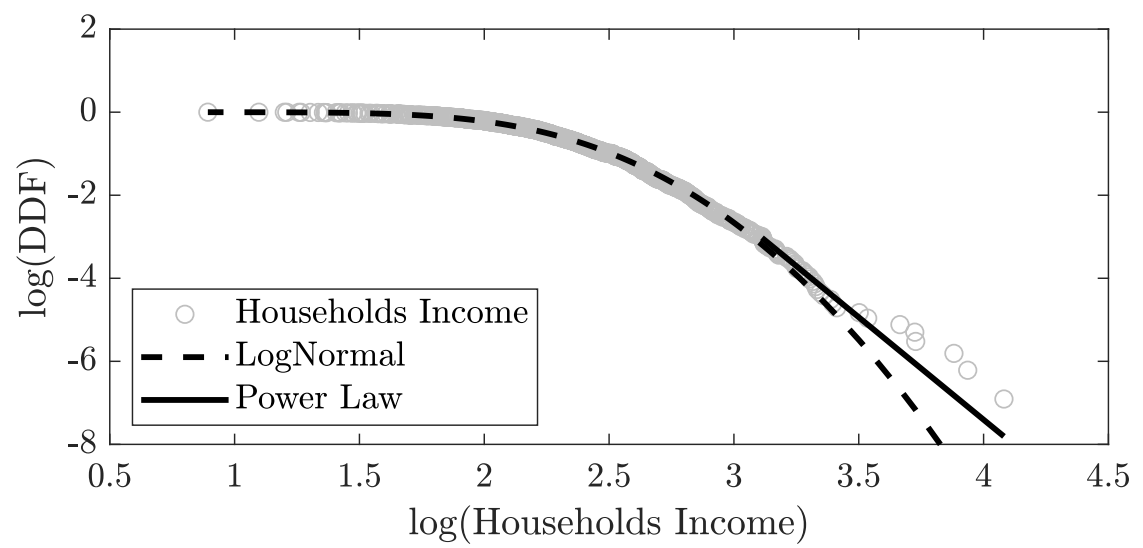

Figure 2.35: Distribution of Households Income (Intermediate)

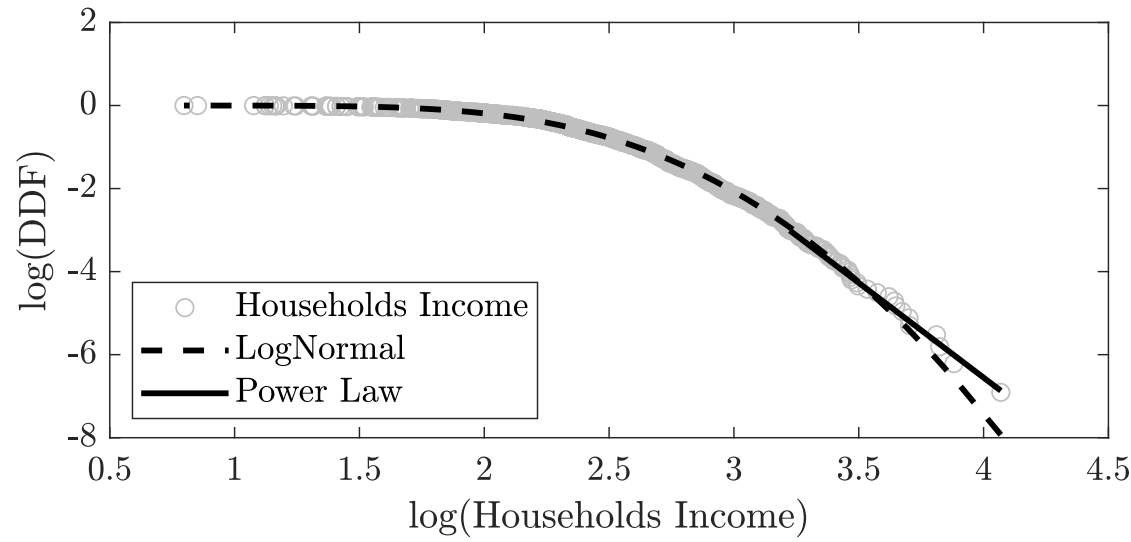

Figure 2.36: Distribution of Households Income (Decentralized) 

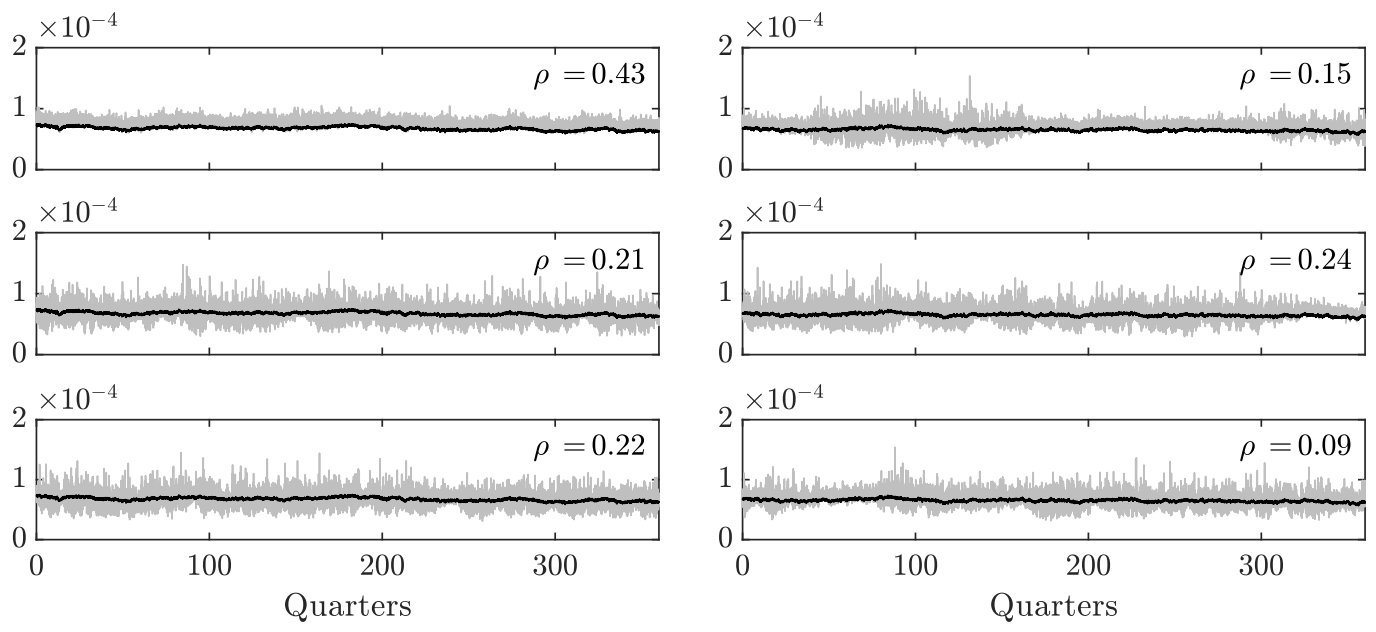

Figure 2.37: Volatility Clustering (Centralized)

Figure 2.38: Volatility Clustering (Intermediate)

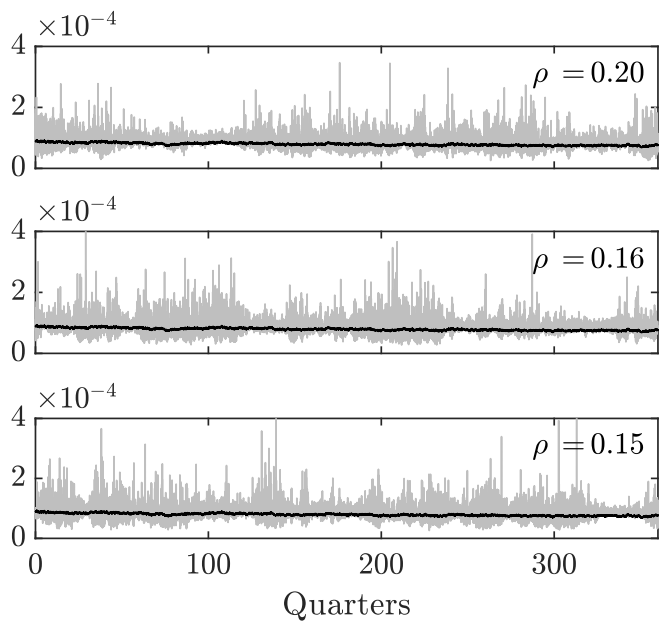

Figure 2.39: Volatility Clustering (Decentralized)

Note: interest rates of the three largest intermediaries (gray line) and aggregate returns (black line). Boxes indicate the correlation coefficient between the two variables. 


\section{Chapter 3}

\subsection{Introduction}

Since the seminal work of Arrow and Debreu (1954), all innovations in the financial sector have been welcomed as a positive determinant of economic development and risk management. In fact, from a theoretical point of view, it is possible to achieve the first-best equilibrium in which all states of the world are perfectly edged and correctly priced through an efficient allocation of funds. For this reason, every development of financial markets, moving the system closer to a complete market condition, was acclaimed as positive news. As a result, this sector has played an increasing importance in real economies during the last three decades.

This process, called financialization, captured the interest of researchers in recent time (Palley, 2013). Before the Great Recession in 2009, financial institutions were relegated to the role of simple shock amplifiers (Bernanke and Gertler, 1989: Greenwald and Stiglitz, 1993; Kiyotaki and Moore, 1997) or indisputable growth enhancers (Levine, 2005). However, both the size and the characteristics of the crisis capsized those results. New models of business fluctuations were developed, in which financial intermediaries do not simply react passively to shocks, but act strategically to improve their profits (Christiano and Ikeda, 2011) or preserve their liquidity (Brunnermeier et al. 2013). Furthermore, recent studies found a non-linear relation between aggregate growth and debt (Cecchetti and Kharroubi, 2012; Arcand et al. 2015) or a statistically insignificant or even negative impact of financialization on fixed investments (Davis, 2017). Similarly, also the role of financial institutions as macro stabilizers has been questioned (Dabla-Norris and Srivisal, 2013). In particular, the greater interconnection between intermediaries, while reducing the idiosyncratic risk, has been associated with increased systemic risk (Battiston et al., 2012b; Lenzu and Tedeschi, 2012; Grilli et al., 2015, Berardi and Tedeschi, 2017). Overall, research found a dangerous association between financialization and the reduction of aggregate growth, the increase in income inequality and the overall financial fragility of Western 
economies (Palley, 2013).

In this article, we develop a simple model to study the effects of financialization on aggregate growth and systemic risk. While close in the spirit to the work of Cecchetti and Kharroubi (2015), the theoretical framework introduced here focus on the role of financial institutions as physical capital attractors instead of employers of skilled workers. The main driver of the underlying mechanism is the bargaining power of the intermediaries. Indeed, financial institutions, by absorbing a larger quota of income from entrepreneurs, can reduce the incentive for new firms to enter the market. Because of that, both the long-term growth rate and the overall stability of the system can be negatively affected by an overdeveloped financial sector.

In Section 3.2 we present the theoretical results of a simple endogenous growth model with expanding variety. The main departure from the existing literature is due to the presence of a financial intermediary with a given level of bargaining power. As a consequence, a non-linear relation emerges between the aggregate growth rate and the leverage of the system. Subsequently, in Section 3.3 we focus on systemic risk. In particular, financial institutions, by capturing a larger quota of expected production, do not only reduce the number of entrepreneurs but modify also the quality of their portfolio of credits. Overall, these results are in line with the observed reduction in the growth rates and the increased financial fragility of Western economies. Finally, Section 3.4 concludes and states some directions for future research.

\subsection{Bargaining Power and Growth}

The bargaining power of the financial sector can influence the growth rate of the economy. Indeed, different redistribution of incomes between the owners and the creditors of firms can produce dissimilar equilibria when entrepreneurship and credit are complements. This is due to the power of financial intermediaries to modify the incentive for new entrepreneurs to enter the market.

The model is a stylized version of the vast economic literature on expanding variety and endogenous growth (Romer, 1990; Grossman and Helpman, 1991). Indeed, the idea is not to demonstrate how the entry mechanism of new firms or machinery in the market modifies the long-term growth potential, but how the financial sector can affect this process of new products creation. In a similar manner, also the literature on R\&D and Schumpeterian evolution can be included in this context (Aghion and Howitt, 1992). Indeed, the main driver of our model is the ability of the financial sector to affect both the aggregate interest rate and the profitability of firms and 
investments. Therefore, intermediaries, by modifying the current value of projects, can reduce or increase the incentive for new entrepreneurs to enter the market. In that sense, this framework can be extended to every model which includes a comparison between the current value of an investment and its cost.

Consider a closed economy populated by a representative household, a financial institution and a potentially infinite number of firms. The family is the owner of capital, which is for simplicity the only factor of production. The household can invest its resources in the financial institution $\left(D_{t+1}\right)$ or can sustain a fixed cost $(F)$ to start a new entrepreneurial activity. There are no limits on the number of new firms, hence the overall cost of starting a new set of market activities is given by the product:

$$
F \Delta N_{t}=F\left(N_{t+1}-N_{t}\right)
$$

where $N_{t}$ is the number of enterprises at time $t$. Accordingly, the aggregate investment in the privately owned firms $\left(E_{t+1}\right)$ is equal to the fixed cost $F$ multiplied by the total number of market activities $N_{t+1}$ :

$$
E_{t+1}=F N_{t+1}
$$

Assume for simplicity that there are no risk or uncertainty and that all firms are equal. Therefore, the representative household maximizes the intertemporal problem:

$$
\max _{\left\{C_{t}, D_{t+1}, N_{t+1}\right\}_{t=0}^{\infty}} \sum_{t=0}^{\infty} \beta^{t} \log \left(C_{t}\right)
$$

under the budget constraint:

$$
D_{t+1}+C_{t}+F\left(N_{t+1}-N_{t}\right) \leq\left(1+r_{t}\right) D_{t}+\pi_{t} N_{t}
$$

where $C_{t}$ is consumption, $r_{t}$ the return on the investment $D_{t}$ and $\pi_{t}$ is the individual profit of firms. The solution to the above problem is given by the conditions:

$$
\begin{gathered}
r_{t+1}=\frac{\pi_{t+1}}{F} \\
C_{t}=(1-\beta)\left[\left(1+r_{t}\right) D_{t}+\left(\pi_{t}+F\right) N_{t}\right] \\
D_{t+1}+F N_{t+1}=\beta\left[\left(1+r_{t}\right) D_{t}+\left(\pi_{t}+F\right) N_{t}\right]
\end{gathered}
$$

Notice that equation (3.5) is a no-arbitrage condition. Indeed, in steadystate or along a balanced growth path the cost of investing in a new firm 
must be equal to its discounted value:

$$
F=\frac{\pi}{r}=\sum_{t=0}^{\infty} \frac{\pi}{(1+r)^{t}}
$$

With regards to production, the only input is capital $\left(k_{t+1}\right)$, which is provided by the financial sector. In fact, enterprises have no resources of their own to start production, but they can borrow them at the economywide interest rate $r_{t+1}$ because of the total absence of risk ${ }^{23}$. Finally, the production technology follows a common functional form with decreasing marginal returns:

$$
y_{t+1}=\left(k_{t+1}\right)^{\alpha} \quad \text { with } \quad 0<\alpha<1
$$

In contrast with the solution of perfect competition, firms do not simply maximize profits:

$$
\pi_{t+1}=\left(k_{t+1}\right)^{\alpha}-r_{t+1} k_{t+1}
$$

by taking the interest rate as given, but instead interact with the financial institution to deal the conditions of the loan. Specifically, the intermediary has a given level of contractual power $(\theta \in[0,1])$ and every period the two counterparts solve the Nash bargaining problem:

$$
\max _{\left\{r_{t+1}, k_{t+1}\right\}}\left(r_{t+1} N_{t+1} k_{t+1}\right)^{\theta}\left(N_{t+1}\left(k_{t+1}\right)^{\alpha}-r_{t+1} N_{t+1} k_{t+1}\right)^{1-\theta}
$$

under the budget constraint:

$$
N_{t+1} k_{t+1} \leq D_{t+1}
$$

In other words, as in the literature on wage determination in the labor market (see for example Pissarides (2000)), the bargaining power $\theta$ captures the ability of the financial institution to extract resources from its borrowers. Therefore, the solution to this distributive problem is:

$$
\begin{gathered}
k_{t+1}=\frac{D_{t+1}}{N_{t+1}} \\
r_{t+1}=\theta\left(k_{t+1}\right)^{\alpha-1}=\theta\left(\frac{D_{t+1}}{N_{t+1}}\right)^{\alpha-1} \\
\pi_{t+1}=(1-\theta)\left(k_{t+1}\right)^{\alpha}=(1-\theta)\left(\frac{D_{t+1}}{N_{t+1}}\right)^{\alpha}
\end{gathered}
$$

\footnotetext{
${ }^{23}$ Moreover, firms do not need equity to cover the risk of default.
} 
By inserting equations (3.14) and (3.15) in the no-arbitrage condition (3.5) it is possible to find the optimal allocation of wealth, which is constant through time:

$$
\frac{\theta}{1-\theta}=\frac{D_{t+1}}{F N_{t+1}}=\frac{D_{t+1}}{E_{t+1}} \Longrightarrow \theta=\frac{D_{t+1}}{E_{t+1}+D_{t+1}}
$$

Consequently, the general equilibrium is characterized by a balanced growth path:

$$
\begin{gathered}
g=\beta(1+r)-1 \\
r=(\theta)^{\alpha}(1-\theta)^{1-\alpha}(F)^{\alpha-1}
\end{gathered}
$$

where $g$ is the long-term growth rate.

The bargaining power of the intermediary is fully reflected in the overall leverage of the system (Eq. 3.16). Indeed, a strong financial sector can absorb a large fraction of income from its borrowers and can pay a higher return to its investors. Consequently, households prefer to deposit their wealth in an intermediary rather than investing directly in an economic activity. Put differently, in a closed economy an expansion of the financial sector is the result of an increase in its bargaining power. In fact, different allocations of funds would not be incentive-compatible.

In line with this finding, the interest and the growth rates present a point of maximum:

$$
\begin{gathered}
\frac{d g}{d \theta}=0 \Longrightarrow \theta=\alpha \\
\frac{d^{2} g}{d \theta^{2}}=-\beta(1-\alpha) \alpha(1-\theta)^{-1-\alpha} \theta^{-2+\alpha}(F)^{\alpha-1}<0
\end{gathered}
$$

This non-linear relationship between leverage and growth rates emerges also from Figure 3.1. This is due to the strong complementarity between credit and entrepreneurship. On the one hand, a relatively weak and underdeveloped financial sector is not able to capture a sufficiently high fraction of income from the economy. Therefore, real interest rates are low, households do not have the incentive to save and new firms do not have access to capital and can not start production. Overall, the economy remains at a low or negative growth path. On the other hand, a strong financial sector reduces the incentive for new entrepreneurs to enter the market. Indeed, profits are too low and households prefer to invest their wealth in the financial market rather than starting a new entrepreneurial activity. Also in this case the economy remains at a low or negative growth path because of the decreasing marginal productivity of capital. To end with, as expected a reduction in the 
cost $F$ of starting a new enterprise has a positive effect on the growth rate of the system.

Summing up, the financial sector can have a strong impact on the longterm growth potential. In fact, intermediaries, by modifying the incentives for new entrepreneurs to enter the market or for incumbents to develop a new product or innovation, can either reduce or increase the overall process of economic development. In addition, it also emerges that this mechanism may be more pronounced for enterprises which are heavily dependent on external funding or are in sectors characterized by a high level of R\&D Cecchetti and Kharroubi, 2012, 2015).

\subsection{Bargaining Power and Risk}

In the previous section, we show that a non-linear relation between the leverage of the system and the growth rate can emerge when entrepreneurship and credit are complements. Accordingly, a similar pattern can be found also between systemic risk and the bargaining power of intermediaries. In fact, financial institutions can modify the incentive for new entrepreneurs to enter the market by absorbing a larger quota of firms' expected production. In this way, only less risk-averse investors start a risky activity, while the remaining part of the households prefer to deposit their resources in a financial institution at a risk-free rate.

Consider a closed economy in which a continuum of households/investors must choose between investing their endowment $(e)$ in a risky enterprise or in a risk-free deposit. In particular, agents evaluate the opportunity to start a new privately owned firm (entrepreneurs) or not (depositors). In addition, households can not build a portfolio containing the two assets or, in other words, they can not be both entrepreneurs and depositors at the same time.

Agents have an heterogeneous aversion to risk, which is measured for simplicity in terms of their Sharpe Ratio (Sharpe, 1966). Specifically, the i-th household invest in the risky activity if:

$$
\frac{E\left[r_{i}\right]-r_{f}}{\sqrt{\operatorname{Var}\left(r_{i}\right)}} \geq i \quad i \in \mathbb{I}=\left[0, \frac{1}{\sigma}\right]
$$

where $r_{i}$ and $r_{f}$ are the returns of the risky firm and of the riskless deposit. Notice that agents are ordered in accordance to their Sharpe Ratio, which is distributed uniformly across the population. In particular, risk propensities range from a risk neutral investor $(i=0)$ to an extremely risk averse household $\left(i=\frac{1}{\sigma}\right)^{24}$.

\footnotetext{
${ }^{24}$ The maximum value is set equal to $\frac{1}{\sigma}$ to normalize results.
} 
Lastly, all the agents have the same discount rate $(\beta)$. Hence, the longterm risk-free interest rate is equal to:

$$
r_{f}=\frac{1}{\beta}-1
$$

As stated before, the return paid by the risky asset is simply given by the excess profit obtained from investing the endowment $e$ in a privately owned firm, namely:

$$
\begin{gathered}
r_{i} e=\pi_{i}=z\left(d_{i}+e\right)^{\alpha}-r_{f} d_{i} \text { with } 0<\alpha<1 \\
\Downarrow \\
r_{i}=\frac{z\left(d_{i}+e\right)^{\alpha}-r_{f} d_{i}}{e}
\end{gathered}
$$

where $d_{i}$ is the debt borrowed at the risk-free rate $r_{f}$ and $z$ is a random variable following a log-normal distribution with expected value $E[z]=1$ and variance $\operatorname{Var}(z)=\sigma^{2}$. As before, the production function is a common functional form with decreasing marginal productivity.

Deposits are collected by a single financial institution, which has a given level of contractual power $(\theta \in[0,1])$. Every period the intermediary solves with the households/investors the Nash bargaining problem:

$$
\max _{\left\{r_{f}, d_{i}\right\}}\left(\int_{i \in I} r_{f} d_{i} d i\right)^{\theta}\left(\int_{i \in I} E\left[z\left(d_{i}+e\right)^{\alpha}\right]-r_{f} d_{i} d i\right)^{1-\theta}
$$

under the budget constraint:

$$
D^{d}=\int_{i \in I} d_{i} d i \leq \int_{i \in \mathbb{I} \backslash I} e d i=D^{s}
$$

where $D^{d}$ is the overall demand of credit, $D^{s}$ the supply of deposits and $I$ the set of entrepreneurs. Notice that the set $I$ is taken as given in the maximization process: this will allow to demonstrate later how investors and the financial institution can have conflicting objectives.

As in the previous section, the higher the bargaining power of the intermediary, the larger the quota of income which it can acquire, with the only difference in this case that the final objective is the expected value of production. The solution to the above problem is simply given by the condition:

$$
\begin{gathered}
d_{i}=d \quad \forall i \in I \\
r_{f} d=\theta(d+e)^{\alpha} \\
D^{d}=\int_{i \in I} d d i=\int_{i \in \mathbb{I} \backslash I} e d i=D^{s}
\end{gathered}
$$


To end with, the intermediary does not have any equity to cover the credit risk of its portfolio. Because of this, it imposes an additional constraints on its borrowers (Edge Condition):

$$
r_{f} d \leq e \quad \forall i \in I
$$

In other words, the equity of enterprises has to be sufficiently high to cover the payment of interests in any situation. In this way, the intermediary is able to issue a perfectly risk-free asset to depositors.

The general equilibrium is given by the set of entrepreneurs $I$, the endowment $e$ and the individual debt $d$ compatible with the long-term risk-free interest rate $r_{f}$ (Eq. 3.22.

To start with, by substituting equations 3.24 and 3.28 into 3.21 it is possible to find the set of entrepreneurs $I$ :

$$
\begin{gathered}
\frac{1-\theta-\theta \frac{e}{d}}{\sigma} \geq i \\
\Downarrow \quad \\
I=[0, \bar{i}] \quad \text { with } \quad \bar{i}=\frac{1-\theta-\theta \frac{e}{d}}{\sigma}
\end{gathered}
$$

where $\bar{i}$ is the marginal entrepreneur. As expected, only the households with a low aversion to risk invest in the risky enterprise ${ }^{25}$. In this way the equation for the credit market equilibrium 3.29 can be rewritten as:

$$
D=\int_{0}^{\bar{i}} d d i=\int_{\bar{i}}^{\frac{1}{\sigma}} e d i
$$

Subsequently, the individual debt $d$ can be found by rewriting the endowment $e$ in terms of $d$ (Eq. 3.28) and by substituting it into the credit market equilibrium (Eq. 3.33):

$$
d=\sqrt{\theta}\left(\frac{r_{f}}{\sqrt{\theta}}\right)^{\frac{1}{\alpha-1}}
$$

The overall credit issued $(D)$, the individual $(e)$ and aggregate capital $(E)$, the leverage of the system $(\lambda)$ and the marginal investor $(\bar{i})$ are equal

${ }^{25}$ Notice that: $\theta=0 \Longrightarrow I=\left[0, \frac{1}{\sigma}\right]=\mathbb{I}$ 
to:

$$
\begin{gathered}
e=\frac{1-\sqrt{\theta}}{\sqrt{\theta}} d \\
\bar{i}=\frac{1-\sqrt{\theta}}{\sigma} \\
D=\int_{0}^{\bar{i}} d d i=\frac{1-\sqrt{\theta}}{\sigma} d \\
E=\int_{0}^{\frac{1}{\sigma}} e d i=\frac{1-\sqrt{\theta}}{\sigma \sqrt{\theta}} d \\
\lambda=\frac{D}{E}=\sqrt{\theta}
\end{gathered}
$$

In addition, the aggregate production is defined as:

$$
Y=\int_{0}^{\bar{i}} z_{i}(d+e)^{\alpha} d i=\frac{r_{f} d}{\theta} \int_{0}^{\bar{i}} z_{i} d i
$$

which is a Geometric Brownian Motion that follows a log-normal distribution with parameters:

$$
\begin{gathered}
E[Y]=\frac{r_{f} d}{\theta} \frac{1-\sqrt{\theta}}{\sigma} \\
\sigma_{Y}=\frac{r_{f} d}{\theta} \sigma \sqrt{\frac{1-\sqrt{\theta}}{\sigma}}
\end{gathered}
$$

As in the previous section, the leverage of the system $\lambda$ is an increasing function of the bargaining power of the financial sector (Eq. 3.39). In addition, both the aggregate capital $E$ and debt $D$ follow a non-linear pattern (see Fig. 3.2). In fact, given the decreasing marginal productivity of capital, the intermediary must issue a reduced amount of credit when its contractual power is low to obtain a sufficiently high return from its loans. Consequently, because of the strong complementarity between debt and capital (see Eq. 3.35), also the latter is upper constrained. In this way, the economy remains in a situation of low capitalization and production. However, as the bargaining power of the intermediary increases, this process of economic development reaches a turning point. Indeed, above a certain threshold the growth of credit and deposits profitability is more than compensated by the reduction in the number of entrepreneurs (Eq. 3.36). 
With regards to income distribution, expected production and the corresponding quota to entrepreneurs and the intermediary are:

$$
\begin{gathered}
E[Y]=\left(r_{f}\right)^{\frac{\alpha}{1-\alpha}} \frac{(\sqrt{\theta})^{\frac{\alpha}{1-\alpha}}-(\sqrt{\theta})^{\frac{1}{1-\alpha}}}{\sigma} \\
E[\Pi]=(1-\theta) E[Y] \\
r_{f} D=\theta E[Y]
\end{gathered}
$$

and the points of maximum of the three equations are such that:

$$
\begin{gathered}
\frac{d E[Y]}{d \theta}=\frac{\left(r_{f}\right)^{\frac{\alpha}{1-\alpha}}}{2 \sigma(1-\alpha)}(\sqrt{\theta})^{\frac{3 \alpha-2}{1-\alpha}}(\alpha-\sqrt{\theta})=0 \Longrightarrow \theta^{Y}=(\alpha)^{2} \\
\frac{d E[\Pi]}{d \theta}=-E[Y]+(1-\theta) \frac{d E[Y]}{d \theta} \Longrightarrow \theta^{E}<\theta^{Y} \\
\frac{d r_{f} D}{d \theta}=E[Y]+\theta \frac{d E[Y]}{d \theta} \Longrightarrow \theta^{D}>\theta^{Y}
\end{gathered}
$$

The three maxima are at different levels of the bargaining power of the financial sector (see Fig. 3.3). In particular, entrepreneurs prefer a situation in which the intermediary has a low contractual power $\left(\theta^{E}\right)$, while the latter opts for a completely opposite solution $\left(\theta^{D}\right)$. However, both the agents select an equilibrium point where the expected production is not at its maximum $\left(\theta^{E}<\theta^{Y}<\theta^{D}\right)$.

Lastly, the main aim of this model is to study the nexus between the contractual power of the financial sector and systemic risk. This relation can be assessed under two different viewpoints.

First, with regards to the edge condition (Eq. 3.30), in equilibrium this constraint implies:

$$
\theta \leq \theta^{\text {edge }}=\left(\frac{1}{1+r_{f}}\right)^{2} \Longrightarrow \frac{d \theta^{\text {edge }}}{d r_{f}}<0
$$

From this equation emerges that there is a maximum value of the contractual power above which the equity of the firms is not sufficient to cover business fluctuations. Indeed, when the bargaining power of the financial institution is high, entrepreneurs invest a small number of resources in the system to obtain an incentive-compatible return. Consequently, the equity of the firms is excessively low to cover the volatility of production. Put differently, is not possible to issue a completely risk-free instrument when the leverage of the system is high. In addition, the optimal bargaining power of the intermediary $\left(\theta^{D}\right)$ is the closest to this value. In this sense, when the riskfree interest rate is high and, in turn, this threshold is low, the final objective 
of the financial institution can be in contrast with the type of instrument it issues (risk-free deposits). Similarly, an exogenous increase in the risk-free interest rate can transform a riskless deposit in a risky asset. Overall, a large financial sector can be compatible with low returns, but unexpected changes in the risk-free rate can jeopardize the solvability of intermediaries.

Second, an increase in the bargaining power of the financial institution reduces the set of entrepreneurs (Eq. 3.36). This produces two negative effects on the riskiness of the system. Firstly, by reducing the number of active firms it decreases the diversification of the portfolio of credits. In fact, with only idiosyncratic risk being present in the system, extreme events are rarer when the number of investments rises. Second, an increase in the contractual power does not only modify the quantity but also the quality of the entrepreneurs (as in Stiglitz and Weiss (1981) with interest rates). Indeed, only less risk-averse households remain in the market. Overall, the growth of the contractual power of the intermediary can have a negative impact on systemic risk. This aspect is confirmed by the ratio between the expected production and its standard deviation:

$$
\frac{E[Y]}{\sigma_{Y}}=\frac{1}{\sigma} \sqrt{\frac{1-\sqrt{\theta}}{\sigma}}
$$

which is a decreasing function of the bargaining power of the intermediary (Fig. 3.4).

Summing up, an excessively large financial sector may not have a negative impact only on growth and expected production, but also on the solvability of the intermediaries and systemic risk. In addition, the search for returns of financial institutions can move the system to a suboptimal equilibrium with low production and high volatility.

\subsection{Concluding Remarks}

In this article we develop a simple theoretical framework to study the effects of the bargaining power of the financial sector on the aggregate growth and the systemic risk. With regards to the former, the results are in line with the existing empirical evidence (Cecchetti and Kharroubi, 2012; Arcand et al. 2015: Davis, 2017). On the contrary, the model returns a definitively negative relation between the volatility of the economy and the overall leverage. It is clear that this outcome is in contrast with the literature (Dabla-Norris and Srivisal, 2013). However, the theoretical framework introduced here does not contain any reference to the equity and, in turn, to the profitability of the 
intermediary itself. Indeed, the results of the model would definitively change introducing this additional investment opportunity for the households.

In addition, we consider the contractual power of the intermediary as an exogenous variable. In other words, we do not evaluate the factors influencing this parameter (e.g. the institutional and legal framework, the market structure and technological improvements) and their consequences on the profitability of intermediaries. Therefore, additional work is required to complete the model. Furthermore, this could also explain the constant profitability of the US financial sector over the last century (Philippon, 2015).

Lastly, in this article we focus only on the effects of financialization on aggregate growth and systemic risk. Another important feature of this longrun dynamic is the increased inequality of Western economies (Piketty and Saez, 2003; Palley, 2013; Stiglitz, 2015a). Accordingly, further investigation is needed, focusing in particular on the causal link between these two phenomena.

Summing up, the contractual power of the financial sector and its expression through the overall leverage of the system can have a strong impact both on the aggregate growth and the systemic risk. Indeed, different allocations of funds modify the incentive for new enterprises to enter the market. In other words, financial institutions do not simply function as mere transfers of funds but they can modify the structure of the economic system through their behavior. As a result, the policymaker should be aware of the potentially negative consequences that an overdeveloped financial sector can have on the real economy. 


\subsection{Figures}

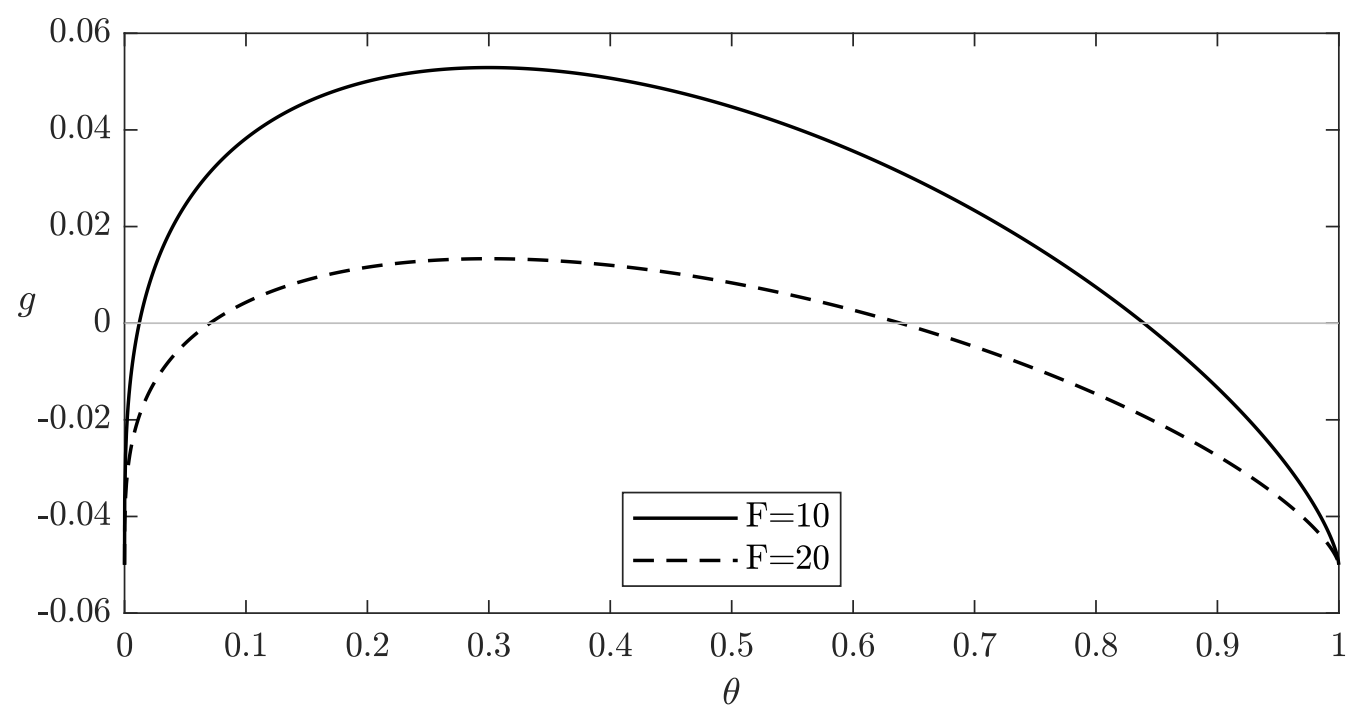

Figure 3.1: Growth Rates and Bargaining Power $\{\alpha=0.3 \wedge \beta=0.95\}$

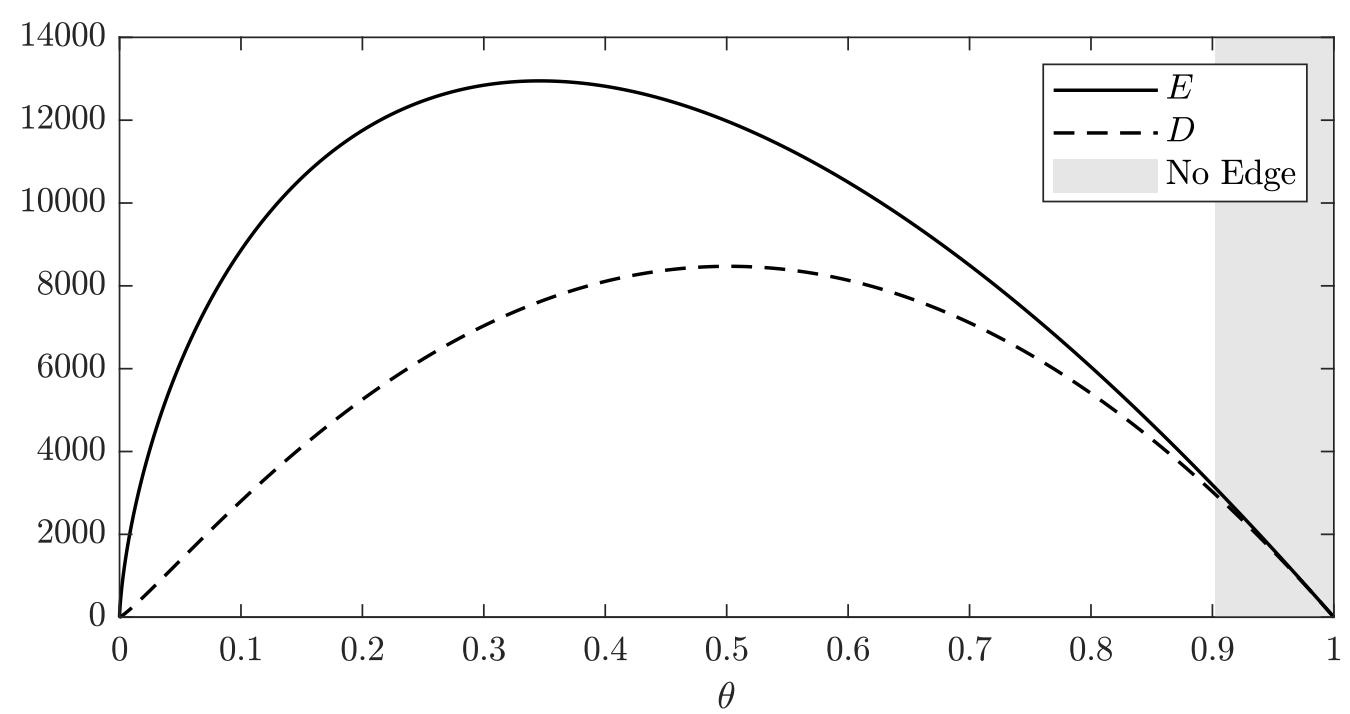

Figure 3.2: Capital, Debt and Bargaining Power $\{\alpha=0.3 \wedge \beta=0.95 \wedge \sigma=0.001\}$ 


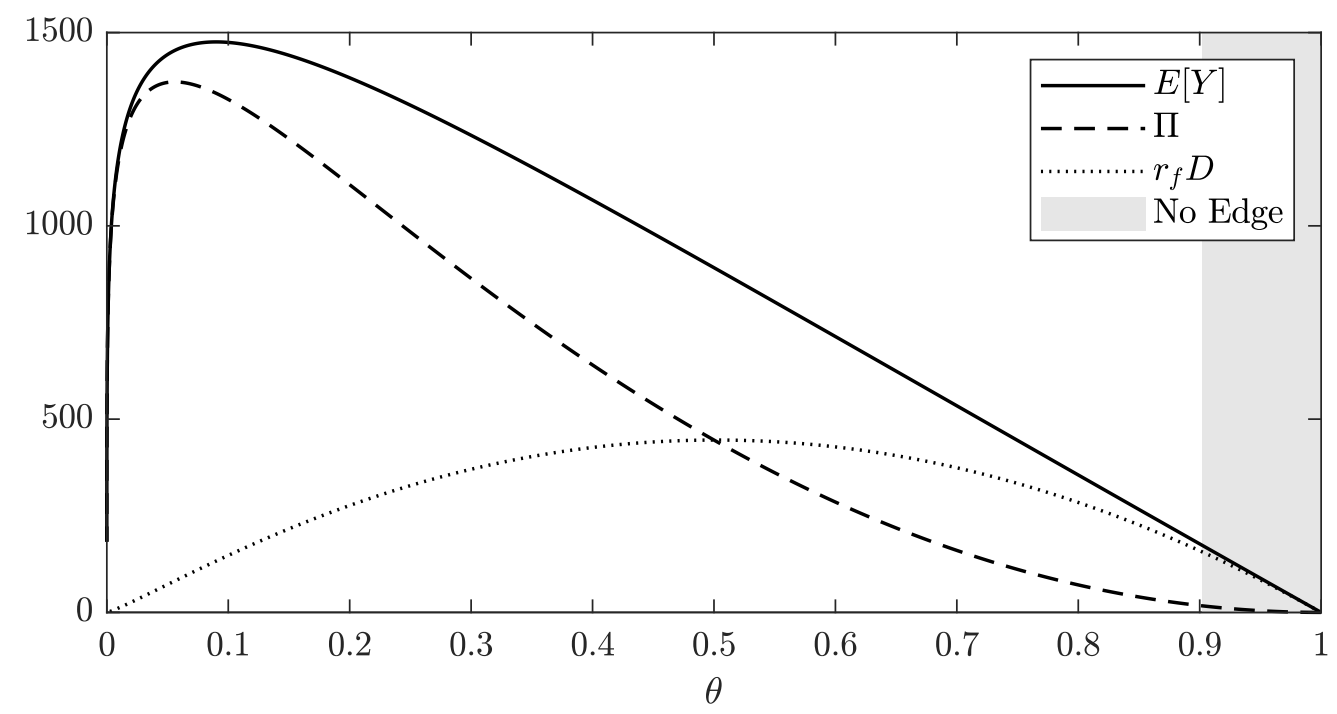

Figure 3.3: Income Distribution and Bargaining Power $\{\alpha=0.3 \wedge \beta=0.95 \wedge \sigma=0.001\}$

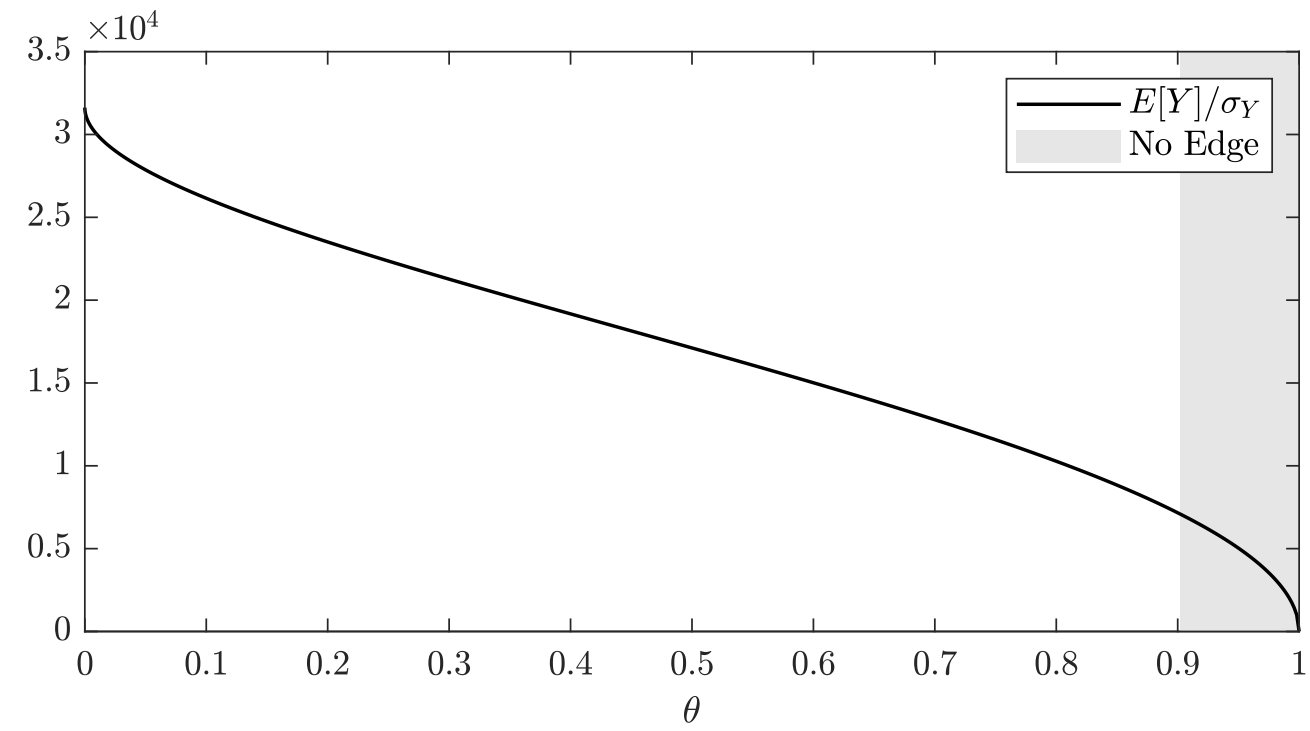

Figure 3.4: Expected Production, Risk and Bargaining Power $\{\alpha=0.3 \wedge \beta=0.95 \wedge \sigma=0.001\}$ 


\section{Conclusions}

The thesis investigates the role of the financial market in shaping the capital structure of the real economy and its effects on the aggregate performance of the system. In particular, the level of competition in this sector seems to be an important aspect of the overall picture. Indeed, the interplay between financial institutions can influence the process of resources allocation, the dynamic of cycles and the long-term growth rate.

First, in Chapter 1 we show that the search for profits of banks can generate endogenous fluctuations because of a strategic complementarity in their behavior. Indeed, the individual financial institution has the incentive to reduce its interest rate on new credits in the short term. In fact, that increases the efficiency of its portfolio by reducing the volume of unallocated resources. However, that prompts the immediate response of the other intermediaries. Indeed, the new funding conditions attract not only new firms but also incumbent entrepreneurs. As a result, the demand for credit in other banks decreases, thus leading to a further reduction in interest rates. Summing up, this produces a withdrawal of resources by the households and a sudden decrease of aggregate capital and production.

Second, the structure of the interbank network can generate a competitive advantage for lenders of this market. Indeed, when financial institutions borrow from other intermediaries, they use their portfolio of credits to firms as collateral. However, entrepreneurs can extinguish their existing loans if they find a better financing opportunity in the market. As a result, the bank incurs further losses in this case because the collateral no longer covers the interests on the interbank loan. Moreover, when intermediaries select their counterparties on the basis of their size, by construction, they do so regardless of the ask interest rate. Summing up, only the hub exploits these mechanisms in a highly centralized context and pays, on average, a higher return to its investors. In this way, it attracts more households and reinforces its market position. Nevertheless, this network topology is subject to large and persistent fluctuations. Indeed, the state of the system depends on the overall efficiency of the core bank and vice-versa. In particular, when the 
hub suffers a sudden withdrawal of resources, the single intermediary in the periphery does not have sufficient resources to sustain it. In other words, the bailout of a core bank would require a perfect coordination of all the other actors of the market or the direct intervention of the government. In the absence of that, the hub closes a considerable number of credit lines, with a massive loss of informational capital and a substantial reduction in the overall productivity of the economy.

Lastly, the bargaining power and, in a similar way, competition in the financial sector can influence the growth rate of the economy. Indeed, financial intermediaries, modifying the redistribution of income between the owners and creditors of firms, can change the incentive for new entrepreneurs to enter the market. Specifically, when bank are subject to a strong competition, they are not able to capture a sufficiently high fraction of income from the economy. Therefore, real interest rates are low, households do not have the incentive to save and new firms do not have access to capital and can not start production. Overall, the economy remains at a low or negative growth path. On the other hand, a pseudo-monopolistic financial sector reduces the incentive for new entrepreneurs to enter the market. Indeed, profits are too low and households prefer to invest their wealth in the financial market rather than starting a new entrepreneurial activity. Also in this case the economy remains at a low or negative growth path because of the decreasing marginal productivity of capital.

Summing up, the level of competition in the financial market seems to affect the allocation of capital in the economy. In particular, a pseudomonopolistic banking sector seems to produce the worst economic outcome. Indeed, both the stability and the growth rate of the system can be negatively affected by the presence of a large intermediary. As stated in Chapter 2, a centralized financial sector is subject to ample and persistent fluctuations. In fact, the state of the system depends on the overall efficiency of the core bank and vice-versa. Moreover, in Chapter 3 we show that a strong bank can also decrease the incentive for new entrepreneurs to enter the market. Consequently, that reduces the potential growth rate of the economy. In view of that, a more homogeneous financial sector would be more sustainable and less subject to large banking crises. Furthermore, it would increase the potential growth rate of the economy.

Lastly, the work is far from being complete and it can be extended in a number of directions to consider important issues. With regards to the two ABMs, we have not included the labor market in these frameworks to maintain our analysis as simple as possible. Nevertheless, researchers show that the mechanism of decentralized matching in the credit sector can have a large impact also on the level of employment (see Wasmer and Weil (2004) 
for a representative agent analysis and Riccetti et al. (2015) for an ABM). Accordingly, an extension of our model in this direction would enrich our economic environment with a fundamental factor of production and would complete our analysis of welfare. In addition, most of the research on interbank and credit networks focused on the role of the financial accelerator as an amplifier of exogenous shocks (Delli Gatti et al., 2010 Tedeschi et al., 2012 Riccetti et al., 2013: Grilli et al., 2014, 2015). In view of that, the introduction of this mechanism in our model would test those results in a complete economic system in which banks' liabilities are not fixed but follow depositors' behavior.

Conversely, with regards to the representative agent model, the theoretical framework introduced here does not contain any reference to the equity and, in turn, to the profitability of intermediaries. Indeed, the results of the model would definitively change introducing this additional investment opportunity for the households. Moreover, we consider the contractual power of the intermediary as an exogenous variable. In other words, we do not evaluate the factors influencing this parameter (e.g. the institutional and legal framework, the market structure and technological improvements) and their consequences on the profitability of intermediaries. 


\section{Bibliography}

Acemoglu, D., Ozdaglar, A. and Tahbaz-Salehi, A. (2015), 'Systemic risk and stability in financial networks', American Economic Review 105(2), 564608.

Adrian, T., Estrella, A. and Shin, H. S. (2010), Monetary cycles, financial cycles, and the business cycle, Staff Reports 421, Federal Reserve Bank of New York.

Adrian, T. and Shin, H. S. (2010), Financial Intermediaries and Monetary Economics, in B. M. Friedman and M. Woodford, eds, 'Handbook of Monetary Economics', Vol. 3 of Handbook of Monetary Economics, Elsevier, chapter 12, pp. 601-650.

Aghion, P. and Howitt, P. (1992), 'A Model of Growth Through Creative Destruction', Econometrica 60(2), 323-351.

Allen, F. and Gale, D. (2000), 'Financial contagion', Journal of Political Economy 108(1), 1-33.

Arcand, J. L., Berkes, E. and Panizza, U. (2015), 'Too much finance?', Journal of Economic Growth 20(2), 105-148.

Arrow, K. J. and Debreu, G. (1954), 'Existence of an Equilibrium for a Competitive Economy', Econometrica 22(3), 265-290.

Axtell, R. L. (2001), 'Zipf Distribution of US Firm Sizes', SCIENCE 293(5536), 1818-1820.

Battiston, S., Delli Gatti, D., Gallegati, M., Greenwald, B. and Stiglitz, J. E. (2012a), 'Default cascades: When does risk diversification increase stability?', Journal of Financial Stability 8(3), 138-149.

Battiston, S., Delli Gatti, D., Gallegati, M., Greenwald, B. and Stiglitz, J. E. (2012b), 'Liaisons dangereuses: Increasing connectivity, risk sharing, and 
systemic risk', Journal of Economic Dynamics and Control 36(8), 11211141.

Becsi, Z., Li, V. E. and Wang, P. (2013), 'Credit mismatch and breakdown', European Economic Review 59, 109-125.

Berardi, S. and Tedeschi, G. (2017), 'From banks' strategies to financial (in) stability', International Review of Economics \& Finance 47, 255-272.

Bernanke, B. and Gertler, M. (1989), 'Agency Costs, Net Worth, and Business Fluctuations', The American Economic Review 79(1), 14-31.

Bianconi, G. and Barabási, A.-L. (2001), 'Competition and multiscaling in evolving networks', EPL (Europhysics Letters) 54(4), 436.

Boot, A. W. (2000), 'Relationship banking: What do we know?', Journal of Financial Intermediation 9(1), 7-25.

Bordo, M. D. and Haubrich, J. G. (2017), 'Deep recessions, fast recoveries, and financial crises: Evidence from the American record', Economic Inquiry 55(1), 527-541.

Boyarchenko, N. and Adrian, T. (2015), Intermediary Balance Sheets, 2015 Meeting Papers 239, Society for Economic Dynamics.

Boysen-Hogrefe, J., Jannsen, N. and Meier, C.-P. (2016), 'A note on banking and housing crises and the strength of recoveries', Macroeconomic Dynamics 20(7), 1924-1933.

Brunnermeier, M., Eisenbach, T. and Sannikov, Y. (2013), Macroeconomics with Financial Frictions: A Survey, Advances in Economics and Econometrics, in 'Tenth World Congress of the Econometric Society. New York: Cambridge University Press'.

Brunnermeier, M. K. and Koby, Y. (2016), 'The reversal interest rate: An effective lower bound on monetary policy', Unpublished, Princeton University, Princeton, NJ.

Cecchetti, S. and Kharroubi, E. (2012), Reassessing the impact of finance on growth, BIS Working Papers 381, Bank for International Settlements.

Cecchetti, S. and Kharroubi, E. (2015), Why does financial sector growth crowd out real economic growth?, BIS Working Papers 490, Bank for International Settlements. 
Christiano, L. and Ikeda, D. (2011), Government policy, credit markets and economic activity, Technical report, National Bureau of Economic Research.

Clementi, F., Di Matteo, T. and Gallegati, M. (2006), 'The power-law tail exponent of income distributions', Physica A: Statistical Mechanics and its Applications 370(1), 49-53.

Clementi, F. and Gallegati, M. (2005), 'Power law tails in the Italian personal income distribution', Physica A: Statistical Mechanics and its Applications $\mathbf{3 5 0}(2-4), 427-438$.

Cont, R. (2001), 'Empirical properties of asset returns: stylized facts and statistical issues', QUANTITATIVE FINANCE 1, 223-236.

Cont, R. (2007), Volatility clustering in financial markets: empirical facts and agent-based models, in 'Long memory in economics', Springer, pp. 289309.

Contessi, S. and Francis, J. L. (2013), 'US commercial bank lending through 2008: Q4: new evidence from gross credit flows', Economic Inquiry 51(1), 428-444.

Covas, F. and Haan, W. J. D. (2011), 'The Cyclical Behavior of Debt and Equity Finance', American Economic Review 101(2), 877-899.

Dabla-Norris, E. and Srivisal, N. (2013), Revisiting the Link Between Finance and Macroeconomic Volatility, IMF Working Papers 13/29, International Monetary Fund.

Davis, L. E. (2017), 'FINANCIALIZATION AND INVESTMENT: A SURVEY OF THE EMPIRICAL LITERATURE', Journal of Economic Surveys 31(5), 1332-1358.

Dell'Ariccia, G., Detragiache, E. and Rajan, R. (2008), 'The real effect of banking crises', Journal of Financial Intermediation 17(1), 89-112.

Delli Gatti, D., Di Guilmi, C., Gaffeo, E., Giulioni, G., Gallegati, M. and Palestrini, A. (2005), 'A new approach to business fluctuations: heterogeneous interacting agents, scaling laws and financial fragility', Journal of Economic Behavior \& Organization 56(4), 489-512.

Delli Gatti, D., Gallegati, M., Greenwald, B. C., Russo, A. and Stiglitz, J. E. (2012), 'Mobility constraints, productivity trends, and extended crises', Journal of Economic Behavior \& Organization 83(3), 375-393. 
Delli Gatti, D., Gallegati, M., Greenwald, B., Russo, A. and Stiglitz, J. E. (2010), 'The financial accelerator in an evolving credit network', Journal of Economic Dynamics and Control 34(9), 1627-1650.

Den Haan, W. J., Ramey, G. and Watson, J. (2003), 'Liquidity flows and fragility of business enterprises', Journal of Monetary Economics $\mathbf{5 0}(6), 1215-1241$.

Diamond, P. A. (1990), 'Pairwise credit in search equilibrium', The Quarterly Journal of Economics 105(2), 285-319.

Dosi, G., Fagiolo, G., Napoletano, M. and Roventini, A. (2013), 'Income distribution, credit and fiscal policies in an agent-based Keynesian model', Journal of Economic Dynamics and Control 37(8), 1598-1625.

Fagiolo, G., Dosi, G. and Gabriele, R. (2004), 'Matching, bargaining, and wage setting in an evolutionary model of labor market and output dynamics', Advances in Complex Systems 7(02), 157-186.

Foglia, A., Hancock, D., Alessandri, P., Bayliss, T., Boissay, F., Christensen, I. and Lago, R. (2011), 'The transmission channels between the financial and real sectors: a critical survey of the literature', Basel Committee on Banking Supervision Working Papers (18).

Freixas, X., Parigi, B. M. and Rochet, J.-C. (2000), 'Systemic risk, interbank relations, and liquidity provision by the central bank', Journal of Money, Credit and Banking pp. 611-638.

Gabaix, X. (2016), 'Power laws in economics: An introduction', Journal of Economic Perspectives 30(1), 185-206.

Gaffeo, E., Delli Gatti, D., Desiderio, S. and Gallegati, M. (2008), 'Adaptive microfoundations for emergent macroeconomics', Eastern Economic Journal 34(4), 441-463.

Gaffeo, E., Gallegati, M. and Gostoli, U. (2015), 'An agent-based "proof of principle" for Walrasian macroeconomic theory', Computational and Mathematical Organization Theory 21(2), 150-183.

Gaffeo, E., Gallegati, M. and Palestrini, A. (2003), 'On the size distribution of firms: additional evidence from the G7 countries', Physica A: Statistical Mechanics and its Applications 324(1-2), 117-123. 
Gai, P. and Kapadia, S. (2010), 'Contagion in financial networks', Proceedings of the Royal Society of London A: Mathematical, Physical and Engineering Sciences 466(2120), 2401-2423.

Gottfries, N. (1991), 'Customer markets, credit market imperfections and real price rigidity', Economica pp. 317-323.

Greenwald, B. C. and Stiglitz, J. E. (1993), 'Financial market imperfections and business cycles', The Quarterly Journal of Economics 108(1), 77-114.

Grilli, R., Tedeschi, G. and Gallegati, M. (2014), 'Bank interlinkages and macroeconomic stability', International Review of Economics $\&$ Finance 34, 72-88.

Grilli, R., Tedeschi, G. and Gallegati, M. (2015), 'Markets connectivity and financial contagion', Journal of Economic Interaction and Coordination 10(2), 287-304.

Grossman, G. M. and Helpman, E. (1991), 'Trade, knowledge spillovers, and growth', European Economic Review 35(2-3), 517-526.

Guerini, M., Napoletano, M. and Roventini, A. (2018), 'No man is an island: The impact of heterogeneity and local interactions on macroeconomic dynamics', Economic Modelling 68, 82-95.

Hall, R. E. (2011), 'The high sensitivity of economic activity to financial frictions', The Economic Journal 121(552), 351-378.

Herrera, A. M., Kolar, M. and Minetti, R. (2011), 'Credit reallocation', Journal of Monetary Economics 58(6), 551-563.

Hyun, J. (2016), 'Financial crises and the evolution of credit reallocation: Evidence from Korea', Economic Modelling 56, 25-34.

Inklaar, R., Koetter, M. and Noth, F. (2015), 'Bank market power, factor reallocation, and aggregate growth', Journal of Financial Stability 19, 3144.

Iori, G., Jafarey, S. and Padilla, F. G. (2006), 'Systemic risk on the interbank market', Journal of Economic Behavior \&3 Organization 61(4), 525-542.

Jayaratne, J. and Strahan, P. E. (1996), 'The finance-growth nexus: Evidence from bank branch deregulation', The Quarterly Journal of Economics 111(3), 639-670. 
Kiyotaki, N. and Moore, J. (1997), 'Credit cycles', Journal of Political Economy 105(2), 211-248.

Lenzu, S. and Tedeschi, G. (2012), 'Systemic risk on different interbank network topologies', Physica A: Statistical Mechanics and its Applications 391(18), 4331-4341.

Levine, R. (2005), 'Finance and growth: theory and evidence', Handbook of Economic Growth 1, 865-934.

Okuyama, K., Takayasu, M. and Takayasu, H. (1999), 'Zipf's law in income distribution of companies', Physica A: Statistical Mechanics and its Applications 269(1), 125-131.

Palley, T. I. (2013), Financialization: What it is and Why it Matters, in 'Financialization', Springer, pp. 17-40.

Pareto, V. (1986), Cours d'économie politique, Librairie Droz.

Persky, J. (1992), 'Retrospectives: Pareto's law', Journal of Economic Perspectives 6(2), 181-192.

Philippon, T. (2015), 'Has the US finance industry become less efficient? On the theory and measurement of financial intermediation', American Economic Review 105(4), 1408-38.

Piketty, T. and Saez, E. (2003), 'Income inequality in the United States, 1913-1998', The Quarterly Journal of Economics 118(1), 1-41.

Pissarides, C. A. (2000), Equilibrium Unemployment Theory, MIT press.

Ramsden, J. and Kiss-Haypál, G. (2000), 'Company size distribution in different countries', Physica A: Statistical Mechanics and its Applications 277(1-2), 220-227.

Riccetti, L., Russo, A. and Gallegati, M. (2013), 'Leveraged networkbased financial accelerator', Journal of Economic Dynamics and Control 37(8), 1626-1640.

Riccetti, L., Russo, A. and Gallegati, M. (2015), 'An agent based decentralized matching macroeconomic model', Journal of Economic Interaction and Coordination 10(2), 305-332.

Romer, P. M. (1990), 'Endogenous Technological Change', Journal of Political Economy 98(5), S71-S102. 
Schularick, M. and Taylor, A. M. (2012), 'Credit booms gone bust: monetary policy, leverage cycles, and financial crises, 1870-2008', The American Economic Review 102(2), 1029-1061.

Sharpe, W. F. (1966), 'Mutual Fund Performance', The Journal of Business 39(1), 119-138.

Sichel, D. E. (1993), 'Business cycle asymmetry: a deeper look', Economic Inquiry 31(2), 224-236.

Stiglitz, J. E. (2015a), '8. Inequality and Economic Growth', The Political Quarterly 86, 134-155.

Stiglitz, J. E. (2015b), Towards a General Theory of Deep Downturns, Working Paper 21444, National Bureau of Economic Research.

Stiglitz, J. E. and Weiss, A. (1981), 'Credit rationing in markets with imperfect information', The American Economic Review 71(3), 393-410.

Tedeschi, G., Mazloumian, A., Gallegati, M. and Helbing, D. (2012), 'Bankruptcy cascades in interbank markets', PLoS ONE 7(12), e52749.

Tesfatsion, L. (2006), 'Agent-based computational economics: A constructive approach to economic theory', Handbook of computational economics 2, 831-880.

Upper, C. (2011), 'Simulation methods to assess the danger of contagion in interbank markets', Journal of Financial Stability 7(3), 111-125.

Wasmer, E. and Weil, P. (2004), 'The macroeconomics of labor and credit market imperfections', The American Economic Review 94(4), 944-963. 